\title{
Urban agriculture for poverty alleviation A case study of Hyderabad, India
}

\author{
Charles Devenish
}

Thesis presented in partial fulfilment of

Master of Development Studies

School of Geography, Environment and Earth Sciences

Victoria University of Wellington

Aotearoa, New Zealand

March 2009 


\section{Abstract}

Conceptualising sustainable development as that which seeks to achieve holistic well-being means that as a barrier to attaining and sustaining well-being, poverty takes on a similarly more broad definition. Within this framework it is proposed that the breakdown of community; the extinction of experience; degradation of the natural environment; and food insecurity are examples of poverty in the contemporary urban setting because they obstruct access to overall well-being. Through a case study of the Resource Centres for Urban Agriculture and Food Security - Cities Farming for the Future (RUAF-CFF) project being piloted in Surabhi Colony, Hyderabad, India, urban agriculture is assessed as a means of alleviating these diverse forms of poverty. While the findings indicate some success at the project level, urban agriculture's limited ability to address Hyderabad's more widespread and pressing problems - in particular its water scarcity - coupled with the form of development the city is taking means that it is unlikely urban agriculture will gain the institutional support necessary for its further spread throughout the city. Although such findings do not inspire hope for the future use of urban agriculture as a poverty alleviation strategy within Hyderabad, a number of issues are considered which suggest that urban agriculture should rather be supported for its ability to facilitate 'good change' in our urban centres.

Keywords: Urban agriculture; RUAF-CFF; Hyderabad, India; sustainable development; poverty alleviation. 


\section{Table of Contents}

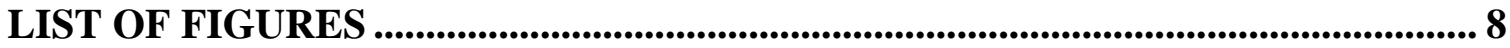

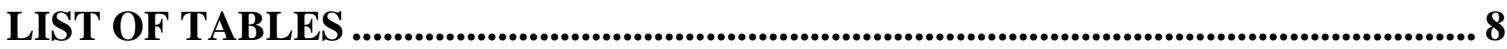

ACRONYMS AND ABBREVIATIONS................................................................. 9

ACKNOWLEDGEMENTS............................................................................................. 10

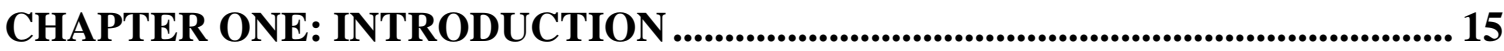

THE IDEAL: DEVELOPMENT IN THE CURRENT CONTEXT................................................ 15

THE PROBLEM: THE SPREAD OF POVERTY IS CREATING BARRIERS TO SUSTAINABLE

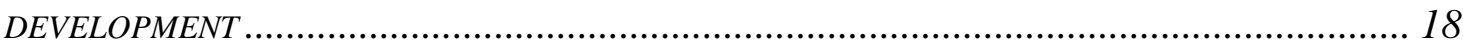

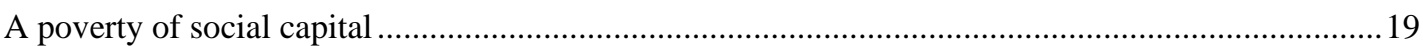

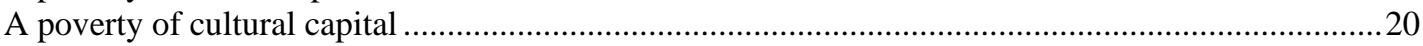

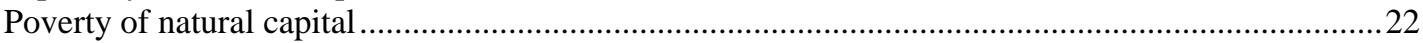

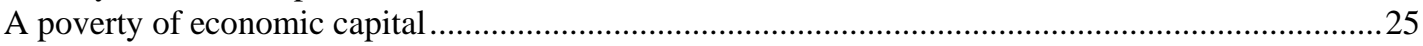

THE PROPOSED SOLUTION: URBAN AGRICULTURE …………………………………... 27

CHAPTER TWO: CONCEPTUAL FRAMEWORK ……............................................ 29

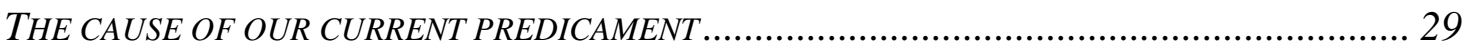

THE NEED FOR A CHANGE OF TACK IN OUR ONTOLOGY.................................................... 30

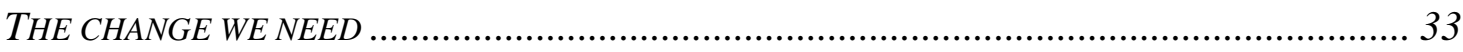

CHAPTER THREE: RESEARCH METHODS ........................................................... 36

RESEARCH IN THE FIELD .......................................................................................... 36

Wisdom of the body ............................................................................................................

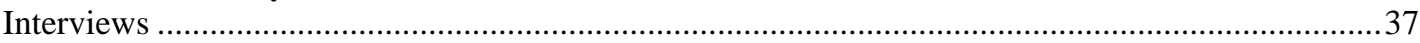

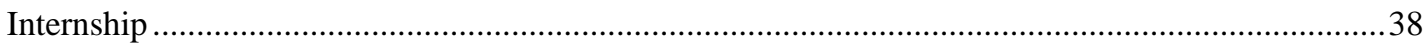

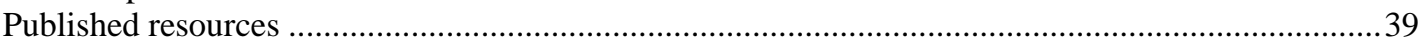

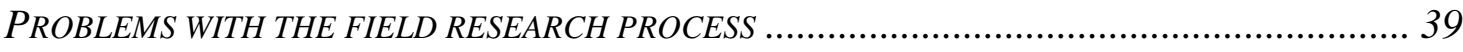

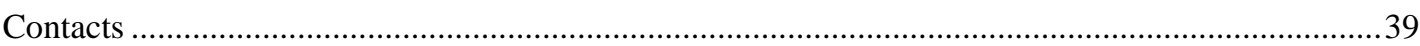

The omission of quantitative research methods ............................................................................................. 40

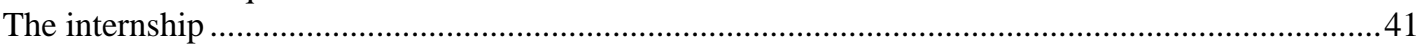

'Insider' / 'outsider' - the politics of fieldwork .........................................................................42

CHAPTER FOUR: LITERATURE REVIEW ............................................................. 44

THE PROBLEMS OF DEFINITION .............................................................................. 44

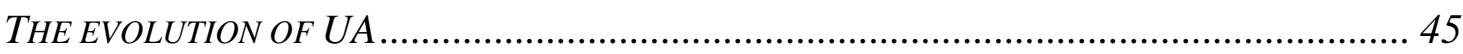

UA and the 'war effort' (c. 1910s - 1940s) ……………………………………………………....4 45

UA and 'development' (c. 1960s - early 2000s) ………………………………………………....4

The greening and globalising of UA (2000s to the present) ………………………………………....4 48

KEY CHARACTERISTICS OF UA IN THE DEVELOPING WORLD........................................... 50

Who? The practitioners of UA......................................................................................................5

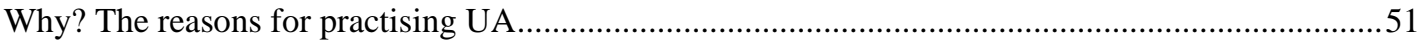

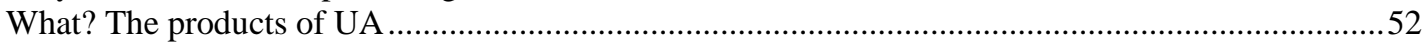

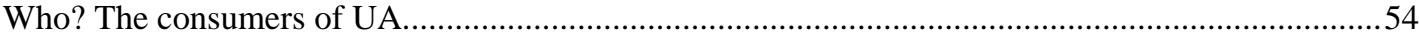

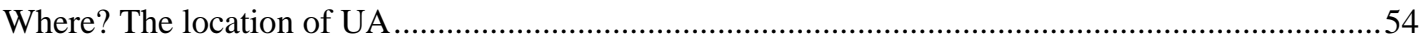

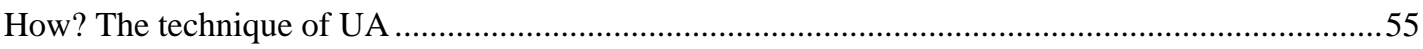

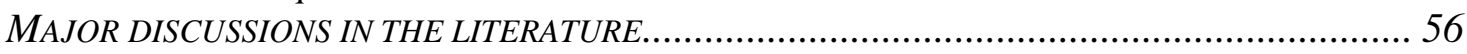

Insecure land tenure and the need for policy support ……………………………………………..56 


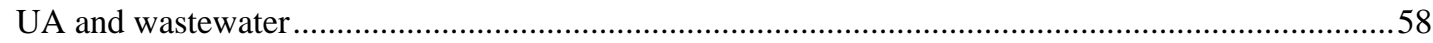

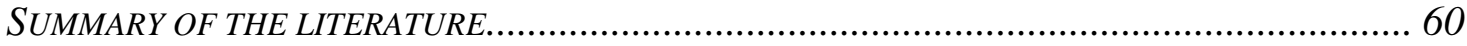

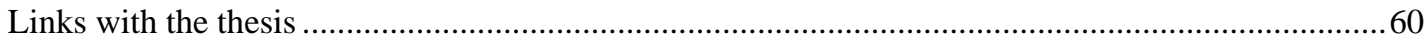

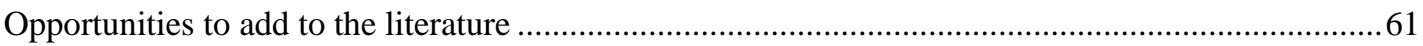

CHAPTER FIVE: INTRODUCTION TO THE FIELD................................................. 64

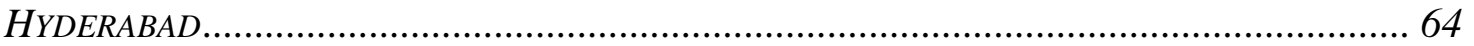

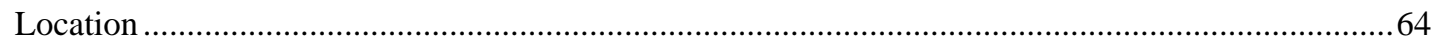

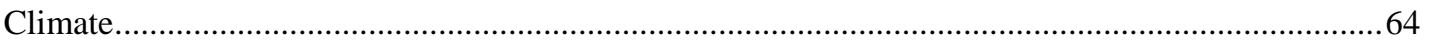

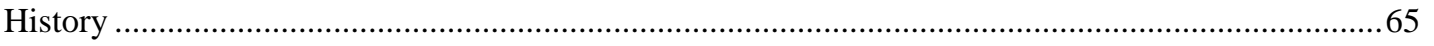

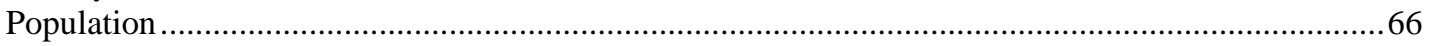

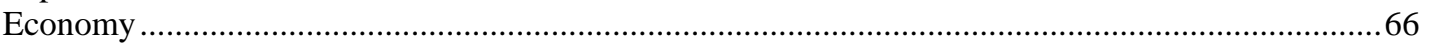

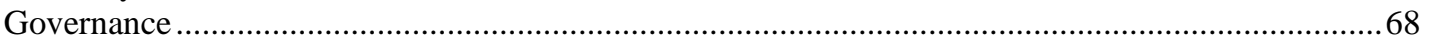

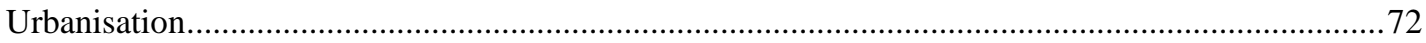

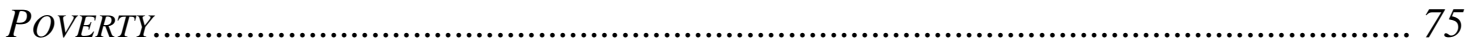

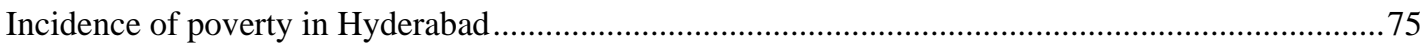

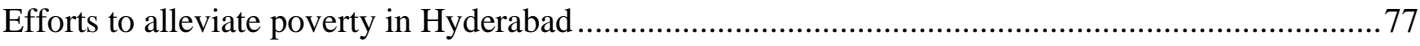

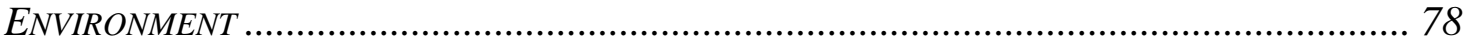

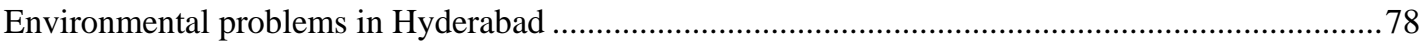

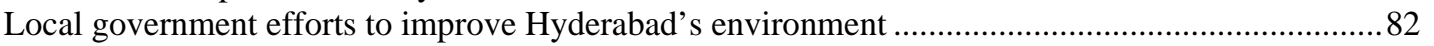

An externally funded project to improve Hyderabad's environment...................................................... 86

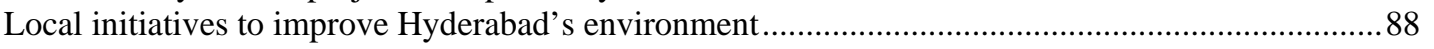

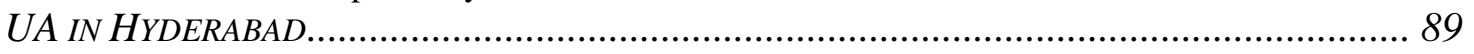

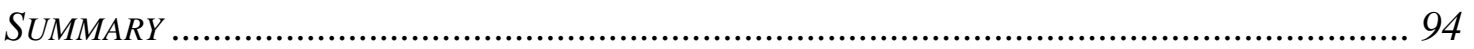

CHAPTER SIX: EXPERIENCE IN THE FIELD............................................... 96

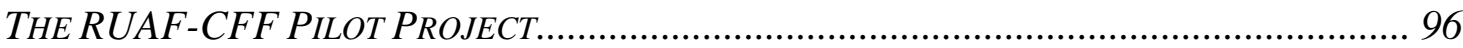

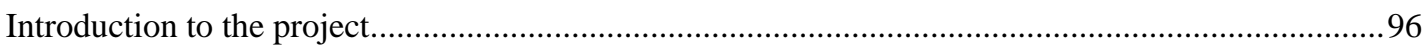

Evolution of the RUAF-CFF pilot project in Hyderabad.....................................................................97

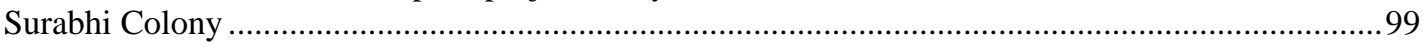

BENEFITS AND SUCCESSES OF THE RUAF-CFF PILOT PROJECT IN HYDERABAD .............. 103

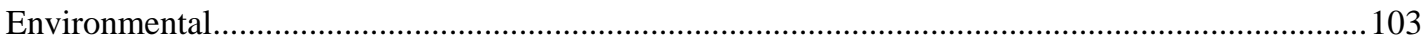

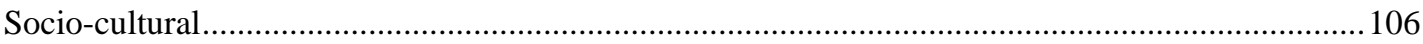

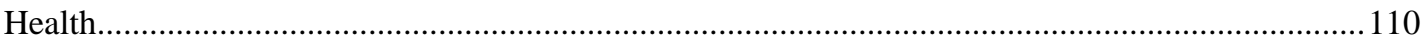

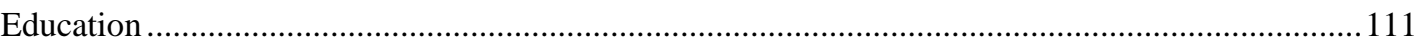

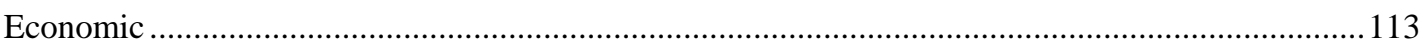

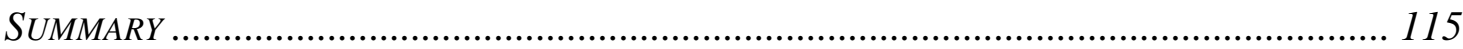

CHAPTER SEVEN: FUTURE PROSPECTS OF AND FOR UA IN HYDERABAD117

LESSON ONE: IT IS DIFFICULT TO ARTIFICIALLY CREATE A CULTURE SUPPORTIVE OF UA. 117

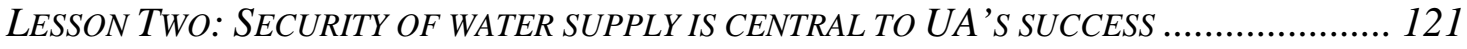

LESSON THREE: TO BE SUCCESSFUL, UA REQUIRES INSTITUTIONAL SUPPORT .................. 126

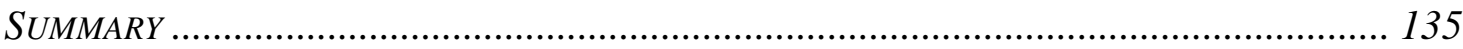

CHAPTER 8: FINAL DISCUSSION AND CONCLUSION .................................. 137

THE NEED FOR A LITERATURE THAT IS CRITICAL .................................................. 137

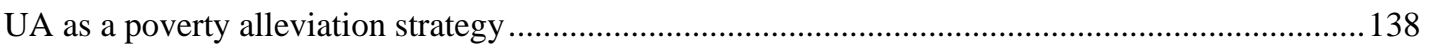

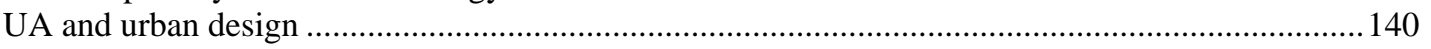

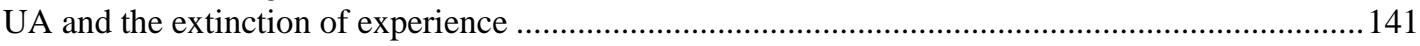

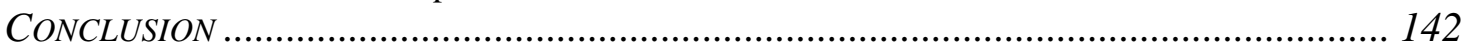

REFERENCES .............................................................................................. 144

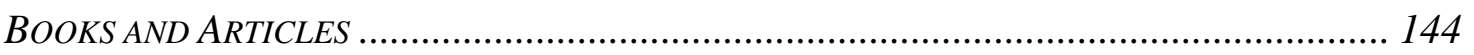


LOCAL GOVERNMENT DOCUMENTS.................................................................. 160

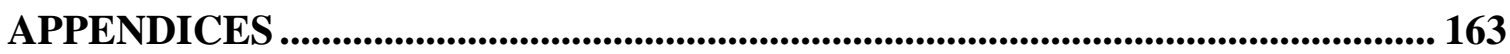

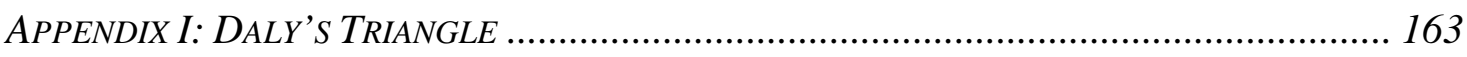

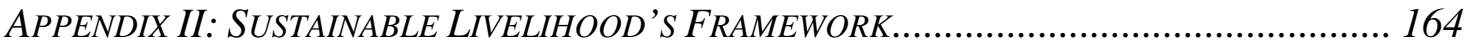

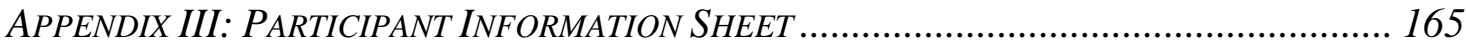

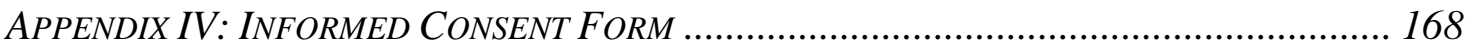

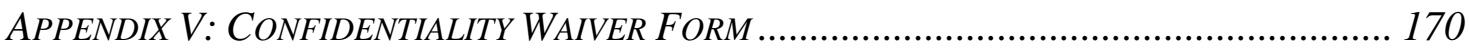

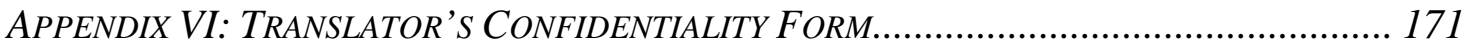

APPENDIX VII: FOCUS GROUP PARTICIPANT'S CONFIDENTIALITY FORM ........................ 172

APPENDIX VIII: PROVIDER'S OF RESEARCH CONTACT STATEMENT OF NON-DISCLOSURE .. 173 APPENDIX IX: "RAINWATER HARVESTING POTENTIAL FOR URBAN AGRICULTURE IN

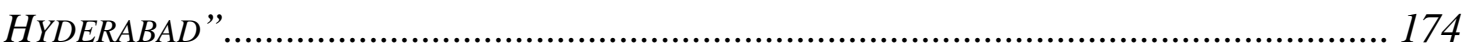

APPENDIX X: STRATEGIES FOR MEETING THE OBJECTIVE OF IKP-(U) ............................ 177

APPENDIX XI: TREE PLANTATION REQUIREMENTS DETAILED IN THE “ANDHRA PRADESH

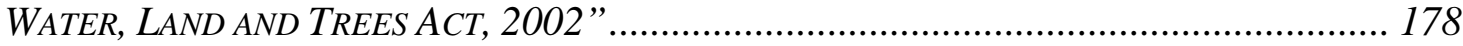

APPENDIX XII: OPEN SPACE STANDARDS AS PER BUILDING REGULATIONS ..................... 179 


\section{List of Figures}

FIGURE 1: DEPICTION OF THE DEFINITION OF DEVELOPMENT BEING USED IN THIS THESIS ...................... 17

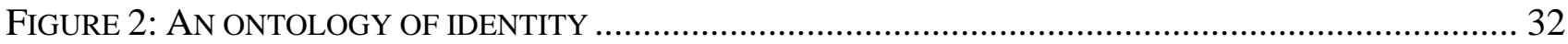

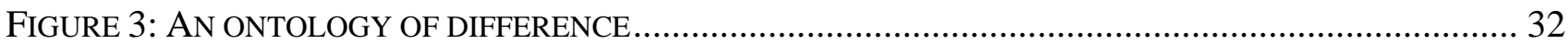

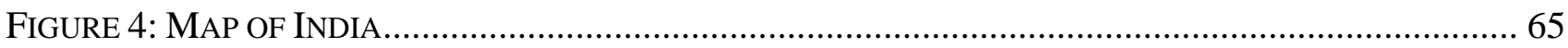

FigURE 5: JURISDICTION OF THE GREATER HYDERABAD MUNICIPAL CORPORATION (GHMC)............ 70

Figure 6: The Musi River, Hyderabad (Photo: Charlie Devenish, 2008) ................................... 80

Figure 7: Sign at Necklace RoAd, Beside Hussain Sagar, Hyderabad (Photo: Charlie

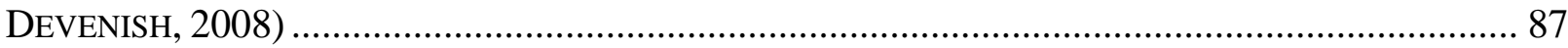

FigURE 8: PARA GRASS HARVESTING ALONG THE MUSI RIVER, NEAR OSMANIA GENERAL HOSPITAL,

HyderABAD (PHOTO: CHARLIE DEVENISH, 2008) …………................................................... 91

FIGURE 9: PARA GRASS BEING TRANSPORTED TO THE KACHIGUDA MARKET, HYDERABAD (PHOTO:

CHARLIE DEVENISH, 2008) ............................................................................................... 92

FIGURE 10: SUCCESSES OF THE RUAF-CFF PILOT PROJECT IN SURABHI COLONY, HYDERABAD ....... 102

FigurE 11: THE NEWLY EXTENDED GARDEN AT VeNKAT LAXMi's HOUSE, SURABHI COLONY,

HyderABAD (PHOTO: CHARLIE DEVENISH, 2008) .................................................................... 104

Figure 12: Construction Beside SuRABHi Colony, Hyderabad (Photo: Charlie Devenish, 2008) 124

\section{List of Tables}

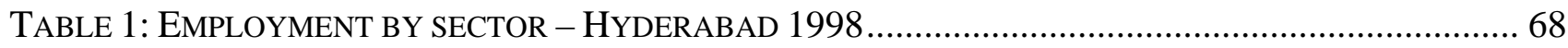

TABLE 2: PAST (2000) AND FUTURE (2020) LAND USE IN THE HUDA JURISDICTION ............................. 73

TABLE 3: PAST AND FUTURE LAND USE IN THE HUDA JURISDICTION (SUMMARISED VERSION OF THE SAME TABLE USED IN CHAPTER 5) ........................................................................................ 133

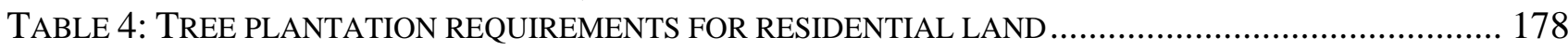

TABLE 5: TREE PLANTATION REQUIREMENTS FOR COMMERCIAL AND INSTITUTIONAL LAND ............... 178 


\title{
Acronyms and Abbreviations
}

\author{
APMEPMA Andhra Pradesh Mission for Eliminating Poverty in Municipal Areas \\ APUSP Andhra Pradesh Urban Services to the Poor \\ AVRDC World Vegetable Centre \\ CFF Cities Farming for the Future \\ DDP District Domestic Product \\ DfID Department for International Development (UK) \\ FAO Food and Agriculture Organisation \\ FSTT From Seed To Table \\ GDI Gender Development Index \\ GEMI Gender Empowerment Measure Index \\ GHEP Green Hyderabad Environment Programme \\ GHMC Greater Hyderabad Municipal Corporation \\ GSDP Gross State Domestic Product \\ ha Hectare \\ HDI Human Development Index \\ HMDA Hyderabad Metropolitan Development Authority \\ HMWS\&SB Hyderabad Metropolitan Water Supply \& Sewerage Board \\ HPI Human Poverty Index \\ HUDA Hyderabad Urban Development Authority \\ ICRISAT International Crops Research Institute for the Semi-Arid Tropics \\ IDRC International Development Research Centre \\ IKP - (U) Indira Kranthi Patham - Urban \\ INGO International Non-Governmental Organisation \\ INR Indian Rupee \\ IWMI International Water Management Institute \\ lpcd litres per capita per day \\ Mld Million litres per day \\ MPAP Multi-stakeholder Process for Action Planning and Policy Design \\ Mt Million tonnes \\ RUAF $\quad$ Resource Centres for Urban Agriculture and Food Security \\ RUAF-CFF Resource Centres for Urban Agriculture and Food Security - Cities \\ Farming for the Future \\ SHG Self Help Group \\ SLA Sustainable Livelihoods Approach \\ STP Sewerage Treatment Plant \\ TI Transparency International \\ UA Urban Agriculture \\ UN United Nations \\ UNDP United Nations Development Programme \\ UPA Urban and Peri-urban Agriculture \\ WCED World Commission on Environment and Development \\ WHO World Health Organisation \\ Exchange rate used: INR48.5 = US\$1 (x-rates.com, 9/2/09).
}




\section{Acknowledgements}

In India I would like to thank in particular Dr. Priyanie Amerasinghe of IWMI, without whose support much of the field research for this work would not have been possible. I would also like to extend a sincere thank you to the rest of the IWMI team, especially Sabaa Ishaq, KB Suleman and Venkat Radha for their patience and willingness to answer my innumerable questions about the RUAF-CFF pilot project.

My time at ICRISAT was made all the more pleasurable for the special friendship of BN Gnanesh, Sridha Kumar Chetneni, Gopal Reddy and Varsha Wesley; you all welcomed me, cared for me and showed me a side of India I would not have known were it not for your friendship. I would also like to thank the staff at Hotel Ranjit, in particular, Das and Raju who kept an eye out for me in my first weeks in Hyderabad.

I am also indebted to the people of Hyderabad. Most importantly I would like to thank the families of Surabhi Colony who allowed me the freedom to walk around, question and photograph their community. My experience was made all the more fun and interesting for your openness. I would also like to acknowledge the officials of the GHMC and HUDA who gave willingly of their time in interviews. Although they were busy, they still found time to talk with me about their city.

In New Zealand I would like to thank Dr. William Hipwell whose critical thinking and willingness to deeply question and challenge the way we live gave rise to this work. To both Bill and Dr. John Overton, thank you very much for your unerring support and belief in me as a scholar. Your questions, comments, suggestions and editing of this thesis have contributed greatly to the finished product and have helped to make it a piece of work of which I am proud to put my name (and I hope that you are too!). I would also like to give special thanks to Dr Michael Grimshaw from the University of Canterbury who inspired me as an undergraduate student and has been a mentor ever since.

Of course no work is possible without the dedicated support of friends and family, many of whom have been seriously neglected in the last year or more! To Claire, thank you for your support, 
especially while I was in India. To Aaron, you have been a great office mate. Cheers for providing evermore inventive excuses for a break! Dan, Paul and Andy: I’m back, finally! To Sean, you saved this work for me and I am eternally thankful for your guidance; future students will be blessed to have your support. Thank you. Lee, Dad and Margaret, thank you for being there to talk, to listen, to laugh and to cry.

And finally, to Mum, I wish that you were here to read this, even if you would probably have edited it beyond recognition! You remain with me daily and it is to you that I dedicate this work. 
Ah, but a man's reach should exceed his grasp, Or what's a heaven for?

Robert Browning

Andrea del Sarto 


\section{Chapter one: Introduction}

\section{The Ideal: Development in the current context}

As Robert Chambers (1997) says, change is inevitable.

"[It] ... is a natural condition of physical, biological and social systems" (Chambers, 1997:

$3)$.

Given this scenario, Chambers (1997: xiv) defines 'development' as 'good change': it is a means of shaping - or at least influencing in a positive way - the change that will occur naturally. To make Chambers' definition contemporary therefore, means equating development with sustainable development. In a world characterised by crises such as global climate change (UNDP, 2007; IPCC, 2007), a rate of species extinction between 100 and 1000 times higher than that to be expected naturally (IUCN, 2004; see also WWF, 2008) and the global economy's recent decline (Rossi, 2008), it would be fair to say that 'good change' necessitates development that is sustainable.

The term 'sustainable development' has gained much attention over the previous two decades (Adams, 2009: 2 - 3, 5), yet its most popular definition remains that published in Our Common Future (WCED, 1987), the report that came out of the World Commission on Environment and Development (WCED) (more commonly known as the "Brundtland Commission"). The WCED defined sustainable development as:

"... development that meets the needs of the present without compromising the ability of future generations to meet their own needs" (WCED, 1987: 43). ${ }^{1}$

Acknowledgement of the mutually dependent relationship between development and the environment forced the recognition that Earth and its inhabitants' main environmental problems were also the main developmental problems (Mitchell, 1997: 27; UNDP, 2007: 1).

Combining 'environment' and 'development' under the umbrella term 'sustainable development' has led to the notion of the 'four pillars of sustainability' (Nurse, 2006). ${ }^{2}$ This framework illustrates the

\footnotetext{
${ }^{1}$ Note that there is debate around the integrity of the very term 'sustainable development'. Mitchell (1997: 28 - 35) touches on some of these issues which include, amongst others: the inherent anthropocentrism of the term; inter- versus intra-generational equity; indigenous rights; and developing versus developed world wants, needs and capabilities. See also: Turner (1997: pp. 412 - 426).
} 
point that sustainability cuts across the four main 'capitals' (i.e. elements) of society: social capital (the structure and networks of society i.e. community), cultural capital (knowledge, identity, morality and ethics), natural capital (non-human species, natural resources and the environmental services they provide) and economic capital (the means of production and generation of income) (see Adams, 2009: 148; Statistics NZ, 2002: Appendix; and Turner, 1997).

Conceptualising development as 'good change' across the four pillars of sustainability therefore broadens the focus, making its aim development that is holistic. By focusing on the ultimate end of 'well-being' (Meadows, 1998: 42, 66; see also Nurse, 2006: 35), sustainable development marks a departure from past development theories' preoccupation with industrialisation and economic growth. $^{3}$ As Donella Meadows has illustrated through presentation of the 'Daly Triangle' (Daly, 1973: 8 cited in Meadows, 1998: 42, reproduced in Appendix I), social, cultural, natural and economic forms of capital ${ }^{4}$ must all be utilised in a sustainable manner if overall well-being is to be achieved.

Thinking of development in this more holistic way has spurred the "Sustainable Livelihoods Approach” (SLA) which posits that natural, social, human ('cultural' capital in my schema), financial ('economic' capital in my framework), and physical (a combination of 'economic' and 'natural' capital in my conceptualisation) forms of capital provide 'income streams' that are integral to one's life and well-being (see the Department for International Development diagram in Appendix II). Access to - and ownership of - streams of benefit ${ }^{5}$ that come from each of the different capitals is necessary to enable a sustainable livelihood, and, ultimately, attain and sustain well-being.

Gaining and maintaining access to these different benefit streams requires development to, as Amartya Sen (1999: 3) puts it:

\section{“... remov[e] [the] major sources of unfreedom ...”}

\footnotetext{
${ }^{2}$ Note that sustainability is traditionally considered to have three pillars - 'social', 'environmental' and 'economic' however, 'culture' has more recently been included as the fourth pillar of sustainability (see in particular Hawkes, Jon (2006) The Fourth Pillar of Sustainability: Culture's essential role in public planning).

${ }^{3}$ Examples here are of Walt Rostow's "The Stages of Economic Growth" (from the 1950s and 1960s modernisation theory) and, more recently, the 1980s neo-liberal theory which applied a single, econo-centric blueprint approach to development (see Preston, 1996), ideas which Chambers (1997: 1) correctly notes we can now see as naïve.

${ }^{4}$ Note that the Daly Triangle uses the terms 'built' and 'human' capital in place of the 'economic' and 'cultural' capitals used respectively within the traditional 'four pillars of sustainability' framework.

${ }^{5}$ Sen (1981) uses the term 'entitlements' while Chambers and Conway (1992) use the term 'assets'.
} 
As such, development must be about alleviating poverty as it is a barrier to well-being. By fusing Sen's definition of development with that described above, the concept of development to be used in this work is as follows:

Development means removing the barriers that obstruct the streams of income / benefit that flow from the four capitals which, when combined, create and sustain well-being (see Figure 1 below).

Figure 1: Depiction of the definition of development being used in this thesis

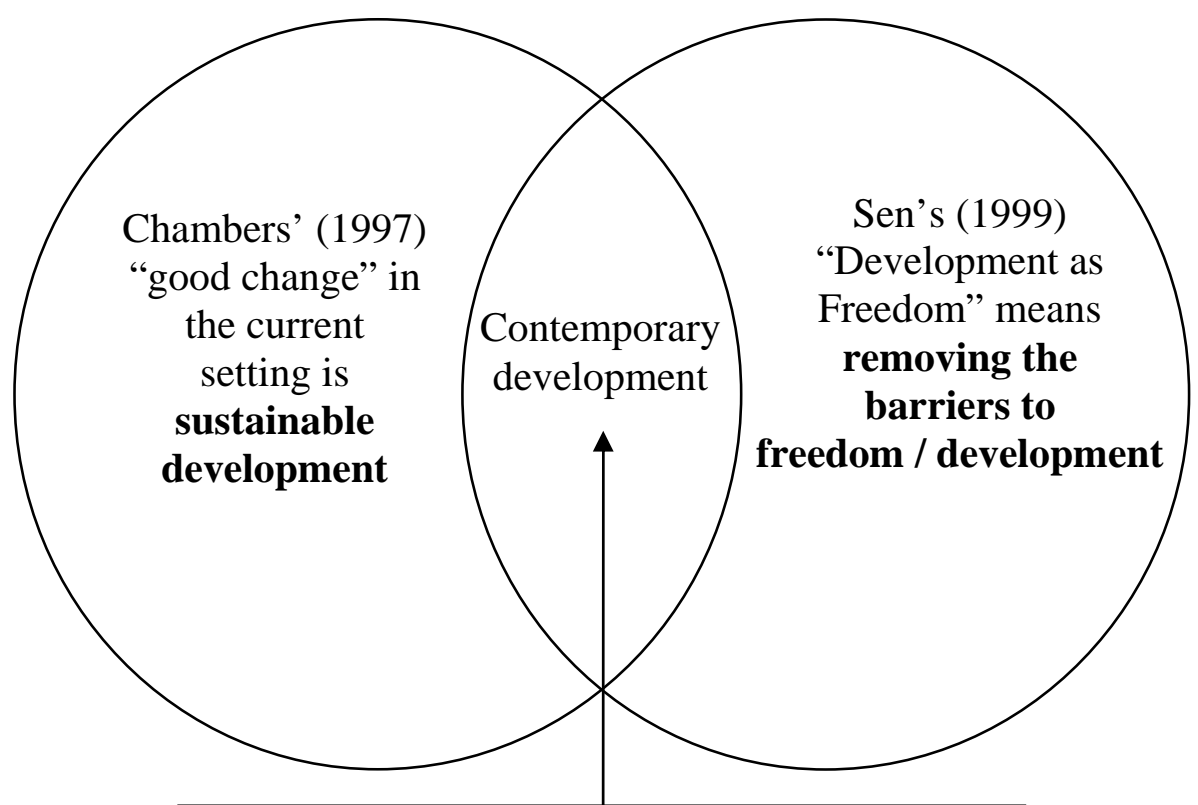

Development is about removing the barriers to social, cultural, environmental and economic capital - the components necessary for sustained, holistic well-being 


\section{The Problem: The spread of poverty is creating barriers to sustainable development}

Conceptualising development in the way it is defined above means that the notion of poverty is farther-reaching and its manifestations inherently more complex as they cut across social, cultural, environmental and economic aspects of society. As such, the definition of poverty to be used in this work is broad, meaning:

“... deficiency, lack, scantiness, dearth, scarcity; smallness of amount ...” (Oxford English Dictionary, 2009).

As will be illustrated presently, framing poverty in such terms reaches beyond the typical - yet still worthy - characterization of poverty, the essence of which is evident in the World Bank's description of poverty:

"Poverty is hunger. Poverty is lack of shelter. Poverty is being sick and not being able to see a doctor. Poverty is not having access to school and not knowing how to read. Poverty is not having a job, is fear for the future, living one day at a time. Poverty is losing a child to illness brought about by unclean water. Poverty is powerlessness, lack of representation and freedom” (World Bank, 2009).

In a world that is rapidly urbanising - indeed over half of humanity now lives in urban areas (UN, 2005) - development is increasingly coming to focus on sustainable urban development and the alleviation of urban poverty (Martine et al., 2008). What follows therefore, are examples of the types of urban ${ }^{6}$ poverty that inhibit sustainable development as it has been defined above. As such they could be seen as examples of the 'unfreedoms' of which Sen (1999) speaks. They could also be considered dams which obstruct the streams of income / benefit that flow from the forms of capital that Meadows (1998) and the SLA specify as necessary to create and sustain well-being.

\footnotetext{
${ }^{6}$ Note that these forms of poverty are not exclusive to, but rather more clearly evident in, urban centres.
} 


\section{A poverty of social capital}

Central to the notion of social capital is community (Adams, 2009: 148). Strong, connected communities are vital for building resilience and for providing the support networks necessary to guide us through the current crises. However, despite the proximity to other people urbanisation creates and the potential this provides for building strong, tight-knit communities, it has had the reverse effect of increased individualisation, inter-personal competition and the breakdown of community.

The desire for urban dwellers to consume at a rate that 'keeps up with the Joneses' - a situation which sees people forever trying to attain, maintain and then ultimately surpass the material status 'enjoyed' by their neighbours - has resulted in a society that not only perpetuates unsustainable lifestyles, but results in a form of social poverty that promotes the competitive acquisition of privately owned land, material possessions, and money. The bankruptcy of such action results in "affluenza"7: a disease-like affliction that motivates the accumulation of wealth and affluence in the hope that these things will bring the individual increased happiness (Hamilton and Denniss, 2005: 56; Hamilton, 2003: 23). As argued by Hamilton and Denniss (2005: 5) however, affluenza ultimately results in increased stress, overwork and waste as individuals strive to surpass the level of affluence attained by their peers.

The spread of affluenza throughout contemporary industrialised and industrialising societies also has negative effects on the community's well-being. As individuals' free time is increasingly taken up by work, community becomes something from which people would rather insulate themselves, than involve themselves (Hamilton and Denniss, 2005: 94 - 97). ${ }^{8}$ Not only does community demand an investment of time - and thus a reduction of the amount of time one could potentially be earning or spending money - but affiliation with a community can be seen as impinging upon the individual's ‘unique’ identity (see Hamilton, 2003: Chapter Three; Hamilton and Denniss, 2005: 13 - 16; Klein, 2000). ${ }^{9}$

\footnotetext{
${ }^{7}$ Hamilton and Denniss (2005: 195) state that the term was popularized by the documentary Affluenza aired on KCTS/Seattle and Oregon Public Broadcasting in 1997.

${ }^{8}$ For a much more elaborate discussion of the breakdown of community and its effects see Freie (1998).

${ }^{9}$ Note the scare marks used around the word unique, for in a society afflicted by affluenza, there are no real opportunities for uniqueness. It is increasingly acknowledged that in our consumer society 'identity' is defined by how one spends their money: we are all choosing from a selection of pre-made, mass-produced - yet marketed as unique 'identities’ (See Hamilton, 2003: Chapter 3; Hamilton and Denniss, 2005: 13 - 16; Klein, 2000).
} 
The spread of affluenza has resulted in a society where individual identity is defined by the accumulation of wealth and consumer goods (Hamilton and Denniss, 2005: 13-14; Holsworth and Wray, 1982 in Freie, 1998: 6; Hamilton, 2003: Chapter Three). The elevation of such material possessions as signifiers of success in our society has eroded the amount of time and effort people are willing to commit to building strong, resilient and genuine communities, the existence of which are vital for sustainable development and holistic well-being. This social poverty, most prevalent in the urban centres of human civilization, is exacerbated by humanity's disconnection from its wider natural environment and has resulted in a form of cultural poverty called "the extinction of experience”.

\section{A poverty of cultural capital}

Recognition of humanity's and our co-inhabitants' dependence on Earth's health for our own (and our co-inhabitants') current and future well-being is clearly evident in the instance of climate change. Indeed, the United Nations has labelled climate change the single most urgent issue of our generation (UNDP, 2007: 1), noting that it serves as a "potent reminder" of the fact that we all share one Earth (UNDP, 2007: 2). ${ }^{10}$

Despite recognition of our utter dependence on Earth, our co-inhabitants and the ecosystem services they provide, humanity continues to exploit, degrade and destroy the host environment that we all share. While Plumwood (2002: 2) has labelled such action irrational, and Miller (2005: 431) has termed it the problem of "biological impoverishment”, I would go further to agree with Hipwell's (2004: 358) appraisal that it is "pathological behaviour”. To knowingly destroy that which makes our very existence possible is nothing short of suicidal.

In an attempt to explain the situation that has led to such degradation of our environment Robert Pyle (1978 cited in Pyle, 2003: 209) has coined the phrase "the extinction of experience”. Pyle’s work is closely linked to E.O. Wilson’s “biophilia” hypothesis (1984 cited in Pyle, 2003: 206): that all

${ }^{10}$ The Millennium Ecosystem Assessment (2005b: 2) stresses the vitally important interaction and inter-connection humanity has with the rest of Earth's inhabitants, the absence of which would make human life on Earth not possible. 
human beings have, to a certain degree, an “innate affection for living things” (Pyle, 2003: 206). As such it can be seen as a form of cultural capital: it is knowledge vital for our survival.

Pyle's argument is that through the gradual reduction in the number of encounters with nature (the extinction of experience), humanity’s curiosity for - and love of - nature dissipates (Pyle, 2003, pg. 209). The fear is that the increasing incidence of the extinction of the experience of nature will eventually lead to a society that is biophobic (fearful and loathing of nature) instead of biophilic (loving of nature).

The threat of this situation is most obvious in the city where unsustainable urban development and expansion is replacing nature (Pyle, 2003: 208; see also Hipwell, 2004: 368; Miller, 2005; and Sánchez-Rodriguez, 2008). In a study of four urban centres in the United States it was found that the potential for experiencing nature had decreased dramatically, especially in locations where rapid suburbanisation had taken place (Pyle, 2002 cited in Pyle, 2003: 209). Miller (2005: 430) cites an Australian report in which it was found that many of the primary school children in the Perth-based survey did not know that the cotton with which their clothes was made came from plants and that the milk they drank had come from cows! A similarly concerning point is the assertion by Paul Hawken (1993 cited in Miller, 2005: 430) that although the majority of Americans can recognise hundreds of commercial logos, they can identify fewer than ten native species.

The damage such ecological illiteracy could cause must not be underestimated. Although Wilson's (1984) biophilia hypothesis posits that affection for nature and living things is innate, if people at a young age do not have the ability to act on such urges to encounter nature for the basic reason that there is no natural habitat in their locale, then there is the real threat that they will grow up apathetic to nature (Pyle, 2003: 208, 209; Dunn et al., 2006: 1815; see also Kahn, 2002 cited in Miller, $2005:$ 431). ${ }^{11}$

\footnotetext{
${ }^{11}$ On this point Miller (2005: 431) speaks of the "shifting baseline syndrome”, otherwise known as "environmental generational amnesia” (Miller, 2005: 431 cites Kahn and Friedman, 1995; and Kahn, 2002). The essence of this notion is that throughout our life we compare the state of the environment back to what we knew it to be in our childhood; with each generation therefore, there is a “...ratcheting down of expectations regarding the quality and ecological function of natural areas closest to people's homes and workplaces” (Miller, 2005: 431).
} 
As inhabitants of a single planet, the culture we share with our co-inhabitants is based on knowing Earth. Urbanisation is exacerbating humanity's dislocation from nature, making more real the threat of an ecologically illiterate and biophobic society. Erosion of this form of cultural capital puts in doubt the benefits that flow from an ecologically literate society and serve to obstruct sustainable development's aim of holistic well-being.

Brief consideration of a select few examples of humanity's degradation of the environment will help illustrate the consequences of denying our innate cultural connection with the rest of Earth and its inhabitants.

\section{Poverty of natural capital}

Damage to the environment (natural capital) undermines one's own and one's community's ability to achieve a sustainable livelihood and attain holistic well-being. As a process urbanisation can be seen to affect the environment in at least two ways, thereby exacerbating a poverty of natural capital: 1) by converting land to directly urban uses such as housing, roads, industry etc.; and 2) by converting increasingly distant hinterlands and their resources to uses that supply the urban centre's growing demand for food, commodities, natural resources and the like (Sánchez-Rodriguez, 2008; van Veenhuizen, 2006: 8; van Veenhuizen and Danso, 2007: 13; Ramachandraiah and Prasad, 2004: 7; and Nugent, 2000: 68 - 69).

What follows is a brief presentation of a select few examples of poverties of natural capital that urbanisation is, if not explicitly causing, then certainly exacerbating. It is by no means intended to be an exhaustive list.

\section{Climate change}

As a major source of greenhouse gas emissions, the city is an obvious driver of climate change (Sánchez-Rodriguez, 2008: 154 - 157). However, climate change is not in itself a form of poverty meaning a lack or scarcity of something - but rather a cause of poverty. Although climate change will exacerbate poverty of the environmental services and natural resources to be presented, given that it is not a form of poverty per se it will not be further discussed here. 


\section{Poverty of ecosystems}

The conversion of land not currently utilised by humans to serve cities' growing demands results in a form of poverty as ecosystems and their ability to provide environmental services to both human and non-human species is reduced (Sánchez-Rodriguez, 2008: 153). The cutting down of trees to make way for roads, for example, not only destroys a habitat for birdlife but results in a net increase in carbon dioxide emissions. The carbon sequestration capacity (the environmental service) of the forest has been lost and, furthermore, what was once a carbon sink, has, with the construction of a road, been converted into a carbon source. Similarly, the drainage of swamps for residential development or the construction of shopping centres and car parks to serve the suburbs creates a form of poverty that not only destroys an ecosystem, but reduces the potential for natural groundwater recharge and water purification (Deelstra and Girardet, 2000: 52; Midmore and Jansen, 2003: 19).

\section{Water poverty}

The notion "water poverty" (Molden, 2007: 151) seems fitting when one considers that one fifth of the world's population already live in areas of physical water scarcity (Molden, 2007: 10). That this figure is set to increase to 25 percent of the world's population by 2025 is cause for concern (IWMI, NDa: 4).

A brief consideration of Chennai (formerly Madras) in India will illustrate how urbanisation can heighten a regions water scarcity. The 2001 initiation of a scheme by which the Chennai Metropolitan Water Supply and Sewerage Board (CMWSSB) purchases water from private borewell owners in the Magaral area some $40 \mathrm{~km}$ north-west of the city has had considerable impact on that community (Ruet et al., 2007: 113). Of the 59 farmers surveyed in the area, eleven had to stop cultivation altogether while seven others had to change the type of crops they grew due to the water shortage created by the sale of local water to the CMWSSB (Ruet et al., 2007: 116).

Urbanisation not only increases pressure on the surrounding region's water resources, but it pollutes freshwater, thereby exacerbating water poverty. An estimated 75 - 85 percent of the water that enters a city leaves the area as wastewater (Buechler and Scott, 2006: 1; Buechler, 2004: 28); how this wastewater is dealt with has an obvious impact on the inhabitants (both human and non-human) 
of the city and its surrounding area. As will be further discussed in Chapter five, wastewater management is an acute issue in Hyderabad, the location of fieldwork for this thesis.

\section{Poverty of forests}

It is reported that globally the amount of land covered by forest has decreased by 50 percent over the previous 300 years (MEA, 2005 cited in Adams, 2009: 244) and that an area of forest the size of a football pitch is felled every two seconds (Greenpeace, 2005: 6). A poverty of forests not only exacerbates climate change as the amount of carbon dioxide that can be sequestered is decreased with each tree felled, but, as will be illustrated under the heading "Poverty of biodiversity", deforestation has dire consequences for the non-human species that inhabit Earth. While urbanisation cannot be blamed solely for deforestation, the conversion of forested land to produce food and resources for growing urban populations is one of the many issues driving deforestation (see Adams, 2009: Chapter 9 for a discussion of deforestation and its causes).

\section{Soil poverty}

Urbanisation is consuming Earth's already limited supply of available farmland, exacerbating the poverty of arable land. As cities grow and land uses change from rural to urban, increased pressure is placed on land not currently being utilised by humans to be converted to meet the growing wants and needs of the city and its population (Sánchez-Rodriguez, 2008: 153). The Millennium Ecosystem Assessment (2005a: 12) states that more land was converted from forest, savannah, and natural grassland to farmland in the thirty years between 1950 and 1980 than in the 150 years prior to 1950. This has lead to a situation in which almost 25 percent of Earth's land surface is under cultivation (MEA, 2005a: 12). Evans (2008: 4) reports that the Food and Agriculture Organisation (FAO) estimate there to be, at most, 12 percent more land available for cultivation that is not already forested or degraded by erosion or desertification. Indeed, the amount of arable land per capita decreased from 0.235 hectare (ha) in 1951 to just 0.127 ha in 1993 (Gregory et al., 2002: 281).

The loss of topsoil at a rate between 10 and 40 times that at which it can be formed (Diamond, 2005: 489) is resulting in what could be called 'soil quality poverty'. Indeed, it is partly due to this loss of healthy, productive soil that farmers are intensifying their farming techniques - “... producing more of the desired products per unit area of land already used for agriculture” (Gregory et al. 2002: 280) - which in turn further degrades the soil's natural quality. The application of synthetic inputs 
globally has skyrocketed - between 1960 and 2000 the global application of synthetic nitrogen fertiliser increased from 10.8 Million tonnes (Mt) to 85.6 Mt per year (FAO, 2002b cited in Crews and Peoples, 2004: 280) - however, such farming techniques undermine the soil's natural ability to supply crops with the necessary nutrients for plant growth, thereby perpetuating the destructive cycle of more chemicals being applied to make up for the soil’s poverty of nutrients.

\section{Poverty of biodiversity}

Finally, while the destruction of ecosystems and the degradation of natural resources' quality and quantity limit humanity's livelihood and well-being, it has rather more immediate and adverse effects on the habitat of Earth's non-human species and their biodiversity. The Millennium Ecosystem Assessment (2005a: 3) states that:

"Human activities have taken the planet to the edge of a massive wave of species extinctions ...”

It is anticipated that in the next century some 12 percent of birds, 25 percent of mammals and 32 percent of amphibians will be threatened with extinction (MEA, 2005a: 15). WWF's Global Living Planet Index (WWF, 2008: 6) which measures biodiversity across 4642 populations of 1686 species reported a loss of 28 percent of biodiversity between 1970 and 2005.

This growing poverty of biodiversity is echoed in the genetic diversity of crop species. Through the practices of mass production, genetic engineering and the increased use of fertilisers, pesticides and fungicides, crop species’ natural diversity is also being undermined (MEA, 2005b: 3).

\section{A poverty of economic capital}

Poverty in economic terms is perhaps the most obvious and often cited manifestation of poverty: indeed, the poverty line itself is defined in dollar terms. ${ }^{12}$ Conceptualising development in the way it has been done in this work - as seeking to remove the barriers that obstruct the streams of income / benefit that flow from the four capitals which, when combined, create and sustain overall well-being - implies not only access to economic capital in the form of money, but also a certain amount of

\footnotetext{
${ }^{12}$ The World Bank has set the international poverty line at US1.25 per day (2005 Purchasing Power Parity) (World Bank, 2009) which, at time of writing, is equivalent to approximately INR61.
} 
autonomy to enable sustained access to that benefit stream. As Rossi (2008: 7) has pointed out, however, the recent collapse of the global economy has illustrated that:

“... the global economy and financial system ... is now too big for any one country to control on its own.”

If this is indeed the case, it seems that the ability for individuals to gain - let alone sustain - control over their own economic capital is similarly in doubt. Evidence of the vulnerability caused by this situation is evident in the case of food security.

\section{Food (in)security}

Food (in)security is one of the most fundamental issues that illustrates urban dwellers' sensitivity to the global economy (see van Veenhuizen, 2006: 3; van Veenhuizen and Danso, 2007: 8 - 9; ArmarKlemesu, 2000: 100, 102; and Deelstra and Girardet, 2000: 45). Indeed, the riots over rising food prices in Les Cayes, Haiti in April 2008 are clear evidence of this vulnerability (see BBC, 5/4/08).

The FAO (2003) defines food (in)security in the following way:

"Food security exists when all people, at all times, have physical, social and economic access to sufficient, safe and nutritious food which meets their dietary needs and food preferences for an active and healthy life. Household food security is the application of this concept to the family level, with individuals within households as the focus of concern." "Food insecurity exists when people do not have adequate physical, social or economic access to food as defined above” (FAO, 2003: Section 2.2).

Given that urbanites are largely dependent on the supply of food from rural and/or global markets, and, that they are (generally) forced to purchase the majority of their food with their income (Mkwambisi et al., 2007: 6), I would argue that based on the FAO's definition of food (in)security, city dwellers are food insecure because they lack physical access “... at all times ... to sufficient, safe and nutritious food ..."

The reason city dwellers' food supply is insecure is because it is at the mercy of external factors influencing the food supply chain. Issues such as: urbanisation, population growth, climate change, water scarcity, energy prices, income growth, changes to more resource-intense diets and the increasing control that international corporations have in especially developing countries' food 
production systems are all affecting the world economy, food system and, ultimately, the price one has to pay for food at the market (Hubbard and Onumah, 2001; von Braun, 2007; Evans, 2008).

As net buyers of food, urban households are therefore more vulnerable to food price rises than are their rural counterparts (von Braun, 2007: 13; van Veenhuizen, 2006: 3; Armar-Klemesu, 2000 : 100). The FAO (2002a) states that urban populations spend on average 30 percent more ${ }^{13}$ on food but in doing so receive fewer calories than their rural counterparts. With global food prices having risen 83 percent in the previous three years (Evans, 2008: 1), urbanites' food insecurity is made clear and is used in this work as evidence of a poverty of economic capital.

\section{The Proposed Solution: Urban Agriculture}

Given such examples of poverty of the forms of capital necessary for sustained well-being, the obvious next question is what can be done about it? The aim of this thesis therefore is to investigate the efficacy of urban agriculture (UA) as a method of sustainable urban development, one that seeks to alleviate the abovementioned forms of poverty.

A review of the literature relating to UA will be made in Chapter four, for now however, it is suffice to provide the most widely referred definition of UA:

"[UA is] ... an industry located within (intraurban) or on the fringe (periurban) of a town, a city or a metropolis, which grows or raises, processes and distributes a diversity of food and non-food products (re-)using largely human and material resources, products and services found in and around that urban area, and in turn supplying human and material resources, products and services largely to that urban area” (Mougeot, 2000: 10).

Through a case study of the Resource Centres for Urban Agriculture and Food Security - Cities Farming for the Future (RUAF-CFF) kitchen garden pilot project based in Surabhi Colony, Serilingampally, Hyderabad, India, this work will assess the efficacy of UA to alleviate the aforementioned poverties of capital. The objective is to ascertain whether UA can contribute to:

1) building a stronger community, thereby fostering social capital;

${ }^{13}$ Armar-Klemesu (2000: 102) places it at between 10 and 30 percent. 
2) forming a greater connection with nature, counteracting the extinction of experience and thus adding to cultural capital;

3) increasing positive interaction with, and management of, the local environment, thereby helping to improve natural capital; and

4) providing food, thus improving food security and economic capital.

Before embarking on the investigation of UA's sustainable development and poverty alleviation credentials however, a brief overview of the structure of the thesis will illustrate how I intend to achieve the aim of this work. The next chapter (two) will consider the cause of our current predicament: a situation in which we are contemplating our own, our co-species and Earth's future destruction (Plumwood, 2002: 5). As will be proposed, the root cause of our dilemma is philosophical and, as such, its solution lies in a re-working of our ontology. Such a philosophical demand requires that I conduct my own research through an epistemology that avoids perpetuating our past destructive ways of 'being' and 'knowing'. Chapter three will therefore explore the research methods used in this work.

Chapter four will mark the transition from exploring the cause of our current situation to investigating this work's proposed solution: UA. A review of the literature in Chapter four will bring the reader up-to-date with the past and present research and thinking on UA. The following chapter (five) will provide an introduction to Hyderabad, the city in which the field research was conducted. Chapter six will present and discuss the findings from the Surabhi Colony case study which illustrate the success of UA as a method of sustainable development and poverty alleviation. Chapter seven will then consider the barriers to UA's future and further spread throughout Hyderabad more generally. Finally, Chapter eight will conclude the thesis by weighing-up the evidence found to determine how effective UA is as a method of sustainable urban development. In particular, its use for alleviating the poverties of capital presented in this, the first chapter of the work will be discussed.

Without further delay we must turn to a consideration of the cause of our current situation and in so doing, explore the philosophy that underpins this work. 


\section{Chapter two: Conceptual Framework}

\section{The cause of our current predicament}

"Our civilisation, which subsumes most of its predecessors, is a great ship steaming at speed into the future. It travels faster, further, and more laden than any before ... The vessel we are now aboard is not merely the biggest of all time; it is also the only one left. The future of everything we have accomplished since our intelligence evolved will depend on the wisdom of actions over the next few years. Like all creatures, humans have made their way in the world so far by trial and error; unlike other creatures, we have a presence so colossal that error is a luxury we can no longer afford. The world has grown too small to forgive us any big mistakes" (Wright, 2004: 3).

Many have written on the evolution of humanity's growing control and gradual destruction of nature and natural capital. In 1967 Lynn White Jr. pointed out that how we approach ecology depends upon the way in which we perceive the relationship between humanity and nature. White argues that the origin of our current ecological crisis lies in Christianity's elevation of humanity as superior to the rest of God's creation. He writes:

"Man [sic] named all the animals, thus establishing his dominance over them. God planned all of this explicitly for man's benefit and rule: no item in the physical creation had any purpose save to serve man's purposes" (1967: 5-6).

To White (1967: 6) it is this anthropocentric focus of Christianity that has enabled humanity to reign supreme and rule with such indifference to the rest of Earth and its inhabitants' well-being.

A notion linked with, but not exclusive to, Christianity that White (1967: 5) mentions as being worthy of blame for the ecological crisis is the re-working of how we conceptualise time. By replacing cyclical notions of time - often associated with pantheistic, animist and/or pagan belief systems - with those that are linear (i.e. the Christian creation story), an unerring belief in 'progress' as the essence of life is constructed. Our time on Earth thus becomes characterised, and ultimately judged, by the 'progress' we have made. 
As Ronald Wright (2004: 5) has written, however, the notion of progress creates a self-perpetuating cycle that “... can lead beyond reason to catastrophe”. Writing in reference to the advent of the atomic age, Winston Churchill illustrates the point succinctly:

"Mankind [sic] has never been in this position before. Without having improved appreciably in virtue or enjoying wiser guidance, it has got into its hands for the first time the tools by which it can unfailingly accomplish its own extermination.” (Churchill, 1948: 40).

This is, as Wright (2004: 5) would say, evidence of “... rather too much progress”.

In much the same way as "affluenza” (Hamilton and Denniss, 2005) encourages pursuit of a distant, yet ultimately unattainable level of affluence, a preoccupation with 'progress' can lead to a situation in which the 'present' becomes a permanent stepping-stone to a promised future of happiness that in fact never eventuates (Tenbruck, 1991: 199). It is perhaps such a realisation that led the great Indian poet Rabindranath Tagore to write:

“... progress for whom ... progress toward what?” (cited in de Rivero, 2001: 112).

It would be wrong, however, to focus all of the blame for our current crises on such things as Christianity's story of creation or the replacement of cyclical conceptions of time with linear ones that promote progress. As illustrated in Collapse: How Societies Choose to Fail or Survive, Diamond (2005) explains that there have been many past civilisations that have done to themselves what it seems we are in the midst of doing: driving ourselves to extinction (Plumwood, 2002: 5). The obvious aim, therefore, is to work out what needs to be done to: “... plot a wise course between the narrows and bergs looming ahead ... [of our] ... great ship” (Wright, 2005: 3).

\section{The need for a change of tack in our ontology}

In overcoming “Industria” (Hipwell, 2004; 2007) - the metaphorical machine-like organism, which, as the antithesis of Gaia (Lovelock, 2006), Hipwell uses to explain the current destruction of Earth and subjugation of its inhabitants - Hipwell (2004: 359 - 361) invokes Deleuze's call for a shift in ontology (the nature of 'being') from one of identity to one of difference. 
Figure 2 below illustrates very basically what Hipwell (2004: 359) argues: that an ontology of identity leads to an atomistic, and, I would add un-holistic, conceptualisation and interpretation of life. In this ontology, objects, 'things' and ideas are defined in opposition to one another. This process of definition by repudiation leads to a way of viewing the world that is destructive because it sees everything as isolated from the greater web of life, denying that each object, 'thing' or idea is inextricably connected to all other objects, 'things' and/or ideas. As Plumwood (2002: 4) argues, humanity's false sense of independence from nature, a type of "hyperbolised autonomy" has created a:

“... human identity that promote[s] human distance from, control of and ruthlessness towards the sphere of nature as the Other ...” (Plumwood, 2002: 4). 


\section{Figure 2: An ontology of identity}

Atomistic objects, things and/or ideas are connected by restricted lines of communication. Interpretation is limited to the bounds of both the object/thing/idea and its connection with the other defined and identified objects/things/ideas. In this ontology, reality and understanding are based on the modernist ideal of empiricism.
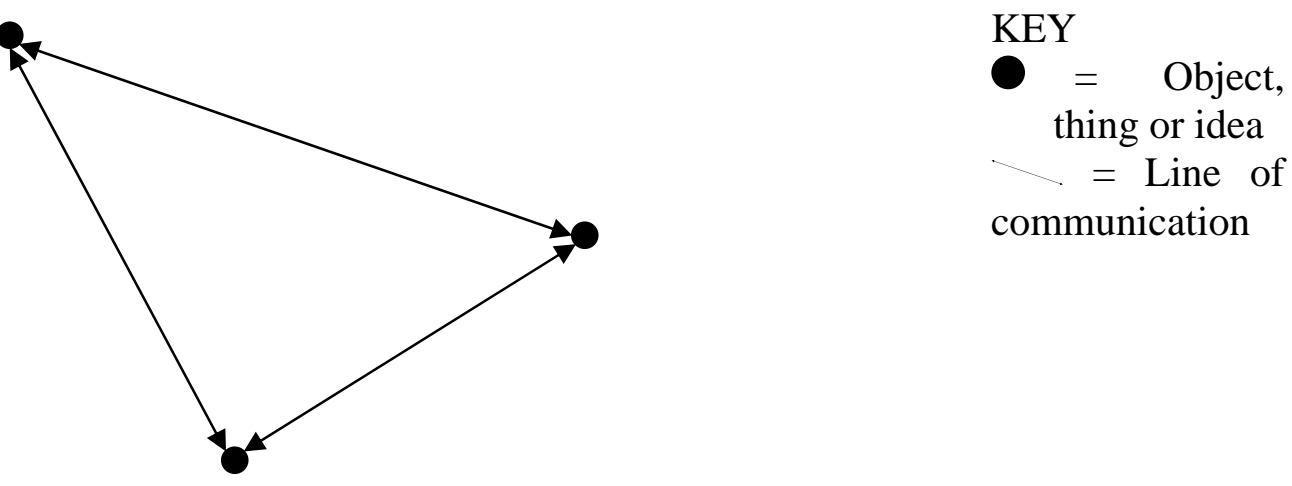

\section{Figure 3: An ontology of difference}

Each object/thing/idea and its line of communication have endless possibilities. Every object, thing or idea is on a spectrum of intensity which is defined in relation to its interaction with its surrounding objects, things and/or ideas. Therefore every entity is unique to its context and is the result of the interaction with its surrounding environment. Understanding and interpreting objects, things and ideas is thus characterized by its opportunity, not limited by its definition.

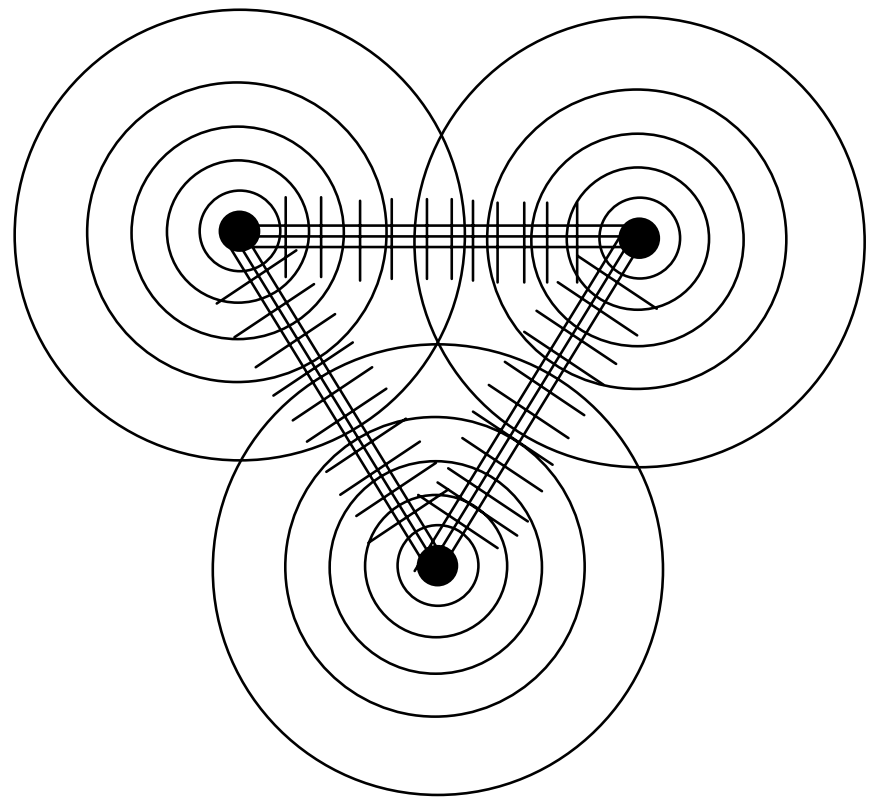

KEY

(Q) = Object, thing or idea

Space
communication 
This notion of the 'other' has of course been used (and popularised) before. Edward Said (1978) has argued that through Western culture's creation of the 'Orient' as the West's 'other' it has been made to appear in much the same way as Plumwood speaks of nature as humanity's 'other'. Be it nature or a different culture, the 'other' is constructed as:

“... passive, mute, irrational, feminised, exoticised and subordinate for the Western masculine gaze, with the will to control, manipulate and incorporate it” (Mohammad, 2001: 103).

It is the West's employment of this ontology that has led to what Plumwood (2002 cited in Rose, 2005: 302) has called "hegemonic anthropocentrism", a term that may be used to explain humanity's current destruction of Earth's natural capital as it was outlined in the previous chapter. Such an approach to the rest of Earth and its inhabitants - that they are for utilisation by humanity and humanity alone - may also explain what Plumwood (2002 cited in Rose, 2005: 302) has dubbed humanity’s “hyperseparation” from other living things.

The ultimate effect of this psychological state is present not only in humanity's growing disdain for nature (through the extinction of experience) and the resultant poverty of cultural capital discussed in the preceding chapter, but it extends beyond, into the realm of inter-personal relations. As explained in Chapter one, the individual's 'hyperseparation' from the wider community is eroding social capital as community becomes something from which the individual insulates, rather than involves themselves (c.f. Hamilton and Denniss, 2005 and Freie, 1998).

\section{The change we need}

Overcoming this disjuncture between humanity, Earth and our co-inhabitants of Earth is necessary if we are to attain and sustain well-being that cuts across the four pillars of sustainability. Figure 3 above illustrates how by shifting to an ontology of difference, we are enabled to view life in a much more holistic way.

Like deep ecology (Halsey, 2006: 28), an ontology of difference perceives that rather than being single, isolated and explicitly defined, objects, 'things' and ideas are comprised of - and informed by 
- all other surrounding objects, 'things' and ideas (Hipwell, 2004: 360). By re-connecting with the surroundings (both physical and metaphysical), an ontology of difference appreciates that everything is made up of intensities of everything else. In this way the interconnection of objects, 'things' and ideas is made more apparent (c.f. Capra, 1997 and the idea of systems thinking). By interpreting life in its entirety, a more holistic and nurturing relationship can thus be established between Earth and its inhabitants.

Promoting such an ontology and epistemology in today's world represents a 'post-modern' approach $^{14}$ which, in a development setting, draws links with post-development theory. Installing a conceptual framework based on holism and sustainability seeks to, in a sense, 'right the wrongs' of past development. In an attempt to make development more relevant to - and informed by - the local context, its people and their culture, post-development seeks to avoid the mistakes made by past modernist-tinged, West-centric and proscriptive forms of development (Escobar, 1995: 218).

Adoption of a post-modern approach has not come easily, nor naturally, to the historically Westerninspired and defined field of 'development'. Indeed, the “Truman Doctrine” which signalled the beginning of the 'age of development' put the aim of development in rather stark, modernist terms. On January 20, 1949 US President Truman said:

"We must embark on a bold new program for making the benefits of our scientific advances and industrial progress available for the improvement and growth of underdeveloped areas” (Truman cited in Esteva, 1992: 6).

With such words, the modernist ideals of economic growth and material advancement came to dominate development of the 'modern' era (Berthoud, 1992: 72). It is for this reason that utilising an ontology of difference, with its broader focus on sustainability and holism, is considered evidence of a post-modern approach to development. In short, it illustrates a move beyond mainstream modernist thinking about development, the like of which Chambers (1997: 1) believes we can now see as "naïve”.

\footnotetext{
${ }^{14}$ There is much discussion about how to define 'modernity' and 'post-modernity'. Indeed as Crotty (1998: Chapter 9) points out, much of what is called 'post-modern' was in fact formed in and used as a part of modernity. However, in this context I use the term post-modern to characterise a movement that extends beyond the mainstream ideals of modernity's epistemology: science, technology, empiricism, rationality, logic etc.
} 
It is important to point out that an ontology of difference, one that engenders a holistic interpretation of life, is not new. The essence of sustainability has always existed. What makes it 'new' in this context is its elevation as the ultimate aim of development, and, that as an aspect of postdevelopment theory, it is an approach that is genuinely willing to interact with - and be informed by - that which has in past development theories often been disregarded (i.e. 'traditional' and/or 'premodern’ ideas).

It must be acknowledged that taking such an approach is an ambitious task. As a white, male, middle-class Westerner there is undoubtedly a certain amount of that culture and its modernistinspired heritage ingrained in my ontology and epistemology. As Kapoor (2004: 631) has argued, disentangling oneself from a culture that has a history of oppression and exploitation of the 'other', be it the 'Third World' or 'nature', is not as simple as acknowledging one's complicity. In a similar way, I cannot simply proclaim that I will change my ontology, thereby relinquishing myself from a history and a culture that are to blame for the damage they have caused in the past.

As a student of development studies, however, I approach 'development' in much the same way as Appiah (2006) conceptualises the role of conversation in the ethics of cosmopolitanism:

“... [it] doesn't have to lead to consensus about anything ... it's enough that it helps people get used to one another (Appiah, 2006: 85).

If, as I believe to be the case, an aspect of development is about getting to know one another better, then it is through interaction and conversation that we can find common ground. For this to happen, we must be willing to, as I intend in this thesis:

“... upend our thinking, to turn values on their heads, to invent and adopt new methods, and to behave differently ... to question our values; to be self-critically aware ... [and] to encourage decentralization and diversity ...” (Chambers, 1993: ix).

With this sentiment in mind, presentation of the research methods used in this thesis follows. As and where necessary a discussion of how these methods exhibit use of a differential ontology will be made. 


\section{Chapter Three: Research methods}

\section{Research in the field}

Field research was conducted in Hyderabad, India from 14 March to 31 May 2008. The research methods used in the field are described below.

\section{Wisdom of the body}

To fully embrace an ontological shift from that based on identity to one founded on difference requires a similar change in one's epistemology (the way we 'know'). If, as I argue, an ontology of difference engenders a more holistic way of being, then we must also seek a more holistic way of knowing. Given that shifting to an ontology of difference increases exponentially an entity's 'possibilities' (remember Figures 2 and 3 from the previous chapter), we therefore need suitably more diverse ways of interpreting and understanding what we experience. It is for this reason that Hipwell (2004: 361) reiterates Deleuze's call for the "epistemological rehabilitation of intuition": a demand that requires renewed use of the body's senses and 'wisdom' as a source of knowledge (see also Maxwell, 2005: 79; and Brockington and Sullivan, 2003: 70).

As a tool for research therefore, the so-called "wisdom of the body" requires:

"... a greater reliance on the unconscious, on instinct and on knowing through the heart. It requires, in many senses, an un-focusing” (Hipwell, 2004: 361).

Taking this approach to the field was vital given the language barrier experienced in certain situations and the cultural differences enjoyed in others. It helped fill out a picture of the city and its people. Numerous trips around Hyderabad on foot, in auto-rickshaws and on buses, as well as conversations, interactions and (mis-)communications with residents of the city enabled a better understanding of the local context, culture and environment. As such, using the body's wisdom enabled a deeper, more textured experience of the field.

By drawing on my intuitive experience of Hyderabad, I was able to get a feel (if only limited) for the local dynamics, pressures, politics and powers at play. As such, this experience acted as a form of 
triangulation: it enabled me to better interpret what I was being told in interviews, reading in the local media and observing in the city.

It is important to stress that within an ontology of difference there is no such thing as a single, universal 'truth', rather, there are interpretations of truths. Given this situation, using the body’s wisdom enabled a tempering of the different truths revealed in (and by) the other research methods used in this work. Ultimately, using the wisdom of the body helped relate back to the wider context the information I was discovering through different avenues and, as such, it was used to help identify areas of enquiry that required further investigation.

\section{Interviews}

Thirteen semi-structured interviews with local government officials, seven semi-structured interviews with practitioners of UA in the city, three semi-structured interviews with peri-urban/rural farmers and one semi-structured interview with an employee of one of Hyderabad's main dairy companies were conducted. Although it was intended to record these interviews with a digital voice recorder, all of the interviewees specified that they would prefer not to be recorded. Thorough notes were taken during the interviews and interviewees were given the opportunity to read over the transcripts and make changes where necessary. In situations where the interviewee did not speak English, a translator was used. In these interviews I had another native speaker of the language taking notes in English and I too took notes of the translated replies to questions. This meant that I could compare my own notes with those of the other scribe to reduce the incidence of mistranslation and/or misinterpretation.

The Victoria University of Wellington Human Ethics Committee approved the research methods relating to participation in interviews and focus groups, a brief description of which follows. Participants of the research were provided with an information sheet (reproduced in Appendix III) detailing the focus of the study and outlining for what the findings could and would be used, how long and under which circumstances the transcripts would be stored, who would have access to the transcripts, and, how they as participants had the opportunity to revise any information they had given before a designated date, after which the data would be unchangeable. 
The informed consent form (Appendix IV) detailed issues concerning how participants were to be referred to in the publication of research results and offered them the opportunity to be kept informed of the researcher's findings. Those participants willing to waive confidentiality were asked to sign a separate sheet (Appendix V) detailing to what they were agreeing. This was done to reinforce the conditions of waiving confidentiality and to help avoid any confusion in the analysis of results. Separate forms were also provided regarding confidentiality for translators (Appendix VI), focus group participants (Appendix VII), and providers’ of research contacts (Appendix VIII).

Although Human Ethics approval was gained for both interviews and focus groups, only interviews were conducted in the field. ${ }^{*}$ The main reason for this was logistical. Life in Hyderabad is often ad hoc: many interviews took place at short notice or else never in fact eventuated as participants were either double booked or simply too busy to commit to - or attend - a designated meeting. These factors proved a deterrent to attempts to organise focus group meetings and it was decided while in the field to focus only on one-to-one semi-structured interviews.

Semi-structured interviews were selected as the preferred field research technique because they offer an amount of flexibility and use of the body's wisdom within the interview while still maintaining focused, efficient research. Semi-structured interviews were conducted with participants that were recruited either by “purposeful selection” (Maxwell, 2005: 88) or snowball sampling (Bedford and Burgess in Limb and Dwyer, 2001: 26). Purposeful selection sought to access knowledge from specific pre-identified stakeholders. Relying only on purposefully selected interviewees does, however, run the risk of directing the research and interviews to suit the anticipated findings. As a result the more spontaneous and flexible nature of snowball sampling (Bedford and Burgess, 2001: 26) was utilised to enable the opportunity to follow emerging leads and gain access to people that were not immediately 'visible’.

\section{Internship}

From 14 April to 31 May 2008 I undertook an internship at the Hyderabad office of the International Water Management Institute (IWMI), the locally-based international non-governmental organisation (INGO) co-ordinating the RUAF-CFF pilot project which is the case study for this thesis. The

\footnotetext{
* Note that I was involved with two focus groups run by IWMI and reference is made to these in Chapter six.
} 
internship allowed an 'inside look' at the use of UA as a specific method for sustainable development and poverty alleviation. Trips to Surabhi Colony and Andhra Pradesh Social Welfare Residential High School and Junior College for Girls - the sites of the pilot project - enabled interviews with participants of the project and an evaluation of both the project and its co-ordination. Other work during my internship with IWMI included: co-authoring the article "Rainwater Harvesting Potential for Urban Agriculture in Hyderabad" (Amerasinghe et al., 2008) published in issue 20 of Urban Agriculture Magazine (re-produced in Appendix IX); conducting initial research for an IWMI working paper on alternative sources of water for UA; and, helping construct a database of contacts of people and organisations involved with UA throughout India.

\section{Published resources}

Various local government policy documents, plans and information brochures as well as newspaper articles and local media publications were used to enable a varied and deeper understanding of the local context. These resources were also used to prepare myself for interviews with local government officials and to triangulate information given by interviewees.

\section{Problems with the field research process}

\section{Contacts}

The lack of contacts made before arriving in Hyderabad was a factor that limited the research. Before embarking on the trip numerous emails were sent to various government departments (Hyderabad Urban Development Authority; Greater Hyderabad Municipal Corporation; and the Government of Andhra Pradesh), research institutes (National Academy of Agricultural Research Management; Rajendra Nagar Agricultural University; Roda Mistry College of Social Work on Research; Osmania University; University of Hyderabad; and the International Crops Research Institute of the Semi-Arid Tropics (ICRISAT)), organisations (IWMI, Consultative Group on International Agricultural Research), and individuals involved with UA in the city. However, only one reply was received from a staff member at IWMI. 
Going into the field with such little local contact meant that a lot of time was initially spent trying to get established in the city. This undoubtedly negatively affected the research. For example, the failure to get a translator until the latter weeks in Hyderabad meant that the interviews conducted were disproportionately in favour of government officials who could speak English. While this outcome is regrettable, I would say in hindsight that it was to a certain degree inevitable. My experience of Indian culture is that people prefer to meet in person, it is therefore understandable that I struggled to make any strong contacts prior to my arrival in Hyderabad.

\section{The omission of quantitative research methods}

Quantitative research methods were explicitly omitted from the outset of this work in an attempt to avoid conducting research that perpetuates an ontology of identity. The thought process behind this move was that modernist-inspired development operates within an identitarian ontology and, as a result, emphasises 'progress' that can be quantified. Taking a more holistic, post-modern approach to development as has been done in this work requires the consideration of overall 'well-being', an inherently more subjective and qualitative aim than that encompassed in modernist development's drive for, amongst other things, economic growth.

While I felt (and still feel) that using only qualitative methods of research was (and is) necessary to remain true to the philosophy underpinning this work, it did have its drawbacks. For example, it would have been useful to include a survey of project participants to quantify the yield gained and savings made by growing their own vegetables. As it turned out, the project participants spoken with were keen to offer such facts and figures. However, given that this information was received through anecdotes, not a specifically designed survey, it is not statistically robust or academically sound. As such, the data gathered through interviews cannot be used in the same way as if it had been collected through a tested and proved survey. As a result, the figures gained are interpreted in reference to 'process theory': it is information that is indicative rather than definitive and is used only to support what the interviewees had otherwise expressed (Maxwell, 2005: 75). 


\section{The internship}

The opportunity that arose in being offered an internship with IWMI was, as a result of the lack of other contacts, seized by the researcher with too little forethought. It must be acknowledged here that Dr William Hipwell was very cautious in giving his approval for my undertaking of the internship. Among other things, Dr Hipwell raised concerns about the academic freedom that could be lost by affiliating myself with the organisation coordinating the RUAF-CFF pilot project. Naivety and inexperience led to my limited deliberation of the issues raised by Dr Hipwell. It is with hindsight that I can now see Dr Hipwell’s concerns as valid and indeed central to the research's and researcher's - resulting limitations.

While the internship with IWMI was in many ways a great opportunity for both the research and my own personal development, it did also impose a number of restraints upon the thesis. First, the internship meant trying to juggle between work on my thesis and work for IWMI. Perhaps inevitably, work for IWMI took precedence: as I was working in their office I felt obliged to do more work for them. Second, working with IWMI resulted in living some $35 \mathrm{~km}$ out of the central city. This distance became a barrier to conducting more interviews with local government officials whose offices were in the centre of Hyderabad. Travelling to the city required three auto-rickshaws and one train ride, a journey that took, at best, two hours return. Third, I was seen by the locals participating in the RUAF-CFF pilot project as being affiliated with IWMI before I could say otherwise: my first trip (and numerous subsequent trips) to Surabhi Colony was in an IWMI vehicle and I did work with the community under IWMI auspices before I had the opportunity to conduct my own, independent research. Fourth, and finally, IWMI were conducting their own impact assessment at the same time as I was doing my research in Hyderabad. I was (perhaps overly) wary of participants' 'consultation fatigue’ and thus too brief in conducting my own interviews with project participants.

Identification of the above problems is not intended to excuse any work conducted - or not conducted as the case may be - but rather to illustrate that I am aware of the issues and politics involved with having undertaken the internship with IWMI. Although the position imposed certain restrictions upon my work, it also offered opportunities that may not have arisen otherwise. For example, I was given the opportunity to see, from the inside, how an INGO operates and how a development project is managed 'on the ground'. I was invited to meetings and allowed to sit-in on discussions that, had I not been working with IWMI, I would not have been permitted entry. 
From a personal perspective, I made friends with local people and was invited to a colleagues wedding; I travelled with a friend to his family’s home in Vijayawada and experienced firsthand, family life in India. Although such experiences may not link explicitly to the topic of this research, they nonetheless contribute to my overall understanding of Hyderabad, India, its people and their culture. Such experiences do, I believe, provide invaluable insight for this work.

\section{'Insider' / 'outsider' - the politics of fieldwork}

Despite breaking down social, cultural and personal 'barriers' in some instances, the internship at IWMI also made my role ambiguous at other times. In many ways I was an 'insider': I lived in accommodation at the ICRISAT campus (the site of IWMI's office), I worked alongside the team coordinating the RUAF-CFF pilot project and I have good reason to suspect that the residents of Surabhi Colony saw me as an employee of IWMI. However, for the most part, I felt like an outsider in Hyderabad. I did not speak the local language - Telugu - or the national language Hindi. As the product of two Caucasian parents I did not look the same as most people in Hyderabad, and, as a guest of both IWMI and Hyderabad, I did not feel that it was my place to openly critique how they were running their projects or managing their city respectively.

Being an outsider did, however, afford a certain amount of freedom. The fact that I was not intertwined with the local politics and inter-personal power dynamics meant that I could see things from a different point of view. Interestingly, it was this 'outsider's' perspective that the staff of IWMI were keen to hear about in a presentation I gave before leaving the organisation.

Issues of inclusion and exclusion are, of course, central to the work of 'development'. They offer opportunities for personal growth and reflection; excitement and enlightenment. They can, however, also lead to misunderstandings. While the best efforts were made to be objective in designing this research, the reality of fieldwork in a foreign country means that it is, in my opinion, an inevitably subjective experience.

It is with the struggles of research - both personal and structural; real and imagined - and the reality of 'development' in mind that I take full responsibility for the research that follows. Any 
misinformation, misinterpretation or misrepresentation is obviously regrettable and I do not intend for what I have written to cause any disrespect or harm to any of the people with whom I have worked or spoken.

With the above provisos in mind, it is my aim in writing this thesis to paint a picture as representative as possible of what I saw of UA in Hyderabad in the months March, April and May 2008. I must stress the importance and specificity of these dates. I do not doubt that were I to go back to Hyderabad today and repeat my fieldwork, I would have significantly different findings. As will be illustrated throughout this work, Hyderabad is a fast-changing city and it is simply not possible for me to keep abreast such change. The findings for this work and the conclusions drawn therefore relate to the period for which I was in Hyderabad in 2008.

Before introducing the site of fieldwork however, a review of the literature relating to UA must be made so as to locate the research for this thesis within the broader field of work associated with UA. 


\section{Chapter four: Literature review}

The topic of UA is vast and attention to its practice is spreading. In many ways, it is evolving as quickly as the cityscapes in which it is found. This situation makes definitive explanation of its practice difficult, and, as a result, this chapter will commit a considerable effort to explicating what is meant by UA in the context of this thesis. Following an evolution of its history and the key characteristics of its practice in the developing world, a discussion of two of the main factors influencing UA will be made. First, insecure land tenure and the resultant need for policy support will be addressed and then a consideration of wastewater irrigation of UA will be made. As will become clear throughout the course of the following chapters, these two issues are of particular importance to UA in Hyderabad. Finally, the chapter will conclude by identifying areas of research that have not yet been thoroughly investigated. As such, the opportunity for the present work to contribute to these so-called 'gaps in the literature' will be identified.

\section{The problems of definition}

Mougeot's (2000) ${ }^{15}$ rather unwieldy definition of UA remains the most often cited, describing UA as:

“... an industry located within (intraurban) or on the fringe (periurban) of a town, a city or a metropolis, which grows or raises, processes and distributes a diversity of food and non-food products (re-)using largely human and material resources, products and services found in and around that urban area, and in turn supplying human and material resources, products and services largely to that urban area" (Mougeot, 2000: 10).

Although this definition is broad and seeks to identify the hallmarks of UA's practice, a brief look at the history will illustrate that, as Lynch et al. (2001) have argued, the context specificity of UA means that the reasons for its practice, and therefore the form that it takes, cannot be generalised (see also UNDP, 1996: Chapter two).

${ }^{15}$ The basis of this definition dates to Mougeot's work in the book Cities Feeding People: An examination of urban agriculture in East Africa (A. G. Egziabher et al. eds., 1994). 


\section{The evolution of UA}

\section{UA and the 'war effort' (c. 1910s - 1940s)}

Ellis and Sumberg (1998: 214), UNDP (1996) and Lynch (1995) have stated that UA is 'not new', indeed Smit and Bailkey (2006: 149) have traced UA as far back as 4000 years. However, the most common historical reference in the literature is to its practice during the war years of the twentieth century. ${ }^{16}$ Deelstra and Girardet (2000: 46) cite the Schrebergaerten in Germany and the city farming movement in Paris during the First World War in which city dwellers were encouraged to grow their own vegetables for improving wartime food security. While the "British Allotment Act" established UA in that country in 1925 (Ashebir et al., 2007: 219), the "Dig for Victory" campaign during the Second World War saw an increase in the amount of land under cultivation in British cities (Deelstra and Girardet, 2000: 46). "War Gardens” were utilized in Canada between 1924 1947 (Ashebir et al., 2007: 219) and in the United States "victory gardens” were used throughout the Second World War (Smit and Bailkey, 2006: 149).

As part of the 'war effort' UA was not only limited to Europe. UA was promoted by the colonial government in Accra, Ghana to supply Allied forces based in West Africa (Asomani-Boateng, 2002: 592) and in Zimbabwe a similar emphasis was placed on UA as a way of supporting colonial forces in that country (Hubbard and Onumah, 2001).

\section{UA and 'development' (c. 1960s - early 2000s)}

While the above examples stress UA's role as a part of the war effort, the post-war period saw the focus shift to UA's potential as a response to economic and political crises in developing countries (IDRC, 2006). Mougeot (2000: 1) traces UA in the developing world more generally to the 1960s, while evidence from Uganda (Maxwell, 1995) dates to the 1970s. A number of authors (ArmarKlemesu, 2000; Maxwell et al. 1998; Maxwell, 1996; Drakakis-Smith et al., 1995; Binns and Lynch, 1998; and Howorth et al., 2001) have suggested that UA gained particular attention in Africa during

\footnotetext{
${ }^{16}$ Note that the UNDP (1996) provide a comprehensive history of UA that traces its history in each continent. In many cases UA is seen to predate the war years, however, the majority of articles referred to in this research provide case studies that chronicle UA's history since the war years.
} 
the period between the 1970s and the early 1990s when it was initiated as a response to the local economic hardship caused by structural adjustment programmes.

Although UA has been used as an incidental, local response to economic and political instability in a number of developing countries for several decades, it was not identified as a method intended specifically for 'development' until the 1980s. Mwale (2006 cited in Ashebir et al. 2007) and Madaleno (2000) cite the Canadian-based International Development Research Centre’s (IDRC) funding of research and promotion of UA in the developing world in the 1980s as the first major project of its kind (see also UNDP, 1996: 149 for a table of international development agencies’ involvement with UA in the 1980s and early 1990s). In 1987 the World Commission on Environment and Development (WCED) described UA as a practice that

“... could become an important component of urban development and make more food available to the urban poor" (WCED, 1987: 254).

1991 saw the United Nations Development Programme (UNDP) form the Urban Agriculture Advisory Committee (UAAC) and the Support Group on Urban Agriculture (SGUA) was established the following year (van Veenhuizen and Danso, 2007: 2). Lynch (1995) cites chapter seven of Agenda 21 (UNCED, 1992) which relates to sustainable human settlements as further evidence that the potential of UA was gaining increased political support during this period.

While UA was being hailed as the 'next big thing' in development circles in the late 1980s and early 1990s, Ellis and Sumberg (1998) have argued, perhaps with the luxury of hindsight, that such promotion was at that time unfounded. Their concern was that UA's ability to alleviate poverty had not been critically evaluated nor compared with other poverty alleviation strategies (see also Lynch et al., 2001). The direction of already tight budgets toward projects promoting UA was, to Ellis and Sumberg, therefore unwise until further research had been undertaken. This critique could be seen as valid when one considers a 1993 report from the International Food Policy Research Institute (IFPRI) which opined that information about UA was at that time:

“... so limited that policy and program designs are often based on speculation” (von Braun et al, 1993: 38 cited in Maxwell, 1995: 1669).

It was perhaps due to the recognition of this situation - that the international community had jumped to support UA before its worth had been proven - that the 1990s and early 2000s saw a wave of 
research being undertaken, especially in Africa, to assess the incidence, impact and opportunities of UA in developing countries' cities (in Nairobi, Kenya see Lado, 1990; in Kampala, Uganda see Maxwell, 1995 and Maxwell et al., 1998; in Dar es Salaam, Tanzania see Lynch, 1995; Sumberg, 1997; and Howorth et al., 2001; in Harare, Zimbabwe see Drakakis-Smith et al., 1995; in Bulawayo, Zimbabwe see Mutengu et al., 2007; in Kano, Nigeria see Lynch et al., 2001; in Accra, Ghana see Asomani-Boateng, 2002; in Mekelle, Ethiopia see Ashebir et al., 2007; in Lilongwe and Blantyre, Malawi see Mkwambisi et al., 2007; in Africa in general see Maxwell, 1996; in Sub-Saharan Africa in particular see Binns and Lynch, 1998; in Belém, Brazil see Madaleno, 2000; in Mexico City, Mexico see Losada et al., 2000; in Dhaka, Bangladesh see Remenyi, 2000; in Kathmandu, Nepal see Rutkowski et al., 2007; in Hyderabad, India see Buechler and Devi, 2003; in Asia in general see Midmore and Jansen, 2003; and for an overview of UA in general see UNDP, 1996).

A common conclusion drawn in many of these case studies was that UA was shown to be an important practice for the economic and nutritional security of practitioners and their families (Armar-Klemesu, 2000; Mougeot, 2000; Drakakis-Smith et al., 1995; Lado, 1990; Maxwell, 1995; Maxwell et al., 1998; Binns and Lynch, 1998; Lynch et al., 2001; Asomani-Boateng, 2002; Hubbard and Onumah, 2001; van Veenhuizen, 2006; and Mkwambisi et al., 2007). However, a similar finding was that UA's future was under threat due to rapid changes in urban land use and the failure of local governments to provide policy and planning support for the continuation of its practice. As a result, a widely held opinion in the literature was that more government support in the form of policy was needed to secure UA’s future (Lado, 1990; Maxwell, 1995; Maxwell et al., 1998; Binns and Lynch, 1998; Lynch et al., 2001; Asomani-Boateng, 2002; see also Bakker et al., 2000; Hubbard and Onumah, 2001; and van Veenhuizen, 2006).

In line with what much of the literature was suggesting, the turn of the $21^{\text {st }}$ century saw a number of agreements made and legislation passed to provide official support to UA. In 2000 the Quito Declaration gave official municipal support to UA in 22 Latin American and Caribbean countries (van Veenhuizen, 2006: 5). In Africa in 2003 the Harare Declaration was signed by officials from Kenya, Swaziland, Malawi, Zimbabwe and Tanzania. The declaration

“... commits ourselves to developing policies and appropriate instruments that will create an enabling environment for integrating urban and peri-urban agriculture into our urban economies" (from IDRC, 2006: 27). 
In Mekelle, Ethiopia the Mekelle Urban Agriculture Office was established in 2001 to support UA in that city (Ashebir et al., 2007) while in Cuba the Ministry for Agriculture has created the Urban Agriculture Office for Havana (Mougeot, 2000: 18). In Belém, Brazil, UA has been given increased municipal support in recent years (Madaleno, 2000) and in Rosario, Argentina, UA has been permitted since 2001 (IDRC, 2006). Mougeot (2000: 18) cites a number of other examples of local

government supporting UA in cities such as Doala in Ivory Coast, Dodoma and Dar es Salaam in Tanzania, Kinshasa in Democratic Republic of Congo, Maputo in Mozambique and in countries such as Costa Rica and the Philippines.

While urban poverty alleviation in the form of food and economic security can be cited as perhaps the dominant factor driving UA's promotion and support in the developing world, it has taken on an increasingly global - and environmental - focus in the face of recent international issues.

\section{The greening and globalising of UA (2000s to the present)}

While the literature from the previous era in which UA was discussed as a method of 'development' did identify and discuss the environmental impacts of UA (see for example: Lynch, 1995; Maxwell, 1995; Drakakis-Smith et al., 1995; UNDP, 1996; and Binns and Lynch, 1998), the point is that environmental issues have, generally speaking, come to characterise the more recent literature. This shift in focus of the literature has brought with it a greater recognition of UA's worth as a method of sustainable development and urban design that is relevant to both 'developing' and 'developed' world settings.

In saying this, however, there remain differences in the general motivation for its practice and support in the two settings. Work by Jarosz (2008) on alternative food networks (AFNs) in North America, Europe and Australia, by Smit and Bailkey (2006) and Fleury (2007) on community supported agriculture (CSA) in America and France respectively and by Heinberg (2006) on UA being used as a local response to the potential peaking of world oil production are examples that illustrate the desire for urbanites of the 'more-developed' world to source food that has less adverse effects on the environment and, in so doing, supports their local community. 
Meanwhile, in developing world settings, the recent focus has been more on UA's opportunity to manage the local environment. Examples include the recycling of urban waste (see Deelstra and Girardet, 2006; Buechler et al., 2006; Yasmeen, 2001; and Midmore and Jansen, 2003), and the utilisation of wastewater for irrigation of UA (see Buechler et al., 2006; Buechler and Devi, 2003; Rutkowski, 2007; and Mutengu et al., 2007). There is also spreading interest in the negative effects localised air pollution has on UA (see Agrawal, 2003) and, simultaneously, UA itself is coming under increased scrutiny for its potential to pollute urban soil and waterways through, for example, the leaching of fertiliser (see Vagneron, 2007; Khai et al., 2007).

Given such a varied past it seems clear that while the basic practice of UA may be generalised in the way defined by Mougeot, the motivation for UA is, as Lynch et al. (2001) have pointed out, highly contextual. Given this situation it seems necessary to expand upon Mougeot's (2000) definition to better illustrate how UA relates to the specific context of this thesis: as a method of sustainable development and poverty alleviation in the developing world.

By identifying a number of UA's key characteristics - who its practitioners are; why it is practiced; what it produces; who its consumers are; where it is practiced; and how it is practiced - the following intends to exhibit how (or how not) and why (or why not) UA has (or has not) been used to alleviate the poverties of capital necessary for sustained, holistic well-being as they were detailed in Chapter one.

It is through this process that this work's objective - to ascertain whether UA can contribute to: 1 ) building stronger community; 2) form a greater cultural connection between its practitioners and their local environment; 3) improve the local environment and its management; and 4) improve food and economic security - will be located within the broader field of research on UA and, as such, a more explicit understanding of how this thesis intends to contribute to the literature will be established. 


\section{Key characteristics of UA in the developing world}

\section{Who? The practitioners of UA}

Generally speaking women are the main practitioners of UA. Evidence from case studies in Dhaka, Bangladesh (Remenyi, 2000); Kampala, Uganda (Maxwell et al., 1998; UNDP, 1996: 67); Hyderabad, India (Buechler and Devi, 2003); Belém, Brazil (Madaleno, 2000); and Nairobi, Kenya (Lado, 1990) support the assertion that van Veenhuizen (2006) has made: that 65 percent of urban farmers around the world are female. However, there are of course exceptions to this claim. In Mekelle, Ethiopia 94.4 percent of urban farmers are male (Ashebir et al., 2007) while in both Accra, Ghana (Asomani-Boateng, 2002) and Kano, Nigeria (Lynch et al., 2001) the vast majority of urban farmers were found to be men.

As indicated by its history, UA in the developing world has typically been used as a means of improving food and economic security meaning that the majority of its practitioners are characterized as poor (Ellis and Sumberg, 1998: 216). However, there is evidence, as well as growing reason, to suggest the contrary. In Kampala, Uganda, Maxwell et al. (1998: 415) found no specific connection between UA and the poor, while in Nairobi, Kenya (Lado, 1990: 263) only 32 percent of urban farmers surveyed were classified as 'low income'. In Belém, Brazil, Madaleno (2000: 75) discovered that most practitioners of UA were more affluent. As will be further discussed later in this chapter (under the heading "Insecure land access and the need for policy support"), rising urban land prices are proving a barrier to UA and thus its potential to alleviate economic poverty for the urban poor is in doubt.

One final stereotype of UA is that it is predominantly practiced by recent migrants to the city (Maxwell, 1995). UA is often seen as a basic means of survival for families that have their roots in agriculture but have recently moved to the city in search of new livelihoods. While recent migrants dominate UA in Accra, Ghana (Asomani-Boateng, 2002: 596) and Nairobi, Kenya (Lado, 1990), well-established families were found to be the main practitioners of UA in Kampala, Uganda (Maxwell, 1995) and Belém, Brazil (Madaleno, 2000). As Ellis and Sumberg (1998: 217) have pointed out, longer-term residents of a city are more likely to have secure access to land meaning that Maxwell's (1995) characterization of UA as a practice suited to recent arrivals may not in fact be correct. 


\section{Why? The reasons for practising UA}

\section{Food and economic security}

As already identified, the main reason for practicing UA in the developing world has been its ability to improve economic capital in the form of food security and/or monetary income. Urban households reportedly spend 30 percent more on food than their rural counterparts (FAO, 1998 cited in Hubbard and Onumah, 2001) and the poor are said to spend anywhere between 30 and 80 percent of their income on food (van Veenhuizen and Danso, 2007; Armar-Klemesu, 2000; and UNDP, 1996). As Mkwambisi et al. (2007: 6) have pointed out, in comparison to those living in rural areas, urban dwellers depend almost entirely on financial income for food security which is why UA can be seen as contributing both directly and indirectly to food and economic security.

A number of authors (Mougeot, 2000; Armar-Klemesu, 2000; van Veenhuizen and Danso, 2007; and Hubbard and Onumah, 2001) have argued there is an urbanisation of economic poverty as people who migrate to the cities in search of work are left either un- or under-employed and thus financially vulnerable. As an informal sector UA provides an opportunity for the growing urban poor to improve both their economic capital and food security: it requires little training, is relatively easy to enter, and can be practiced at a small-scale (Howorth et al., 2001: 286; and UNDP, 1996: 4). UA is therefore pursued as either a means of basic survival (Howorth et al., 2001: 286) or as a way of supplementing families' weekly food provisions, thereby making money available for other expenses (van Veenhuizen and Danso, 2007: 21; Nugent, 2000: 72, 83; Vagneron, 2007; Binns and Lynch, 1998; and Mkwambisi et al., 2007: 6 - 7).

The evidence for UA improving economic capital is widely reported in the literature (ArmarKlemesu, 2000; Mougeot, 2000; Drakakis-Smith et al., 1995; Lado, 1990; Maxwell, 1995; Maxwell et al., 1998; Binns and Lynch, 1998; Lynch et al., 2001; Asomani-Boateng, 2002; Hubbard and Onumah, 2001; and van Veenhuizen, 2006; and Mkwambisi et al., 2007). Indeed Nugent (2000: 74) reviewed 17 case studies of UA from around the world and found that the top six motivations for UA were related to the economic benefits UA offered the practitioners and their families.

Howorth et al. (2001: 287) found that urban farmers in Dar es Salaam, Tanzania saved ten percent of their expenditure on food by growing some of their own produce while RUAF say that urban 
agriculturalists can save up to 20 percent of their weekly expenditure on food (RUAF, 2008a). In terms of nutrition and food security, Maxwell (1995: 1675) found in Kampala, Uganda, a correlation between families who grow their own vegetables and a lower incidence of malnutrition. However in a later study in Kampala, Uganda, Maxwell et al. (1998: 418) found no such link between UA and improved nutritional status of practitioners and their families. In Hyderabad, India, Buechler and Devi (2003: 11) have anecdotal evidence of families that grow vegetables eating a diet with increased fresh vegetables.

\section{UA as a temporary land use}

Other reasons cited for UA are more context-specific. In Kano, Nigeria land owners have allowed third-party urban agriculturalists to farm their land because it protects the owners' rights to the land and prevents encroachment from neighbouring developments (Lynch et al., 2001). In Bangkok, Thailand, UA is used as a way of utilising the land until a more profitable option for that land becomes available (Vagneron, 2007: 527).

\section{UA for environmental management}

In other settings, UA's benefit for the city's natural capital in the form of environmental management has been identified as motivation for its practice (UNDP, 1996: 179 - 190). In Dar es Salaam, Tanzania, UA has taken on a role that could be consider environmental risk management: it is practiced on the flood planes to prevent people from living on hazardous land (Howorth et al., 2001; for similar findings in Kano, Nigeria see Lynch et al., 2001: 169). Meanwhile, in Accra, Ghana, UA is considered a good way of keeping the urban environment clean as cultivated land is unlikely to be used by citizens as a site for dumping their urban waste (Asomani-Boateng, 2002).

\section{What? The products of UA}

\section{The opportunity to improve economic capital in the form of food and financial security}

Despite Mougeot's (2000) broad definition of UA as including the production of both food and nonfood items, the fact that the main reason for its practice is food and economic security means that the majority of the literature concerns the production of food (van Veenhuizen and Danso, 2007: 1; Mougeot, 2000: 12; and Ellis and Sumberg, 1998). This point, coupled with UA's proximity to consumers means that it naturally favours the production of perishable goods and, as a result, it is 
seen as complimentary to rural agriculture (van Veenhuizen, 2006: 2). Case studies throughout the developing world support this notion. Danso et al. (2002 cited in Buechler et al., 2006: 249) report that in Kumasi, Ghana, 90 percent of lettuce and spring onions consumed by the city's residents are produced within the city. In Hanoi, Vietnam, De Bon (2003: 353) writes that 80 percent of the city’s vegetables come from within the city's province and Asomani-Boateng (2002) cites work by Cencosad (1994) which reports that 90 percent of the vegetables consumed in Accra, Ghana, are produced within the metropolitan area. Deelstra and Girardet (2000: 46) point out that city farmers in Bamako, Mali, supply all of the city's vegetable- and over half of its poultry-requirements while in Kampala, Uganda, Maxwell (1995: 1672-3) found that 70 percent of the poultry consumed by its citizens was produced within the city.

UA's closeness to consumers also means savings in the cost (and environmental impact) of distribution of its products (Sumberg, 1997), while a reduction in the post-harvest losses sustained during transit improves UA’s efficiency (Lynch, 1995). Mougeot (2000: 23) and Armar-Klemesu (2000: 105) point out that urban farmers' proximity to markets also means they have increased profits because they cut out the 'middleman' and have better information about the state of the market.

\section{Non-food products: An opportunity to improve natural capital}

Such practicalities and improved efficiencies, coupled with the food and economic motivations for UA means the relative scarcity of literature concerning the supply of non-food items seems logical. In saying this however, Madaleno (2000: 75) did find medicinal herbs to be the second most popular plant grown (behind fruit trees) in Belém, Brazil while in Dhaka, Bangladesh Remenyi (2000) found a vibrant nursery business. In Hyderabad, India, Buechler and Devi (2003: 10) discovered the smallscale production of ornamental flowers for religious ceremonies alongside the production of food crops.

Finally, with the present growing interest in, and need for, sustainable development and urban environmental management, Kuchelmeister (2003) believes that the non-food giving attributes of trees - recycling of natural gases; reducing localised air pollution; regulating the local climate; improving water storage; and reducing soil erosion etc. - means that urban forestry will become an increasingly important aspect and common manifestation of UA. 


\section{Who? The consumers of UA}

In most cases the food produced from UA is for self-consumption (Nugent, 2000: 72, 83; van Veenhuizen and Danso, 2007: 21; and Armar-Klemesu, 2000). Case studies from Dhaka, Bangladesh (Remenyi, 2000), Kampala, Uganda (Maxwell, 1995, 1996; Maxwell et al., 1998), Nairobi, Kenya (Lado, 1990), Kano, Nigeria (Lynch et al., 1998) and Belém, Brazil (Madaleno, 2000) found that the produce was predominantly consumed by the grower and their family with any excess being sold or traded. Findings in Mekelle, Ethiopia (Ashebir et al., 2007) and Hyderabad, India (Buechler and Devi, 2003) were the opposite with the harvest primarily destined for the market.

Work in Kano, Nigeria (Lynch et al., 2001), Lilongwe and Blantyre, Malawi (Mkwambisi et al., 2007) and Accra, Ghana (Asomani-Boateng, 2002) has found two distinct streams of UA practitioners - rich and poor - meaning that there are similarly two different destinations for their produce. As could perhaps be assumed richer farmers with larger-scale operations supply markets for income whereas smaller-scale, typically poor farmers, use their produce to feed their families directly.

\section{Where? The location of UA}

Asomani-Boateng (2002) and van Veenhuizen and Danso (2007) make a similar differentiation as Mougeot (2000) does between 'intra-urban' and 'peri-urban' agriculture, noting that intra-urban takes place in the inner city while peri-urban agriculture is practiced on the city's periphery. Binns and Lynch (1998), Ellis and Sumberg (1998), Lynch et al. (2001) and Ashebir et al. (2007) note that the increasingly blurred lines between 'urban', 'peri-urban' and 'rural' make it difficult to define UA in such terms. It is perhaps for this reason that Maxwell (1996), De Bon (2003), Midmore and Jansen (2003) and Moustier (2007) prefer to characterise UA simply as that which takes place on land that is in direct competition with other urban land uses.

While such characterisation fails to encompass manifestations of UA like rooftop, balcony and/or hanging gardens, it alludes to an issue central to UA's potential as a poverty alleviation strategy: access to land by the urban poor. Indeed, the increasing competition for urban land has led some (van Veenhuizen, 2006: 9; and Drechsel et al. 2006 cited in van Veenhuizen and Danso, 2007: 14) to characterise UA as a form of "shifting cultivation". While this ability to change location could be 
seen as an advantage of UA as it allows the urban poor the dynamism necessary to evolve with the changing cityscape, the issue of insecure land tenure is one that increasingly threatens the very future of UA and, in particular, its use as a poverty alleviation strategy. Given the importance of this issue to the topic of this thesis it will be further addressed later in the chapter under the heading "Insecure land tenure and the need for policy support”.

\section{How? The technique of UA}

\section{The effects on, and opportunities for improving, natural capital}

Characterising UA as a practice that takes place on land that is in direct competition with other, potentially more economically profitable, urban land uses implies the opportunity cost of the land (see Maxwell, 1996 for more on this). This seems to have led Remenyi (2000) and De Bon (2003) to portray UA as involving intensive farming techniques as farmers are forced to seek the highest available returns from their chosen land use. As cautioned by van Veenhuizen (2006), such profitseeking can result in over-application of fertiliser and, ultimately, degradation of the city's natural capital. According to Vagneron (2007) this very situation has occurred in Bangkok, Thailand where fertiliser leaching from UA plots has contaminated local water and soil resources.

The potential for UA to improve a city's natural capital, however, is evident in the opportunity to reuse city's wastewater and organic matter in the place of synthetic inputs (Deelstra and Girardet, 2000; van Veenhuizen, 2006; Madaleno, 2000; van Veenhuizen and Danso, 2007; Armar-Klemesu, 2000; Nugent, 2000; Buechler et al., 2006; UNDP, 1996; and Midmore and Jansen, 2003). Deelstra and Girardet (2000), UNDP (1996: 178) and Midmore and Jansen (2003) argue that this aspect of UA provides the opportunity to “close the loop" by recycling city 'waste' back into inputs for growing food for the city’s population.

Reusing wastewater for irrigating UA is one such example that will be discussed in greater detail later in the chapter. For now the case study of an urban composting operation in Dhaka, Bangladesh (Zurbrügg et al., 2005) will be used to illustrate the potential reuse of urban organic waste. 70 percent of Dhaka's urban waste is organic, meaning that between 2100 and 2450 tons of potentially compostable waste is sent to landfill every day. Through a project run by the local non- 
governmental organization Waste Concern, three tons of organic waste is converted into compost by a “non-mechanised aerobic and thermophile composting procedure” (Zurbrügg et al., 2005: 281). The project employs ten local people and sells its product primarily to a local fertiliser company. The project makes an annual profit of US\$3745 and saves the local municipality approximately US\$15,000 in collection and transportation costs alone (Zurbrügg et al., 2005).

While the opportunity for UA to reuse such urban organic waste is clear, the experience of Ho Chi Minh City in Vietnam (Midmore and Jansen, 2003) has illustrated the difficulties of a larger-scale operation. The failure to adequately separate collected green waste has resulted in the application of raw, un-composted waste on fields, thus making tillage more difficult. Another issue to consider in the use of organic as opposed to synthetic fertiliser is the increased amount of labour necessary for application. In China, the extra labour required for the use of organic fertiliser has been cited as a reason for the increased use of synthetic fertiliser over the last 50 years (Gardner, 1997 cited in Midmore and Jansen, 2003: 18).

\section{Major discussions in the literature}

Having identified the characteristics of UA in the developing world that are evident in the literature and pertinent to the focus of this thesis, I will now provide a brief overview of two of the main issues repeatedly discussed in the literature: 1) insecure land tenure and the need for policy support; and 2) wastewater reuse in UA. As will become clear through the course of this thesis, these two issues proved to have specific relevance to UA in Hyderabad. Following presentation of these two points, a discussion of those issues central to this thesis, but absent from the literature, will be made.

\section{Insecure land tenure and the need for policy support}

As illustrated throughout this chapter the most widely cited and promoted attribute of UA is its contribution to the food and economic security of people in the developing world. Unfortunately however, it is this aspect of UA that is most under threat from the changing dynamics of the cityscape, thus leading Midmore and Jansen (2003:23) to caution that UA's future is uncertain. 
On the one hand a 'gentrification of UA' is occurring as rising urban land prices mean it is becoming dominated by wealthier families (for example: in Lilongwe and Blantyre, Malawi see Mkwambisi et al., 2007; in Bangkok, Thailand see Vagneron, 2007; and more generally Midmore and Jansen, 2003). On the other hand, the fact - or in some instances simply the perception - that there are more economically profitable uses for land than that provided by UA (implying the opportunity cost of land) means that urban authorities are less willing to set aside land specifically designated for UA's practice. As such, these issues are set to exacerbate the urban poor's lack of secure access to land, and, by virtue, their potential to practice UA.

As illustrated by Hubbard and Onumah (2001), Asomani-Boateng (2002), Lynch et al. (2001) and Maxwell (1995; 1996), uncertain land rights are already the main issue constraining UA in the developing world. Maxwell (1996) has argued that: 1) so long as the poor are unable to secure access to land in urban centres, and 2) there is a need for the poor to grow supplementary food, then there will be a demand for informal access to, and use of, publicly owned vacant urban land. It is for this reason that Maxwell says that urban land use is about

“... balancing overall economic growth at the system level with economic survival at the individual or household level” (1996: 194).

While UA could be used as a way of achieving this balance, it has failed to receive the necessary policy support in many countries. Despite a number of examples of successful policies supporting UA around the world (outlined earlier in the chapter), UA has failed to gain official recognition in other cities because it is continually (mis)perceived by local government officials as, amongst other things: of "marginal value" to the city's poor (Maxwell, 1995: 1669; UNDP, 1996: 3); a “backward” practice that harks back to “pre-modern” times (IDRC, 2006: 26; Drakakis-Smith et al., 1995: 187; and UNDP, 1996: 212); a health hazard (Asomani-Boateng, 2002; Maxwell, 1995); an inefficient use of high-value urban land (Maxwell, 1996); or, simply as a practice that belongs to rural areas and should therefore not be continued in the city (Maxwell, 1995). The main impact these institutional attitudes have on the practitioners of UA is that their future livelihoods are constantly in question.

Given that UA is most often about enhancing food security and improving economic capital, a number of authors have suggested designing, in dialogue with urban farmers, policy and plans that 
set aside urban land with the specific purpose of hosting UA (see Deelstra and Girardet, 2000; Nugent, 2000; Armar-Klemesu, 2000; Remenyi, 2000; Maxwell et al., 1998; Hubbard and Onumah, 2001; Maxwell, 1995; Lynch et al., 2001; and Drakakis-Smith et al., 1995).

While on first impressions this may seem to be a good recommendation, Ellis and Sumberg (1998) have cautioned against such a move. Their concern is that richer, more powerful urban dwellers will likely capture the land designated for the poor to practice UA, using it instead for profit-making ventures. As highlighted by Hubbard and Onumah (2001) and Asomani-Boateng (2002), the weak nature of institutions in developing world settings and the generally poor record of enforcement of legislation means the concerns raised by Ellis and Sumberg may well be valid. If legislation designating land for poor urban farmers was indeed flouted as Ellis and Sumberg suggest, the urban poor would effectively be pushed out from accessing land that had been set aside with the express purpose of serving their needs. It is with this concern in mind that Ellis and Sumberg argue against designating land specifically and exclusively for UA, proposing instead that local governments decriminalise UA on publicly owned, vacant land, thereby allowing its practice to continue as an $a d$ hoc, yet officially sanctioned practice.

\section{UA and wastewater}

As already noted it is estimated that between 75 - 85 percent of all water leaves the city as wastewater (Buechler and Scott, 2006: 1; Buechler, 2004: 28). Due to the spreading 'poverty of fresh water' (Molden, 2007), wastewater - storm water, urban run-off, grey-water (domestic wastewater without human faeces or urine), black-water (domestic wastewater that is contaminated with human faeces and/or urine) and effluent from industry, hospitals etc. (Buechler et al., 2006: 246) - is increasingly being utilised for irrigating UA (for an overview see: Raschid-Sally et al., 2005; in the Middle East and North Africa see Faruqui in van Veenhuizen, 2006: 264 - 266; Deelstra and Girardet, 2000: 52 - 53; in Bulawayo, Zimbabwe see Mutengu et al., 2007). Indeed, Rutkowski et al. (2007: 84) state that based on available data, an estimated 350,000 ha in 75 cities throughout the world rely on wastewater for irrigation of fields in urban areas.

The use of wastewater has both potential benefits and drawbacks for practitioners of UA, consumers of its produce and for the natural capital of cities that host UA. On the positive side, wastewater 
provides free extra nutrients that can help plant growth (Rutkowski et al., 2007; Mutengu et al., 2007; Ensink et al., 2002). Indeed, research in Haroonabad and Faisalabad in Pakistan found that urban farmers using wastewater earned approximately US\$300 more per year than farmers using non-wastewater sources for irrigation (Ensink et al., 2004: 91 - 99). Buechler and Devi (2003: 8) found that 250 households in Hyderabad, India depend on wastewater for irrigating their fields, while an estimated 40,000 people depend on the city’s Kachiguda market which supplies para grass ${ }^{17}$ grown using the city's wastewater.

However, poor infrastructure and the inability to adequately treat and manage wastewater can result in the possible mixing with, and contamination of, other water resources (for examples in Hyderabad, India see Buechler and Devi, 2003, 2005; in Kathmandu, Nepal see Rutkowski et al., 2007; and in Bulawayo Zimbabwe see Mutengu et al., 2007). The use of insufficiently treated wastewater (or other water contaminated by wastewater) in UA presents a health risk to farmers and agricultural labourers. Davis and McGinn (2001 cited in Buechler et al., 2006: 246) found that in most developing countries, less than 15 percent of wastewater is treated. In a study of 109 urban farmers using wastewater to irrigate their fields in Kathmandu, Nepal, Rutkowski et al. (2007: 87) found that 55 percent of respondents had experienced adverse health effects such as skin irritations, headaches, and in two instances, intestinal parasites. Tests of water quality in Hyderabad, India (Buechler and Devi, 2003: 5), Kathmandu, Nepal (Rutkowski, 2007: 86) Bulawayo, Zimbabwe (Mutengu et al. 2007: 1195) and Haroonabad, Pakistan (Ensink et al. 2002) have found that the water urban farmers are using to irrigate their land exceeds, in particular, total coliform standards set by the World Health Organisation (WHO) and FAO for use in agriculture.

Despite such findings however, there is a belief that the use of wastewater in UA must continue. Raschid-Sally et al. (2005) and Keraita and Drechsel (in Buechler et al., 2006) argue that the WHO and FAO standards are too high for developing countries to reach because they lack the infrastructure and funding to achieve such levels of treatment. This has led a number of authors (Buechler and Devi, 2005; Faruqui in Buechler et al., 2006; van Veenhuizen, 2006; Buechler et al., 2006; and Armar-Klemesu, 2000) to argue that instead of attempting to reach these unattainable targets, the focus should be on minimising the risk to farmers and consumers.

\footnotetext{
${ }^{17}$ Para grass is a type of fodder used to feed cows and buffalo in Hyderabad's dairy industry.
} 
Through local innovation and farming practices urban agriculturalists can - and in many cases already are - taking steps to minimise the risk wastewater poses. By wearing protective clothing, using drip irrigation, diluting wastewater with other, less contaminated water, improving farmer education, cooking vegetables grown using wastewater and by changing the crops they grow to suit the water source they are using, Buechler and Devi-Mekala (2005) believe that the risk of contamination from irrigation with wastewater can be greatly minimised (see also Drechsel et al., 2008).

\section{Summary of the literature}

\section{Links with the thesis}

As illustrated there is a large body of literature relating to UA's contribution to the alleviation of economic poverty as it was discussed in the first chapter of this thesis (i.e. through improved food security, UA practitioners' economic capital is similarly enhanced). There is, however, also growing evidence to suggest that this aspect of UA is under threat due to the rising price of urban land, a factor which makes the urban poor's access to land in the city even more uncertain. As an increasingly common issue confronting UA's economic poverty alleviation potential throughout the world, this point will be further explored in relation to this work's case study of Hyderabad, India.

Running parallel to this discussion in the literature is the growing interest in, and awareness of, UA's environmental attributes. The opportunity to use UA as a means of urban environmental management and the potential this holds for enhancing cities’ natural capital is thus becoming more apparent. As will be illustrated in the next chapter, the example of urban forestry, itself a form of UA, is gaining particular attention in Hyderabad, India.

The potential to re-use urban organic waste and wastewater is another issue that highlights UA's potential to contribute to the city's natural capital. However, as pointed out above, the use of wastewater brings with it certain risks. Through a review of the literature relating specifically to UA in Hyderabad, the next chapter will show how the use of wastewater is forcing urban farmers to change both their cultivation practices and the crops they grow. 


\section{Opportunities to add to the literature}

The preceding has made clear UA's potential to alleviate the poverties of economic and natural capital presented in the first chapter of this thesis. However, the literature is much more limited in regard to UA's potential to alleviate the forms of social poverty (the breakdown of community) and cultural poverty (the extinction of experience of nature) discussed in chapter one.

Of the literature relating to UA's contribution to social capital, the vast majority relates to community gardens which have been shown to act as a central meeting point for communities, thereby increasing interaction with, and connection to, the wider community (Bailkey et al., 2007; Smit and Bailkey, 2006). By bringing people outside the home to work in a public space there is an improved sense of security within the locale as individuals get to know other members of their community (UNDP, 1996: 167; see also Lynch et al., 2001). Furthermore, community gardens have been shown to empower marginalised and weaker sections of society (Bailkey et al., 2007). Mubvami and Manyati (2007) cite the example of UA empowering sufferers of HIV/Aids in Zimbabwe while Smit and Bailkey (2006) document the use of UA as a tool for rebuilding communities in Asia after the tsunami of 2004 . UNDP (1996: 167) provides a case study from Lima, Peru to illustrate the potential UA has to empower women, helping to improve their selfimage and elevate their status within both the family and the community.

There is, however, very little information relating to the community building potential of privately owned and tended gardens. This situation seems logical given the fact that private gardens are isolated from the wider community. In saying this, however, Deelstra and Girardet (2000: 57) cite the improved community cohesion in the apartment buildings of Albania as a result of residents using balcony and hanging gardens to diversify their streams of income after the fall of communism in that country. Meanwhile, Mougeot (2000: 23) has mentioned that the gifting of food has encouraged reciprocity in Port-au-Prince, Bissau. Given that the case study being used for this research concerns privately owned and tended kitchen gardens, there is opportunity to add to the literature concerning such garden's potential to contribute to the wider community's well-being.

Regarding the opportunity for UA to re-connect urbanites with the natural environment, thereby seeking to alleviate the poverty of cultural capital as it was discussed in the first chapter, the literature is sparse. Deelstra and Girardet (2000: 54 - 55) note that UA can help re-educate urban 
populations - many of whom "harvest at the supermarket" - about the food production system, thereby fostering greater concern for, and interest in, the techniques used to produce their food. The “Becontree Organic Growers, London” project which is maintaining the thistles, weeds and wildlife that inhabit a derelict site in the city so as to support the local bee population (Deelstra and Girardet, 2000: 55) could be used as an example of how UA can help counteract the extinction of experience. This case illustrates the theory behind "The Pigeon Paradox" (Dunn et al., 2006) which suggests that instead of trying to re-create 'idyllic wilderness' in the city, it is perhaps best to embrace the naturally occurring manifestations of urban nature. Although this may mean conservation of socalled 'pest' species such as pigeons, rats, and thistles, Dunne et al. propose that this action may help pique urbanites' interest in, and subsequent protection of, other, ecologically more valuable tracts of land outside the city.

While no literature relating specifically to UA's ability to counteract the extinction of experience in the developing world has been found, agro-tourism in China, known locally as “Nonjiale”, indicates the potential for this to occur. Nonjiale sees city dwellers stay with a rural family for the weekend to eat the locally grown produce and enjoy the surrounding environment. It is believed that this form of tourism has contributed to the increased uptake of UA in Chengdu, China and, as such, illustrates the potential for UA to combat the extinction of experience among urban populations (RUAF, 2009b).

Finally, the growing interest in, and use of, gardens for educating school students about the environment in the more-developed world gives further reason to believe that UA could be used as a way of re-connecting urbanites of the developing world with the environment. Price's (2001) findings at Edmund Hillary School in Papakura, New Zealand may indicate this potential: as a result of teaching the students how to grow vegetables, teachers saw the children:

“... picking up the rubbish that used to litter the school - to keep it away from the plants" (Price, 2007).

Evidence from Iowa, USA (Hilgers et al., 2008) also suggests the value of lessons based in the garden. The "Growing in the Garden” curriculum trialed in kindergartens and schools up to grade three was found to have a positive effect on children's interest in science and the environment. Although such examples cannot be applied directly to UA in the developing world, they do at least illustrate the potential gardening has for environmental education and thus the opportunity UA may 
have for overcoming the extinction of experience. As such, the present research intends to contribute to the literature regarding this aspect of UA.

The bulk of this chapter has been concerned with explaining, and exhibiting through case studies, the centrality context plays to the form that UA takes in different cities. The following chapter (five) will therefore provide a thorough background to Hyderabad so that presentation of this work's research findings in Chapter six will have the necessary anchor to its context. 


\section{Chapter Five: Introduction to the field}

As the site of the case study for this thesis it is necessary to understand the different issues and factors influencing Hyderabad's urban development. A brief overview of the city's geographical details, its population, economy, governance, and the form its urbanisation is taking will provide the context required for a more thorough consideration of economic and environmental poverty - and their alleviation - in Hyderabad. The chapter will conclude with a review of the literature and research conducted relating to UA in the city, thereby setting the scene for the following chapter's presentation of this study's findings.

\section{Hyderabad}

\section{Location}

Located on the Deccan Plateau between 480 and 650m above sea level Hyderabad is the state capital of Andhra Pradesh in southern India (HUDA, 2003: 63). With an area of 275,045 sq. km and a population of 75.7 million in the 2001 Census (EPTRI, 2004: 19), Andhra Pradesh is India’s fifth largest state in terms of both area and population (EPTRI, 2004: 21). Andhra Pradesh is the heart of Telugu culture but its location in the centre of the Indian sub-continent enables the blending of cultures from the North and South of the country (HUDA, 2008a). Chhattisgarh and Orissa border Andhra Pradesh to the North, Maharashtra to the North and West, Karnataka to the South and West and Tamil Nadu to the South. The Bay of Bengal forms the state’s eastern border (see Figure 4).

\section{Climate}

Hyderabad is considered to be semi-arid with a mean minimum temperature of $14.1^{\circ} \mathrm{C}$ in December and a mean maximum of $38.8^{\circ} \mathrm{C}$ in May. The mean annual rainfall for the city is $804.5 \mathrm{~mm}$ falling in 51 days per year. The monsoonal rainfall pattern means that the majority (703.5mm on 42.9 days) of this rain falls in the months June to October inclusively (Indian Meteorological Department, 2008). 
Figure 4: Map of India

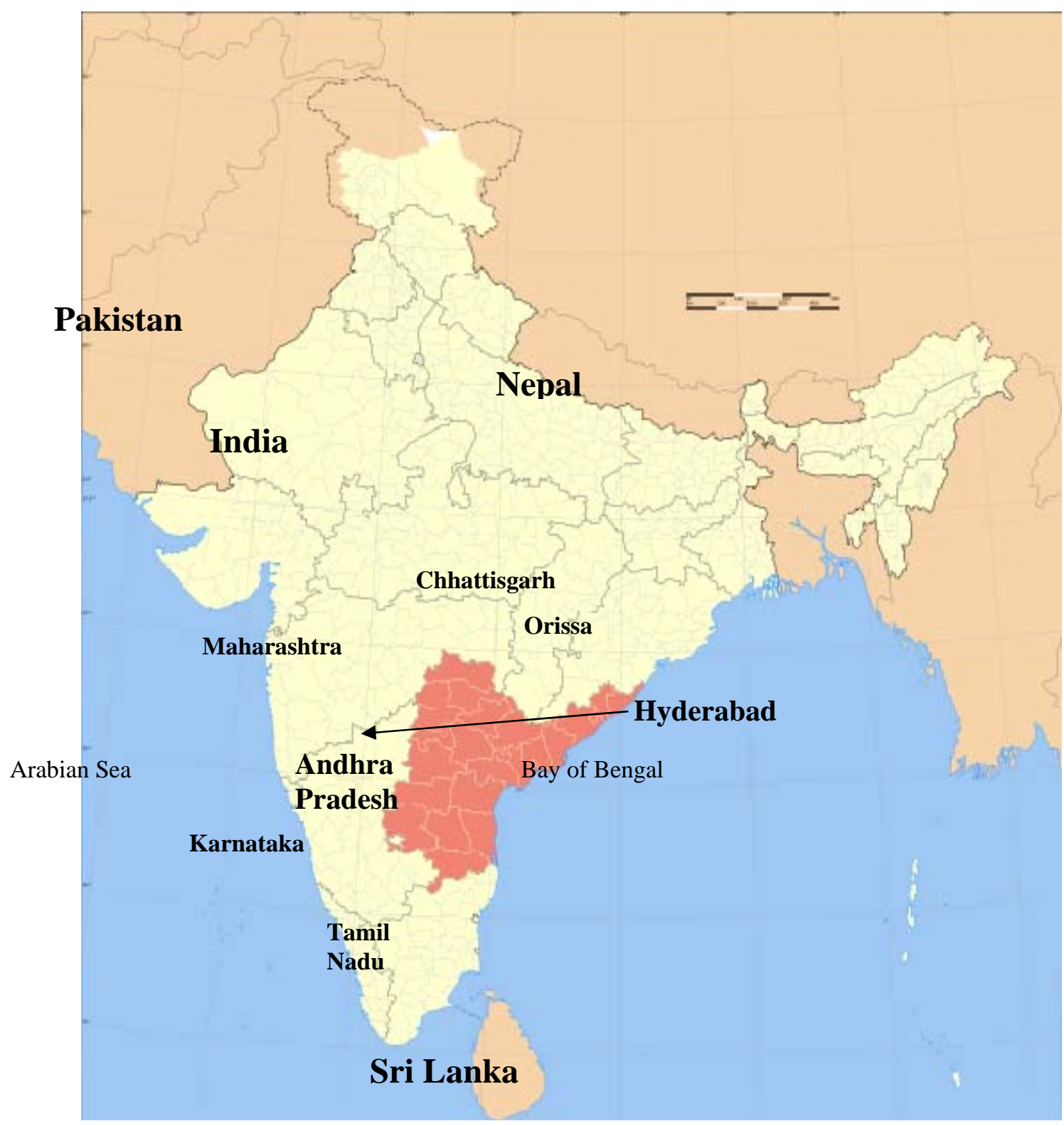

Source: Wikipedia (2008)

\section{History}

Hyderabad was founded in 1591 when the ruler of the region, Muhammad Quli Qutub Shah, established a settlement centred around the Charminar, some $11 \mathrm{~km}$ east of Golconda fort which had 
been the region's stronghold since at least 1364 (APTDC, ND, No Page). While some reports say that Hyderabad was formed due to over-crowding in Golconda (HUDA, 2008a), others say that it was due to water shortages and frequent outbreaks of disease in the fort that a new settlement was formed at Hyderabad (GHMC, 2008c).

Although the foundations of Hyderabad city were laid in 1591, it did not become the centre of political rule in the region until Nizam Ali Khan (Asif Jah II) made the city his capital in 1769 (GHMC, 2008c). Under the rule of the Nizams - established in 1724 by Asif Jah I - the Deccan region remained independent from the rest of India until joining the Indian Union in 1948 (GHMC, 2008c). In 1956 India’s state boundaries were re-drawn to correspond to regional linguistic variations and Hyderabad was made the capital of the Telugu-centred state Andhra Pradesh (GHMC, 2008c).

\section{Population}

As will be further discussed under the section of this chapter relating to governance, defining the jurisdiction and thus the population of Hyderabad is difficult given the changing structure of, and areas governed by, the institutions guiding the city. For the purposes of this thesis, data relating to the Hyderabad Urban Development Authority (HUDA) will be used.

Based on the latest (2001) Census, HUDA (2003:18) has placed the population within its jurisdiction at 6,144,522. Population projections for the HUDA jurisdiction vary between 8.4 and 8.8 million for 2011 and between 11.5 and 13.4 million by 2021 (HUDA, 2003: 73). ${ }^{18}$

\section{Economy}

Compared to the rest of Andhra Pradesh, Hyderabad recorded the highest growth rate in terms of district domestic product (DDP) between 1993 and 2004 (Dev, 2007: 33). This has translated into the highest per capita DDP growth rate in the state (Dev, 2007: 33) which shows that Hyderabad is

\footnotetext{
${ }^{18}$ Depending on the methodology used the figures obviously differ. The lower of the two numbers for both projections is composed by taking an average of all growth rates recorded since 1981 in all individual regions that combine to form the HUDA jurisdiction. The second number projects population for each individual component of the HUDA jurisdiction based on previous decadal growth rates. These figures are then added together to form the single, HUDA-wide population projection (HUDA, 2003: 73). Note also that these figures have been adapted from the HUDA (2003) document because they included the population projections for the Secunderabad Cantonment Board which is not considered part of HUDA.
} 
leading Andhra Pradesh regarding economic growth. In 2007 the average per capita income for Andhra Pradesh was INR29,074 (approximately US\$600), an increase of INR3,000 on the previous year (The Hindu, 20/2/2007). This figure is only slightly higher than the all-India average income of INR29,069 per capita (The Hindu, 20/2/2007). It must be kept in mind that the poverty line is reportedly INR24,000 (US\$495) per person per year, a figure that equates to INR66 (US\$1.36) per day.

Determining what is driving economic growth in Hyderabad requires a mixing of available data (which is often promptly out-dated given the fast-changing nature of the city) with first-hand experience of the city. The Hyderabad region has a rich history in trading diamonds, pearls, steel, arms and fabric (GHMC, 2008c), however, its current economic growth is most often attributed to its manufacturing and service sectors which recorded 11.56 percent and 10.24 percent growth respectively in the 2006/07 year (The Hindu, 20/2/2007).

The booming Information Technology (IT) and pharmaceutical industries (GHMC, 2003: 15; LuckBaker, 2008; Dev, 2007: 10) are also cited as drivers of the city's economic growth. Hyderabad manufactures 30 - 35 percent of the country’s pharmaceuticals (MCH, 2003: 15), and 10 percent of India’s IT exports (MCH, 2003: 1) are produced within the city making it the fourth largest exporter of software in the country (MCH, 2003: 17). In the 2006-7 year there were 1408 registered units in the "Software Technology Park in Hyderabad", up from just seven in 1991-2 (The Economic Times May 30, 2007 cited in CESS, 2008: 37). Districts of the city called “Cyberabad” and "Hi Tec City" combined with the fact that IT exports grew at an annual rate of 80 percent between 1993 and 2003 (MCH, 2003: 17) illustrate the importance of IT to both the local economy and the psyche of some of the city's residents.

While the 1991 Census gathered information concerning individual's employment details, the 2001 Census did not. This makes it difficult to construct a picture of Hyderabad's local economy. The latest data providing a breakdown of the city’s employment by sector (Table 1) comes from the 1998 Andhra Pradesh Enterprise Survey (cited in $\mathrm{MCH}, 2003: 16$ ). Although this data is now over a decade old, it may help give at least a rough guide to the city's economic structure. It is important to note that the participation rate in full-time employment for Hyderabad has been stable at 29 percent of the total population over the last three decades (MCH, 2003: 15). 


\section{Table 1: Employment by sector - Hyderabad 1998}

\begin{tabular}{|l|l|}
\hline Sector of work & Percentage of workforce (\%) \\
\hline Raising of livestock & 1.68 \\
\hline Agriculture service and hunting & 0.16 \\
\hline Mining and quarrying & 0.42 \\
\hline Manufacturing & 16.58 \\
\hline Electricity, gas and water & 0.11 \\
\hline Construction & 0.93 \\
\hline Wholesale trade & 3.74 \\
\hline Retail trade & 31.64 \\
\hline Restaurants and Hotels & 4.24 \\
\hline Transport & 2.17 \\
\hline Storage and warehousing & 0.48 \\
\hline Communication & 1.6 \\
\hline Financial & 7.3 \\
\hline $\begin{array}{l}\text { Community, social and personal } \\
\text { services }\end{array}$ & 28.94 \\
\hline Others & $<0.01$ \\
\hline Total & $\mathbf{1 0 0 \%}$ \\
\hline
\end{tabular}

Source: Andhra Pradesh Enterprise Survey, 1998 (cited in MCH, 2003: 16)

\section{Governance}

Hyderabad is governed by the Greater Hyderabad Municipal Corporation (GHMC) and the Hyderabad Metropolitan Development Authority (HMDA) (which has recently replaced HUDA). Both of these institutions have recently been constituted by the Government of Andhra Pradesh and are larger than their predecessors in terms of both bureaucracy and size of jurisdiction. The formation of these governing bodies can be seen as a sign of the fast-growing and changing nature of Hyderabad city and its surrounding area.

In April 2007 the Government of Andhra Pradesh formed the GHMC by combining the former Municipal Corporation of Hyderabad (MCH) with the twelve surrounding municipalities and eight gram panchayats (village-based governing bodies) (Government of Andhra Pradesh, 2007). The twelve municipalities are L.B. Nagar, Gaddiannaram, Uppal Kalan, Malkajgiri, Kapra, Alwal, Qutbullahpur, Kukatpally, Serilingampally, Rajendranagar, Ramachandrapuram and Patancheru (Government of Andhra Pradesh, 2007). The eight gram panchayats are Shamshabad, Satamarai, 
Jallapalli, Mamdipalli, Mankhal, Almasguda, Sardanagar and Ravirala (Government of Andhra Pradesh, 2007). The enlarged governance of the GHMC extends over 625 $\mathrm{km}^{2}$ and, in terms of city municipal corporations in India, it is second in size to that of New Delhi (IWMI, 2007: 6).

The map below (Figure 5) shows all the components of the GHMC except the eleventh and twelfth municipalities of Ramachandrapuram and Patancheru which are to the West of Serilingampally. 


\section{Figure 5: Jurisdiction of the Greater Hyderabad Municipal Corporation (GHMC)}

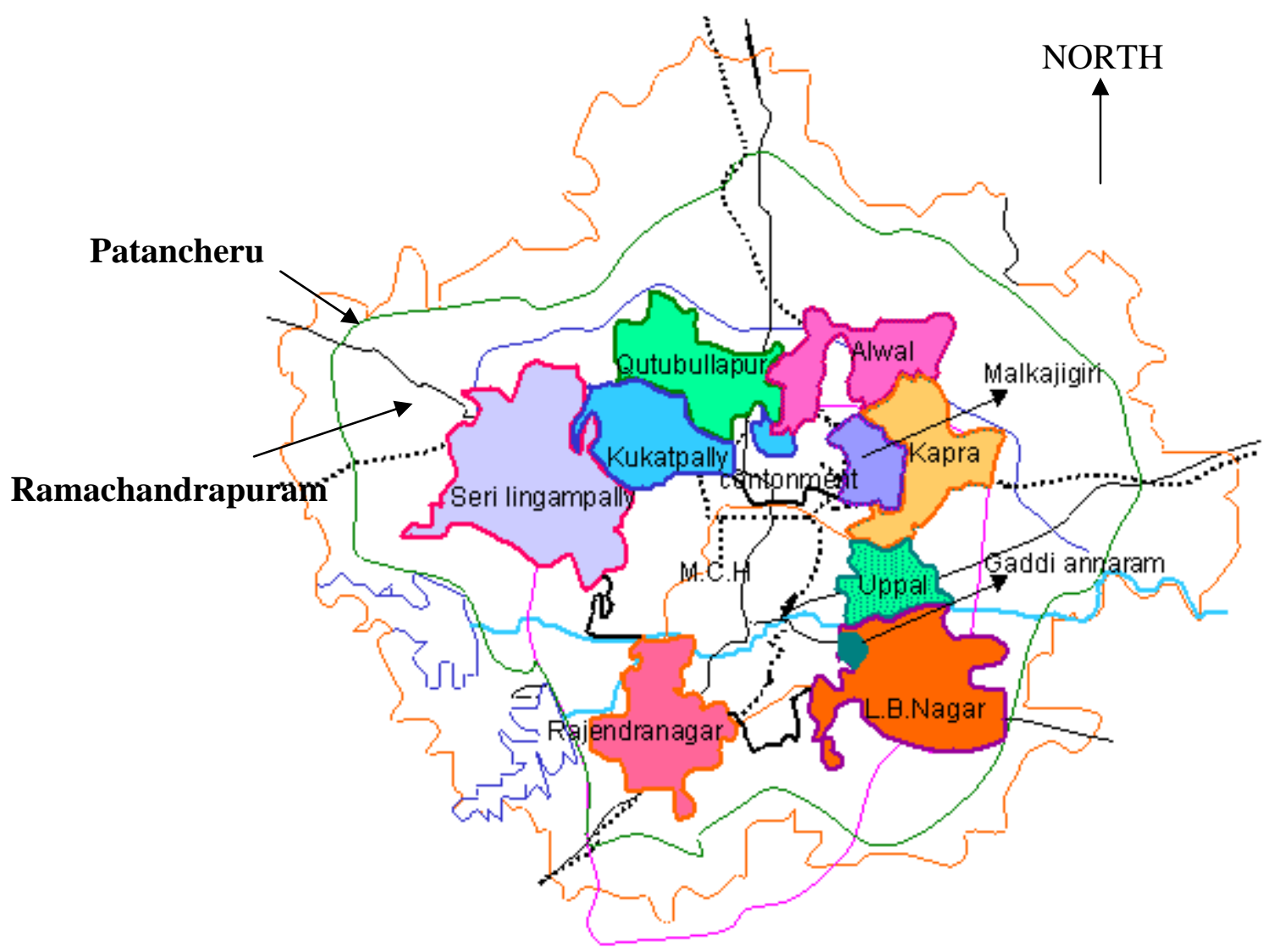

Source: HUDA (2008a)

At its central office in Hyderabad the GHMC has various departments concerned with the overall management of the city. These include departments for: planning and projects; administration and legal issues; finance; electricity and parks; elections and estates; urban community development and sports; works (utilities); transport and advertising; and health and sanitation (GHMC, 2008e). The twelve formerly independent municipalities have retained individual offices in their regions of the city which, under the authority of the GHMC, oversee the management of their locality. 
While the GHMC is concerned with the day-to-day running of Hyderabad, the HMDA is in charge of the greater region's planning and development (HUDA, 2008b). HMDA was only recently (9 April, 2008) constituted by the Government of Andhra Pradesh and came about due to the fact that Hyderabad's development was extending beyond the jurisdictional boundaries of HMDA's predecessor, HUDA (HUDA, 2007: 1). While the role of HMDA will remain much the same as that of HUDA - formulating future plans and regulating development for the city and its surrounding regions (HUDA, 2008b) - the main difference is the greatly enlarged area that the HMDA covers: 6300 sq. $\mathrm{km}^{19}$ compared with HUDA's 1864.87 sq. km (HUDA, 2007: 2). The HMDA intends to improve co-ordination between local governing institutions with the ultimate aim of a more balanced approach to the region’s development (HUDA, 2007: 6).

Although HMDA was formally established in April 2008, it remains, at time of writing in February 2009, an as yet under-realised institution. The website for the HMDA consists only of a link to the HUDA branded website which continues to be updated with the latest news on the city's planning and development. Given the elusive nature of HMDA and the fact that the field research for this thesis was conducted in the midst of the HUDA / HMDA restructuring (March to June 2008), the information gathered concerning Hyderabad's future development came from HUDA, not HMDA.

For the purposes of this thesis the acronym HUDA will therefore continue to be used for referring to the institution that has guided the currently available information concerning Hyderabad's development. The main document concerning the city's development - A Plan for Sustainable Development: Hyderabad 2020 - A Draft Master Plan for Hyderabad Metropolitan Area (HUDA, 2003) - was passed with specific amendments into law by the Government of Andhra Pradesh Government Order 288 on 3 April, 2008. This plan is intended to remain in place for development of the area formerly known as HUDA. Meanwhile, a plan is being drafted for development of the area of HMDA that falls outside the purview of the abovementioned development plan (HUDA, 2007).

${ }^{19}$ Although this figure was published by HUDA on 26/4/07, an article in the local newspaper Deccan Chronicle (31/3/08: 5) put the figure at 6,856sq.km. 


\section{Urbanisation}

The recent increase in size of both the GHMC and HUDA/HMDA jurisdictions reflects the city's rapid expansion. While changes to the region's land use are to be expected, consideration of just how this will affect the city's future landscape is important. Again, as it is the current document guiding the city's urban development, HUDA's A Plan for Sustainable Development: Hyderabad 2020 (2003) is referred to here to construct a picture of the city’s planned future land-use.

The sheer size of HUDA's jurisdiction means that as a percentage of total land use, that which is classified as 'forest', 'water bodies', ‘open space' and 'agricultural and vacant' - in other words land which is 'not built-on' - is large. As Table 2 below illustrates, in the year 2000, 71.18 percent of land under the HUDA jurisdiction fell under one of the above-listed categories. In effect, what this means is that the remaining 28.82 percent of HUDA land in 2000 could be classified as 'built-on': it is made up of land falling into the categories 'residential', 'commercial', 'manufacturing', 'public and semi-public', ‘special reservation', ‘transportation and communication' and 'public utilities' (HUDA, 2003: 32). 
Table 2: Past (2000) and future (2020) land use in the HUDA jurisdiction

\begin{tabular}{|c|c|c|c|c|}
\hline \multirow[t]{2}{*}{ Broad land use group } & \multicolumn{2}{|c|}{$\begin{array}{l}\text { Land use in the HUDA } \\
\text { jurisdiction as at 2000* }\end{array}$} & \multicolumn{2}{|c|}{$\begin{array}{l}\text { Proposed land use in the } \\
\text { HUDA jurisdiction for } 2020\end{array}$} \\
\hline & Sq. km & $\%$ of total & Sq. km & $\%$ of total \\
\hline \multicolumn{5}{|l|}{ Land 'built-on' } \\
\hline Residential & 289.37 & $15.52 \%$ & 575.77 & $30.87 \%$ \\
\hline Commercial & 22.12 & $1.19 \%$ & 54.1 & $2.9 \%$ \\
\hline Manufacturing & 63.88 & $3.43 \%$ & 77.76 & $4.17 \%$ \\
\hline $\begin{array}{l}\text { Public and semi-public } \\
\text { (incl. military) }\end{array}$ & 111.07 & $5.96 \%$ & 155.4 & $8.33 \%$ \\
\hline Multiple use & 0 & 0 & 15.07 & $0.81 \%$ \\
\hline $\begin{array}{l}\text { Heritage buildings, } \\
\text { monuments and areas }\end{array}$ & 0 & 0 & 0.12 & $\begin{array}{r}\text { Less than } \\
0.01 \% \\
\end{array}$ \\
\hline Special reservation & 0.41 & $0.02 \%$ & 0.41 & $0.02 \%$ \\
\hline $\begin{array}{l}\text { Transportation and } \\
\text { communication }\end{array}$ & 48.89 & $2.62 \%$ & 175.16 & $9.39 \%$ \\
\hline Public utilities & 1.56 & $0.08 \%$ & 3.31 & $0.18 \%$ \\
\hline $\begin{array}{l}\text { Sub-totals for 'built-on' } \\
\text { land }\end{array}$ & 537.3 & $28.82 \%$ & 1057.1 & $56.68 \%$ \\
\hline \multicolumn{5}{|l|}{ Land 'not built-on' } \\
\hline Forests & 88.41 & $4.74 \%$ & 88.41 & $4.74 \%$ \\
\hline Water bodies & 92.93 & $4.98 \%$ & 104.07 & $5.58 \%$ \\
\hline Open space zone & 8.4 & $0.45 \%$ & 104.2 & $5.59 \%$ \\
\hline $\begin{array}{l}\text { Conservation / agriculture } \\
\text { group }\end{array}$ & 1137.83 & $61.01 \%$ & 511.09 & $27.41 \%$ \\
\hline $\begin{array}{l}\text { Sub-totals for land 'not } \\
\text { built-on' }\end{array}$ & 1327.57 & $71.18 \%$ & 807.77 & $43.32 \%$ \\
\hline Tota & 1864.87 & 100 & 1864.87 & 100 \\
\hline
\end{tabular}

* This data is made up of land use information provided by NRSA satellite images for $1692.27 \mathrm{sq}$. km of the total (1864.87 sq. km) HUDA area (HUDA, 2003: 100). Data pertaining to the remaining $172.6 \mathrm{sq}$. km of land under the HUDA jurisdiction is based on that given by the Municipal Corporation of Hyderabad (MCH) and relates to the district of the city referred to as the MCH (HUDA, 2003: 80).

Source: HUDA (2003) 
As already noted, the projected population figures for the HUDA jurisdiction vary between 8.4 and 8.8 million for 2011 and between 11.5 and 13.4 million by 2021 (HUDA, 2003: 73). Given such projections for Hyderabad's population in 2021 there will be an obvious change in land use, bringing with it a considerable impact on the greater region's environment and its inhabitants (both human and non-human).

Land that is earmarked for being 'built-on' - the categories 'residential', 'commercial', 'manufacturing', ‘public and semi-public', 'multiple use', 'heritage buildings, monuments and areas', ‘special reservation', 'transportation and communication' and 'public utilities' - will, according to HUDA proposals, increase to 56.68 percent of the total HUDA area by 2020 (HUDA, 2003: 101). This means that the amount of land 'not built-on' within the city will decrease from 71.18 percent of total land use in 2000 to 43.32 percent in 2020. Put another way, the ratio of people to 'land not built-on' will increase from the 2000/01 level of 4,629 people per sq. km to a figure ranging between 14,237 and 16,589 people per sq. $\mathrm{km}$ in 2020/21 depending on the population projections used.

The added stress that this increase in population will apply to the environment, its resources, its services and its non-human inhabitants is an important issue to keep in mind. As evidence of the seeds for exacerbating the extinction of experience of nature - cultural poverty as it was discussed in Chapter one - this issue will be returned to in Chapters seven and eight of this work.

While it is important to remember that these are just population projections and development plans, meaning that the reality may well be quite different, they are still important because they illustrates the attitude of the city's urban planners and the type of city they intend to design. As will be further discussed in Chapter seven, this issue is critical for the future potential of UA in Hyderabad. 


\section{Poverty}

\section{Incidence of poverty in Hyderabad}

The Andhra Pradesh Human Development Report 2007 (CESS, 2008) uses a number of different indicators compiled into indices to measure the state's development. One such indicator is the Human Development Index (HDI) which is comprised of measures relating to: infant mortality; adult literacy; school attendance; and per capita District Domestic Product (DDP) (CESS, 2008: 12). As a district within the state, Hyderabad ranked first in terms of the HDI in both the early 1990s (0.591) and the early 2000s (0.717) (CESS, 2008: 14). The state averages were 0.402 and 0.537 respectively (CESS, 2008: 14).

The Human Poverty Index (HPI) is another indicator used by the Andhra Pradesh Human Development Report 2007 (CESS, 2008) which intends to measure how progress is distributed throughout the state. The indicators used to measure the spread of progress relate to: adult literacy; school attendance for children aged 6 - 14; infant mortality; housing and household access to drinking water, sanitation, cooking fuel and electricity (CESS, 2008: 15).

A measure closer to zero indicates less deprivation and Hyderabad ranked top in the state in both 1991 and 2001 with an HPI of 0.233 and 0.213 respectively (CESS, 2008: 16). The state averages for the two periods were 0.583 (1991) and 0.469 (2001) which shows that, like Hyderabad, the level and distribution of development in Andhra Pradesh is improving (CESS, 2008: 16).

There are two indicators relating to gender-based development in the Andhra Pradesh Human Development Report 2007 (CESS, 2008): the Gender Development Index (GDI) and the Gender Empowerment Measure Index (GEMI). The GDI uses the same indicators as the HDI but considers the difference in measures between men and women. The greater the gender disparity, the lower the GDI is than the HDI. In 2001 Hyderabad ranked first in the state for gender-equality based development: the GDI was 0.692 (CESS, 2008: 17) and the HDI 0.717. While this shows that there is still inequality in terms of the level of development men and women are receiving in Hyderabad, it does at least show an improvement since the last measure in 1991. 
The GEMI seeks to measure women's political and economic participation (CESS, 2008: 16). It does this by incorporating three extra indicators with the GDI. These are:

“... percentage of women representatives elected in local body elections, rate of violence against women and sex ratio of children" (CESS, 2008: 16).

The 2001 measure shows Hyderabad lagging behind the rest of the state with a GEMI of 0.606 compared to the state average of 0.618. As such, for the GEMI Hyderabad ranked 16 out of the 23 districts in Andhra Pradesh (CESS, 2008: 17).

The above indicators measure more general levels of development and equality, however, they do not quantify poverty. Although the percentage of the state-wide population living in poverty ${ }^{20}$ in Andhra Pradesh is comparatively low at 15.5 percent, the incidence of poverty in urban areas was much higher at 28 percent in 2004/05 (CESS, 2008: 40). Indeed, latest GHMC information (April 2008) reports that over two million people live below the poverty line ${ }^{21}$ in Hyderabad alone (GHMC, 2008b: No page). Based on GHMC population data this figure represents 31.6 percent of the city's population (GHMC, 2008b: No page) which is higher than both the state's urban poverty rate of 28 percent (CESS, 2008: 40) and the incidence of urban poverty for India as a whole which the World Bank (2008) places at 24.7 percent.

The GHMC reports that there are a total of $1119^{22}$ slums within its jurisdiction. 779 of these are notified (GHMC, 2008b: no page) which means that they are officially recognized under the Andhra Pradesh Slum Improvement Act, 1956 (APMEPMA, 2008). Notified slums are entitled to redevelopment and improvement which should include being given basic utilities: power, water, roads, street lighting, drainage and sewage. However, this infrastructure is often only developed to varying degrees (pers. comm. with Venkat Radha, IWMI, 22/5/08). The remaining 340 slums in the city are not notified (GHMC, 2008: no page) meaning that they are not entitled to any official support from the local authorities. Under the newly formed (2008) “Indira Kranthi Patham Urban” (IKP-(U))

\footnotetext{
${ }^{20}$ This is according to the official Lakdawala Committee methodology. For a discussion of alternative methods of quantifying poverty in Andhra Pradesh see CESS (2008: 41).

${ }^{21}$ I have been unable to find anything published by the GHMC specifying the poverty line they use, however, when I asked an official at the GHMC he said that the poverty line in India was INR24,000 (US\$495) per person per year which works out at roughly INR66 (US\$1.36) per person per day. This is close to that of the World Bank which has set the international poverty line at US\$1.25 per person per day (2005 Purchasing Power Parity) (World Bank, 2009).

${ }^{22}$ Municipal Corporation of Hyderabad (MCH) data from 2003 puts this figure at 1631 (MCH, 2003: 68).
} 
project there is a drive to notify those slums currently un-notified in urban areas of Andhra Pradesh in order to extend basic services to those most in need (APMEPMA, 2008).

\section{Efforts to alleviate poverty in Hyderabad}

In the 2007/08 GHMC budget, INR1.28 billion (US\$26.4 million) of the total INR6.318 billion (US\$130 million) were proposed to be directed towards infrastructural development of the city’s slum areas. This is an increase in estimated expenditure on Urban Community Development of 29.69 percent from the 2006/07 budget and is to include funding tasks such as the construction and upgrade of roads, providing lighting and sewerage systems, and building schools in the city's slum areas (GHMC, 2008f).

IKP-(U) is implemented by the GHMC's Urban Poverty Alleviation and Livelihood Cell which comes under the State Government's “Andhra Pradesh Mission for Elimination of Poverty in Municipal Areas” (APMEPMA) (GHMC, 2008: No Page). APMEPMA’s objective is to “... formulate and implement all poverty alleviation interventions for eliminating poverty in municipal areas” (APMEPMA, 2008). IKP-(U) replaces the Andhra Pradesh Urban Services for the Poor (APUSP) project which ran from 1999 until March 2008. The project was funded by the UK Department for International Development (DfID) and sought to fulfil the objective of APMEPMA through, amongst other initiatives, the inclusion of the city's poor in decision-making (DfID, 2008) (for a discussion of the Municipal Action Plan for the Poor (MAPP) aspect of APUSP see Dove, 2004).

The objective of IKP-(U) is to:

“... promote, strengthen and nurture self-sustainable institutions of the poor and through them, address all poverty issues like access to credit, financial freedom, health, disability and vulnerability” (GHMC, 2008: No Page).

While there are a number of strategies (listed in Appendix X) designed to meet this objective, the use of self help groups (SHGs) is the pre-eminent among them. SHGs are designed to create stronger social ties within local communities so that the community's problems can be solved by the members themselves (GHMC, 2008: No Page). There are currently 16,050 SHGs encompassing 
240,750 families throughout Hyderabad (GHMC, 2008: No Page). IKP-(U) aims to include all the city’s poor within SHGs by creating an estimated 150,000 further groups (GHMC, 2008: No Page).

An extension of the SHG initiative is the "Pavala Vaddi” interest subsidy scheme whereby SHGs can be reimbursed for interest charged above three percent on bank loans given on or after 1 July, 2004 (Andhra Pradesh State Government, 2008b). This scheme is designed to encourage entrepreneurship amongst the city's poor by protecting them from the exorbitant interest rates - ranging from between 36 and 60 percent - often charged by private moneylenders (GHMC, 2008: No Page).

"Placement Linked Training" is another aspect of IKP-(U) which aims to increase employment of the city's poor by giving unemployed people vocational training in some of the city's businesses. The project currently has a 63 percent success rate for employment after training which IKP-(U) plans to increase to 100 percent (GHMC, 2008: No Page).

One final feature of the IKP-(U) project pertinent to the subject of this thesis relates to food security. SHGs are supplied staple food commodities - rice, dal, chilli, tamarind and oil - in bulk and at discounted rates. Members then redistribute the supplies throughout the SHG. This initiative is designed to avoid black markets for food and is reported to bring savings of between INR600 (US\$12.37) and INR1000 (US\$20.62) per family per month (GHMC, 2008, IKP-(U): No Page).

Given this work's use of a definition of poverty that includes the degradation of natural capital, a discussion of Hyderabad's local environment must be made.

\section{Environment}

\section{Environmental problems in Hyderabad}

In the GHMC's 2003 City Development Plan the introduction to the section on the city's environment read as follows:

"Hyderabad is beset with increasing urban environmental problems due to the growth of unsustainable economic activities, increase in vehicular transport, lack of public transport system and inadequate provision of basic infrastructure such as water supply,[and] 
sewerage. The most important issues of concern include air and noise pollution, depleting ground water and contamination of water bodies and lakes [,] destruction of natural and man made [sic] resources of cultural value and improper management of domestic and industrial effluents. This situation has (and will) lead to depletion of green cover, groundwater table and rising levels of air, water and noise pollution” (MCH, 2003: 75).

Presentation of a select few examples relating to: air quality; noise pollution; sanitation and sewerage; toxic waste; lakes; groundwater; and drinking water will, I believe, justify such a strongly worded summation of Hyderabad's environment.

\section{Air and noise pollution}

The number of vehicles in Hyderabad has increased from 470,000 in 1991 to over one million in 2001 (MCH, 2003: 75). Congested roads and polluting vehicles means that Hyderabad's citizens breathe in an estimated 691 tonnes of polluted air per day (The Andhra Pradesh Pollution Control Board cited in $\mathrm{MCH}, 2003)$. Increasing numbers of cars on the city's streets has also resulted in average noise levels at a selection of the city's main intersections exceeding national noise pollution standards (MCH, 2003: 79).

\section{Sanitation, sewerage and toxic waste}

Although 90 percent of Hyderabad's dwellings have sanitation facilities (CESS, 2008: 154), 97 percent of the city's wastewater (residential sewerage, industrial and hospital effluent) receives little or no treatment before being disposed of within the banks of the Musi River (Figure 6) which runs through the city (Buechler and Scott, 2006: 6; Buechler and Devi-Mekala, 2005: 411). With 231 hazardous-waste-producing industries located within the city (MCH, 2003: 79) an estimated 850 million litres of untreated wastewater, sewerage and effluent is discharged into the Musi River daily (MCH, 2003: 77). 


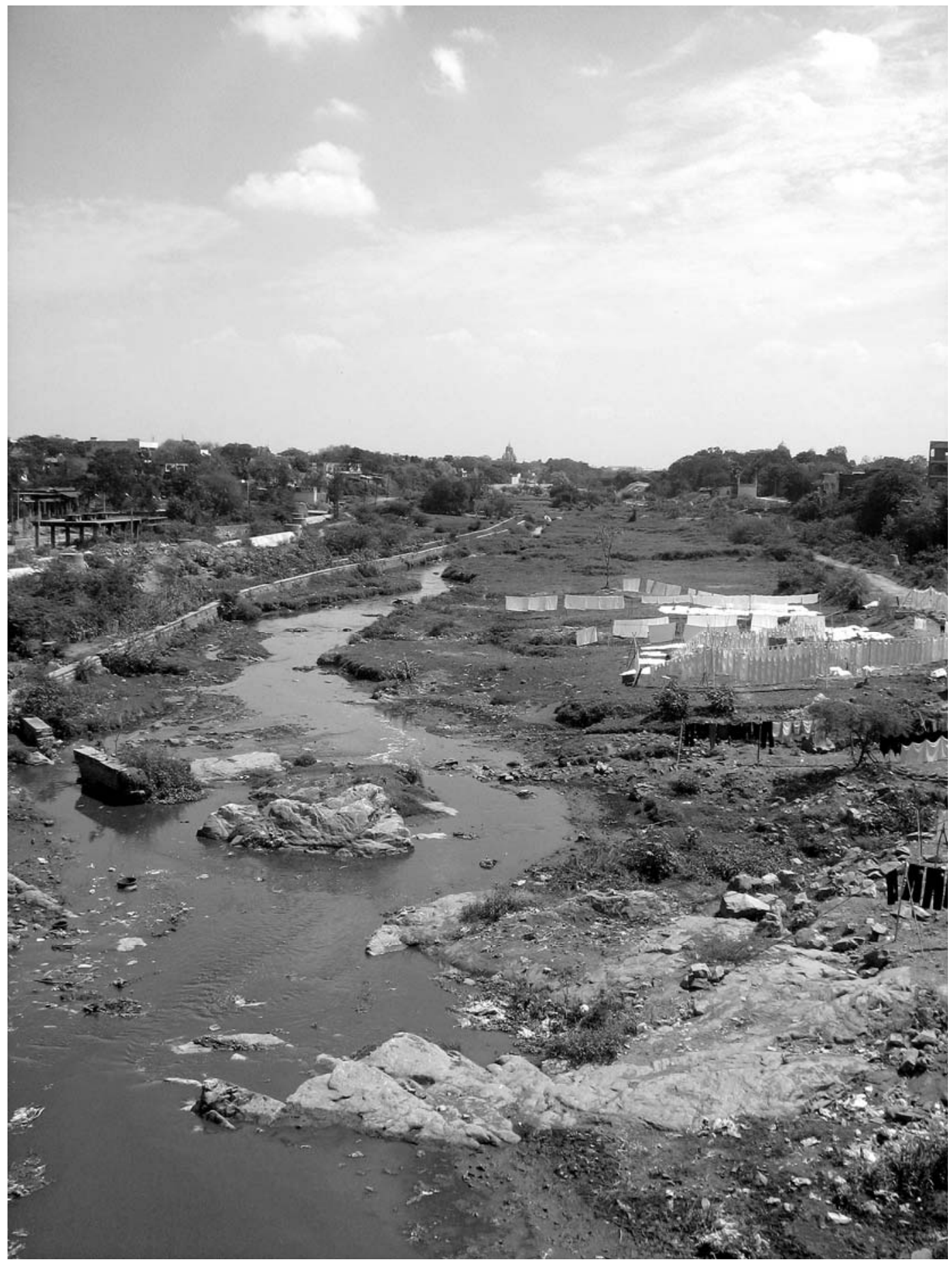

Figure 6: The Musi River, Hyderabad (Photo: Charlie Devenish, 2008) 


\section{Lakes, groundwater and drinking water}

Hussain Sagar - the iconic lake in the centre of Hyderabad - was formed in an attempt to avoid the water shortages that had driven the residents from Golconda fort to begin construction of a new city at Hyderabad in the sixteenth century. Hussain Sager was thus intended to be the city's main source of drinking water. Due to the discharge of untreated industrial effluent and domestic sewerage, however, heavy metals have accumulated to such a level that the water is no longer safe to drink (MCH, 2003: 78).

Ramachandraiah and Prasad (2004) attribute the declining water quality of Hussain Sagar and other of Hyderabad's lakes to the lax enforcement of pollution regulations and the corrupt nature of the city's institutions. They cite a case in which a High Court judge was removed from office overnight after passing an order to close heavily polluting industries situated in the Patancheru district of the city (Ramachandraiah and Prasad, 2004: 18).

Similarly poor enforcement of building regulations has been identified as a factor contributing to the reduction in both the number and size of lakes in the city (Ramachandraiah and Prasad, 2004: 9). Encroachment on - and the private capture of -water bodies has seen the number of lakes in the city reduce from 932 in 1973 to 834 in 1996 (Ramachandraiah and Prasad, 2004: 9).

Indeed, Hyderabad's water scarcity became acute in 2003 when the two main sources for the city's drinking water at that time - Osmansagar and Himayatsagar reservoirs - dried up. It has been reported that urban development within the catchment area of these two reservoirs is partly to blame. The catchment area for Osmansagar has shrunk to 80 percent of its former size while Himayatsagar's catchment is 70 percent of the size that it once was (Ramachandraiah and Prasad, 2004: 12). This situation led the chief of the Hyderabad Metropolitan Water Supply and Sewerage Board (HMWS\&SB) to say in March 2003 that: “... at this rate we do not know how long the reservoirs will survive ...” (The Hindu, 4 March 2003).

A report (Rao and Rao, 1998 cited in Ramachandraiah and Prasad, 2004: 13) has predicted that Osmansagar and Himayatsagar will either dry up completely by 2040 and 2036 respectively, or else they will become so contaminated by urbanisation in the area that the water will be unsafe for 
drinking. Testing of 38 other water bodies as potential sources of drinking water in and around the city found only 6 to be of a suitable standard for drinking (Ramachandraiah and Prasad, 2004: 17).

In 2000 the Supreme Court passed a ruling that forbade the construction of polluting industry within a $10 \mathrm{~km}$ radius of Osmansagar and Himayatsagar and ordered existing polluting industries within this zone to move or else close down (Ramachandraiah and Prasad, 2004: 13). The construction of the city's new airport at Shamshabad has, however, flaunted this ruling as some 809 ha of the airport falls within the 10km radius of Himayatsagar (Ramachandraiah and Prasad, 2004: 13 - 14).

Shortage of water for domestic use has resulted in the Krishna Water Supply Project which, at a cost of INR10 billion (US\$206 million), will, amongst other initiatives, pipe 205 million litres of water per day a distance of 115km from Nagarjuna Sagar to Hyderabad city (HUDA, 2003: 67; Ramachandraiah and Prasad, 2004: 11). Once complete the Krishna Water Supply Project will supply the city with a total of 1230 million litres of potable water per day (HUDA, 2003: 68).

Finally, as a main source of water for both domestic and industrial use in the city, groundwater is in a similar decline to that of the city's lakes as heavy metals from industrial waste infiltrates groundwater reserves (MCH, 2003: 78; Ramachandraiah and Prasad, 2004: 18; see also Asadi et al., 2007). Such loss of water resources is critical in a city that is characterised by water scarcity.

Given such diverse and chronic environmental issues, a number of regulations and specific projects intended to improve Hyderabad's local environment will now be presented.

\section{Local government efforts to improve Hyderabad's environment}

\section{Water resources}

The “Andhra Pradesh Water, Land \& Trees Act, 2002” has a number of articles relating specifically to protection of groundwater. Given the State's particular dependence on - and increasing exploitation of - groundwater reserves, a few of these articles will be highlighted (CESS, 2008: 149).

Article 9 of the Act makes it possible for the Andhra Pradesh State Water, Land and Trees Authority to prohibit the pumping of water from a specific source if it is deemed to cause damage to the local 
groundwater reserves and/or the environment (Government of Andhra Pradesh, 2002: 5). Article 11 allows the State Authority to prohibit the sinking of wells in exploited water basins while Article 12 details the Authority's powers to protect local drinking water resources (Government of Andhra Pradesh, 2002: 5 - 7).

While the above articles are examples of how the Act tries to prevent further damage to the state's water resources, Article 18 relates to rainwater harvesting, a proactive measure to improve the local water resource and, as a part of the RUAF-CFF pilot project, rainwater harvesting is an issue that will be returned to in the next chapter.

Article 18 makes it mandatory for all buildings with an area over 200 sq. m to harvest rainwater. Once harvested, this water is to be directed to recharge local groundwater resources through specifically built recharge pits. The GHMC is charged with enforcing this legislation at the building consent phase while the Hyderabad Metropolitan Water Supply and Sewerage Board (HMWS\&SB) has the authority to enforce the Act upon existing customers who receive water supply from the HMWS\&SB. In an effort to improve the rate of compliance for existing customers the HMWS\&SB drafted generic plans for rainwater harvesting units and offered a ten percent subsidy to help cover construction costs (HMWS\&SB, 2008). Due to continued flouting of this legislation the HMWS\&SB in 2006 made the construction of rainwater harvesting systems a condition of all new or upgraded piped water connections provided by the department. If the owner of a building with an area of over 200 sq. $\mathrm{m}$ does not commit to constructing a rainwater harvesting unit, the HMWS\&SB will not supply them with piped water.

Although discussions with the HMWS\&SB provided positive feedback concerning this project reportedly 60 - 70 percent of all new or upgraded connections are constructing rainwater harvesting units (interview with NR, Hyderabad: 21/5/08) - members of the Hyderabad office of IWMI were less convinced of the schemes' efficacy. They said that the final construction and/or use of rainwater harvesting units was often aborted once the inspector from HMWS\&SB had given clearance for the building's piped water connection. ${ }^{23}$

\footnotetext{
${ }^{23}$ This information is drawn from research conducted with IWMI for the article Amerasinghe et al. (2008).
} 
Article 18 of the “Andhra Pradesh Water, Land and Trees Act, 2002” illustrates the state authority’s efforts to pass legislation that will benefit the local environment, however, the HMWS\&SB's troubles in enforcing the Act show just how difficult it is to enable such legislation to make a sustained difference to the city’s water scarcity issues.

\section{Trees}

As an increasingly recognized aspect of UA, consideration of legislation relating to what could be called a form of 'urban forestry' is necessary to illustrate how the state authorities are working to improve - or at least minimise further damage to - the local environment. What follows is identification of some pertinent articles from the "Andhra Pradesh Water, Land and Trees Act, 2002” as well as evidence that suggests limitations of the Act's efficacy.

Article 28-1 details compulsory tree planting standards for certain land uses and plot sizes (these standards are presented in Appendix XI) while Article 28-5 relates to the cutting down of trees. It reads:

"No felling of the trees or branches is permitted without the prior permission of the designated officer. In case when a tree is to be felled, not less than two seedlings should be planted and when such planting is not possible, cost of raising seedlings and their maintenance shall be recovered from the concerned individual, organisation or other persons for raising plantations in public places” (Government of Andhra Pradesh, 2002: 10).

While the cutting down of old trees is somewhat inevitable in a city developing as quickly as Hyderabad, there is some contention as to whether the replanting as stipulated by Article 28-5 of the “Andhra Pradesh Water, Land and Trees Act, 2002” is being enforced. 60,000 saplings were reportedly planted in the year to 17 May 2008, intending to make up for the 1000 trees cut down during that same period (Times of India, 17/5/08: 2). However, local environmentalists have argued that it is the location of the replacement trees to which attention must be paid. Environmentalists argue that the bulk of replanting has been on the city's outskirts, while the tree-felling has been taking place in the city centre. As M Veda Kumar, president of Forum for a Better Hyderabad states, planting saplings on the city's outskirts to make up for those cut down in the city centre “... [is] not

going to serve any purpose ...” (Times of India, 17/5/08: 2). Furthermore, there is debate over the success rate of those trees planted. While the GHMC reports a survival rate of $80-90$ percent for 
newly-planted saplings, local environmentalists put the rate at closer to 40 percent (Times of India, 17/5/08: 2).

Finally, while the “Andhra Pradesh Water, Land and Trees Act, 2002” states that permission must be sought from the appropriate authority to fell any tree within the city, not a single request was turned down in the year to 17 May 2008 (Times of India, 17/5/08: 2). In an attempt to stop this seemingly unrestricted practice, the GHMC passed an order banning all felling of trees within the city (Times of India, 17/5/08: 2). A similar order was reportedly passed soon after by the Forest Department of the Government of Andhra Pradesh (Times of India, 27/5/08: 3). However, the fact that HUDA the third and final institution within the city that has the authority to grant tree-felling permits - had, at time of research, not passed a similar order undermines the attempt to halt the felling of all trees within the city (Times of India, 17/5/08: 2).

\section{Open space}

The Draft Master Plan for Hyderabad Metropolitan Area (HUDA, 2003) stipulates the open space standard relating to the city's building regulations (for details see Appendix XII). These regulations allow for a certain amount of open space and plantation within urban developments which could possibly be used for UA. It must be stressed that this is purely speculative - UA is neither a specifically permitted nor prohibited land use on the open spaces of land classified as 'residential' and/or ‘commercial’ (HUDA, 2003: 108 - 111). However, it could (I believe safely) be assumed that UA would be permitted on such land were it privately owned It must be noted however, that warehouses used for storing perishable goods are expressly prohibited on residential and commercial land (HUDA, 2003: 108, 110).

Regarding land designated specifically as ‘open space zone' and 'public and semi-public zone' there is, again, no mention of UA (HUDA, 2003: 113, 115). Parks and botanical/zoological gardens are permitted on land classified as 'open space zone' (HUDA, 2003: 115) signalling that there may be enough flexibility within the regulations to permit UA on such land. An interview with Mr P. Shorey (Hyderabad, 21/5/08), lead author of the city's development plan (HUDA, 2003) affirmed that UA was a permissible practice on land classified as 'open space zone', however, it is assumed that permission from the landowner would be necessary. It is undetermined if, in the instance that this land were owned by the civic authorities, UA would be permitted. 
In relation to land classified as 'public and semi-public zone', the fact that 'wholesale markets', 'dairy and poultry farms' and 'farm houses' are specifically identified as prohibited land use practices is reason to believe that UA may similarly be ruled an illegal activity on such land (HUDA, 2003: 113). The only land use on which agriculture and horticulture is explicitly noted as being ‘permitted’ is ‘conservation land’ (HUDA, 2003: 117).

\section{An externally funded project to improve Hyderabad's environment}

\section{The Green Hyderabad Environment Programme (GHEP) 2002 - 2006}

The GHEP was funded in part by the Royal Netherlands Embassy and the Government of India. It was co-ordinated locally by HUDA with the aim to:

"Achieve sustainable improvement of the living environment with active stakeholder participation and a focus on gender and poverty alleviation” (IWMI, ND b, 2).

\section{GHEP and Lakes}

The GHEP set out to clean 87 lakes in the city and construct sewerage treatment plants (STPs) at eight of the most highly polluted lakes. In August 2007, the restoration of seven of the 18 most contaminated lakes in the city had reportedly been completed (The Hindu, 11/8/2007). A HUDA report (2008d) on the project was encouraging, saying that 3 STPs were complete and the construction of the remaining five was underway. 


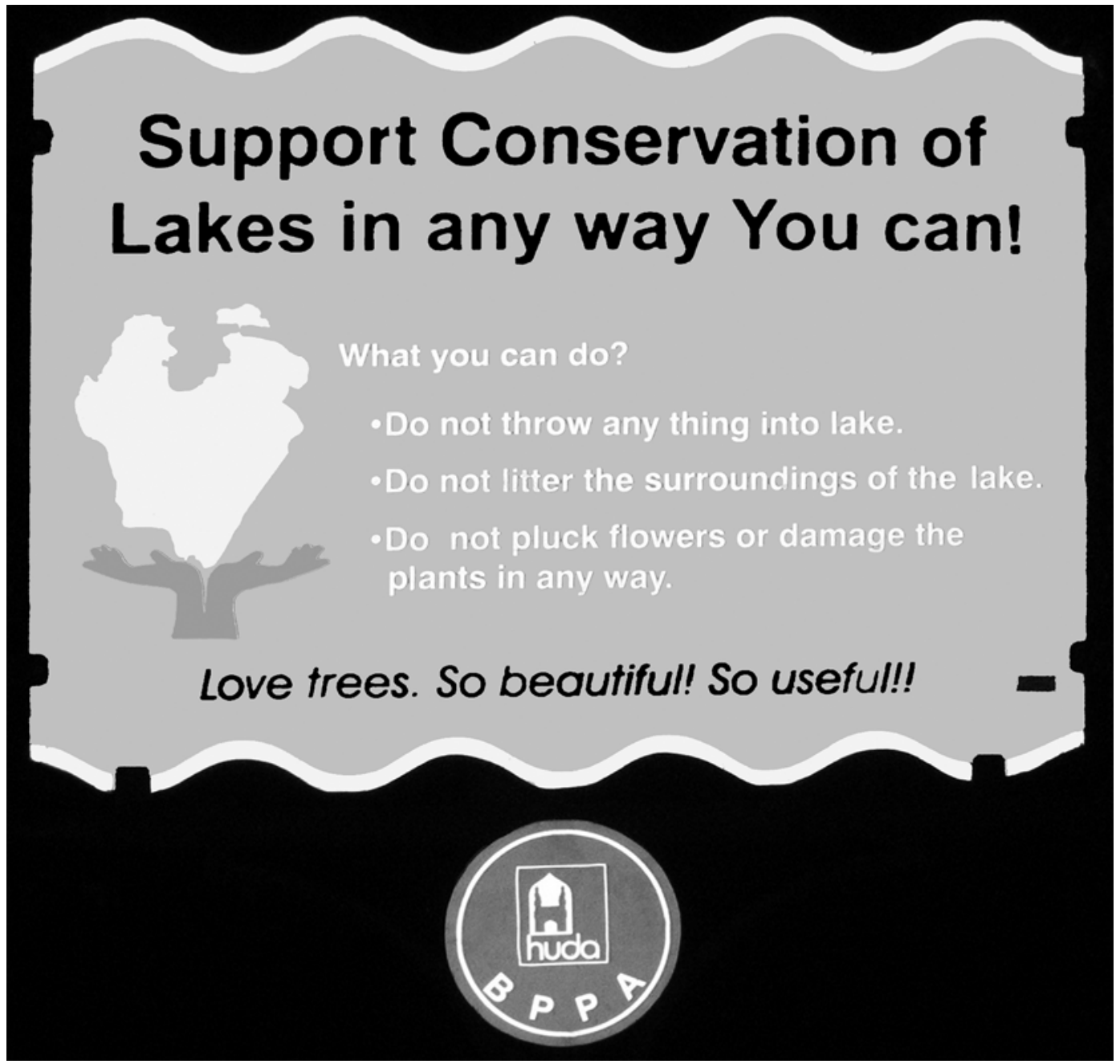

Figure 7: Sign at Necklace Road, beside Hussain Sagar, Hyderabad (Photo: Charlie Devenish, 2008)

\section{GHEP and Urban Greening}

The GHEP initiated a drive for afforestation in Hyderabad. While no documentation of the project's final outcome has been found, a report on its progress up to 31 August 2005 noted that 10,825 hectares within the HUDA jurisdiction had been afforested (HUDA, 2008d: 1). 
The social aspects of note in the GHEP's afforestation drive include the creation of over 9.2 million person-days of work (HUDA, 2006: no page) and HUDA's innovative use of homestead nurseries to supply saplings for the city's afforestation. The use of homestead nurseries is of particular interest to this thesis because it draws some links with, and shows opportunities for, UA. Through the homestead nursery scheme low income rural women were trained how to grow and care for saplings (HUDA, 2006: no page). Seeds, soil, fertiliser and plant bags were all provided to the growers at minimal cost. Once the seeds grew into saplings, HUDA purchased the saplings back off the growers as a value added product and the grower received payment for having nursed the seed into a sapling (HUDA, 2006: no page). While this is a project focused on low income rural women, there is reason to believe that it could be replicated in urban centres.

\section{Local initiatives to improve Hyderabad's environment}

\section{Urban greening by Hyderabad's Municipal Corporations}

Parks: Reviving Nature's Bounty, a brochure published in 2004 by the Municipal Corporation of Hyderabad (MCH), the predecessor to the GHMC, states that the effects of rapid urbanisation, industrialisation and increased congestion on the city's roads have motivated the re-greening of the city in an effort to:

“... bring about a massive change in the environment and in the people's attitude towards it.

Reviving the erstwhile beauty of the city is one part of the agenda, while the other part

includes building awareness among the people towards conserving the environment” (MCH, 2004: no page).

The MCH's initiative has focused on: roadside planting; creation of parks within housing colonies; the erection in public spaces of boards providing information relating to local flora and fauna; and, the creation of so-called 'theme parks' to improve local people's awareness and knowledge of local plant species (see MCH, 2004).

More recently the GHMC has initiated the "Green Hyderabad" project with a motto "Each one, plant one” (GHMC, 2008a). This project sought to plant one million saplings between 30 August 2007 and 30 August 2008, 200,000 of which were to be planted on, in, and around housing colonies. The main focus for planting was on land owned by the GHMC, schools, government institutions and 
private organisations. During the project's duration citrus, curry leaf, papaya, drumstick and other edible plants were sold at subsidised rates to the city's people. Finally, as part of the GHMC's “Green Hyderabad” movement, green saplings replaced flower bouquets and garlands at all official functions.

As part of the "Green Hyderabad” planting season for 2008 a community participation action plan was initiated. In each of the city's districts a member of the GHMC co-ordinated local community based organisations, non-governmental organisations, clubs and private businesses to undertake planting in the region (GHMC, 2008h). This was an innovative way of involving local people in the greening of their city and is a good example of devolution of certain civic duties to the community. Furthermore, it is a model that I think could be used to manage a community garden were one to be established in Hyderabad.

One final way that the local authorities are trying to re-green Hyderabad and involve their citizens in the process is through a project called "Fund your Parks". This project is a public private partnership in which the GHMC puts out for private tender the funding of proposed park development or refurbishment of an existing park. The successful tender effectively sponsors the project and is allocated advertising rights in the park for a pre-arranged length of time (usually between one and three years) (GHMC, 2008g).

\section{UA in Hyderabad}

The above information detailing tree plantation in Hyderabad is, if one uses Mougeot's broad definition, an example of UA in Hyderabad. Given that it is neither specifically identified as such by the civic authorities and nor is there any independent research relating to it as a manifestation of UA in Hyderabad, the following review of the literature does not refer to urban forestry in the city.

The publications concerning UA in Hyderabad have a distinct focus on wastewater irrigation (Buechler and Devi, 2003, Buechler and Devi-Mekala 2005; Buechler and Scott, 2006; Buechler et al. 2006; Buechler et al., 2002; Luck-Baker, 2008; IDRC, 2006; IWMI, ND). All of the estimated 100 ha cultivated on the banks of the Musi River in the central city are irrigated with wastewater 
from that river (Buechler and Devi, 2003: 9). Another approximately 2,000 ha of para grass in and around the city and up to 10,000 ha of rice paddy downstream from the city are irrigated with the Musi River’s waste-contaminated water (IWMI, ND: 2).

Water quality tests of the Musi River found the water to exceed FAO guidelines for the safe use of wastewater in agriculture in terms of faecal contamination, electrical conductivity, total dissolved solids and total nitrogen (Buechler and Devi, 2003: 5). While the risk to consumers of vegetables grown with this water is thought to be minimal due to the fact that the vegetables are cooked before consumption, no specific test results have been published to confirm or deny this assumption (Buechler and Devi, 2003: 5).

Skin irritations have, however, been cited especially amongst rice paddy farmers given the level of contact they have with the water (Buechler and Scott, 2006: 5). This, coupled with the damage wastewater causes rice crops has seen a reduction in rice paddy cultivation and a subsequent increase in para grass production (Buechler and Scott, 2006: 5) (for a discussion of damage to crops and the innovations and adaptations peri-urban and rural farmers have taken to reduce the adverse effects of wastewater irrigation see Buechler and Devi-Mekala, 2005).

While Buechler and Devi's 2003 publication detailing urban, peri-urban and rural agricultural practices along the Musi River is the most detailed account of agriculture in and around Hyderabad, its findings already seem somewhat outdated. In 2003 they paint a picture of rather diverse crop production in the city (including non-fruiting bananas trees (20\%), coconut palms (10\%), vegetables (4\%) various fruit and flowers (1\%) as well as para grass (65\%)). However, by 2006 Buechler et al. report that 95 percent of the area under cultivation in and around Hyderabad is used for producing para grass (Buechler et al., 2006). As they note:

"More and more people are moving out of vegetable production due to the poor water quality and the high labour requirement” (Buechler et al., 2006: 267).

Water salinity and the risk of infection from using wastewater is forcing urban farmers in Hyderabad to change their crops from those that are edible and more labour intensive to para grass which is used to supply the city’s dairy sector (Buechler et al., 2006: 269; Buechler and Devi-Mekala, 2005: 419). 


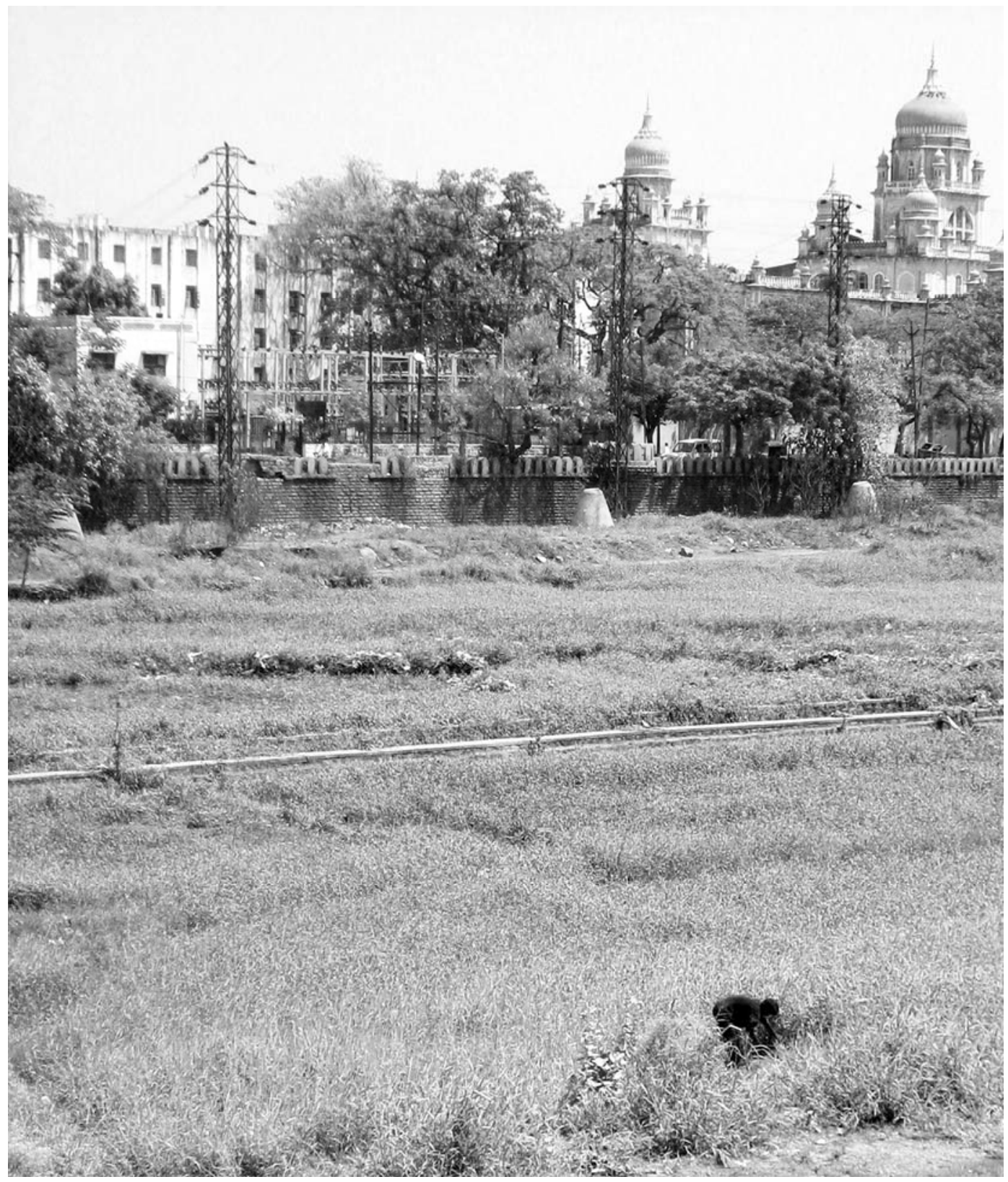

Figure 8: Para grass harvesting along the Musi River, near Osmania General Hospital, Hyderabad (Photo: Charlie Devenish, 2008)

The para grass industry in Hyderabad is big business. It is estimated to contribute INR218 million (US\$4.5 million) annually to the local economy (IRDAS, 2005 cited in IWMI, ND: 2), and employ 
up to 1260 people on a daily basis (Buechler and Devi, 2003: 12). One salesman who is said to have been working at the para grass market in Kachiguda for 20 years estimated that 40,000 people were dependent on the market for supplying, selling and buying para grass (Buechler and Devi, 2003: 12).

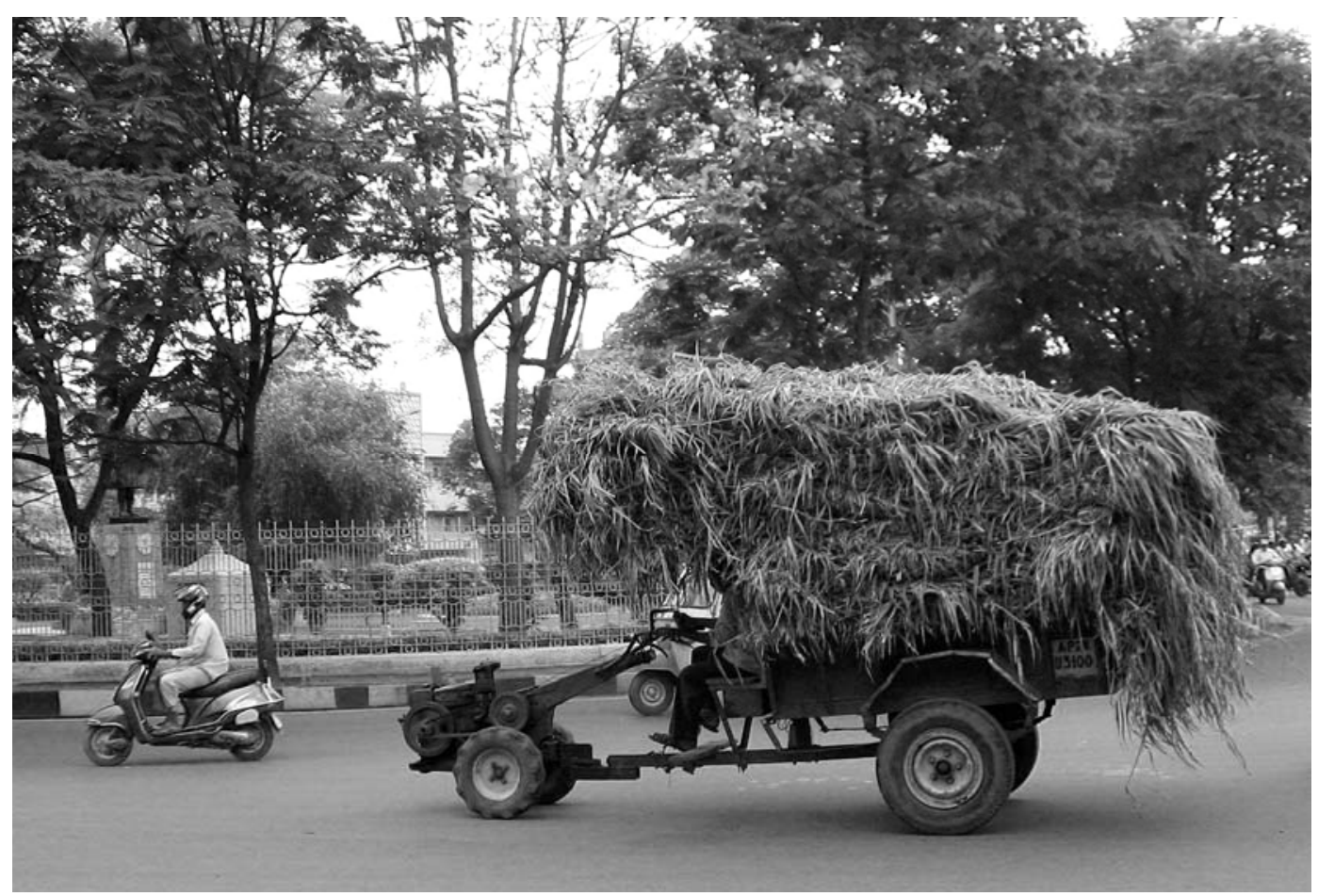

Figure 9: Para grass being transported to the Kachiguda market, Hyderabad (Photo: Charlie Devenish, 2008)

While para grass production is coming to dominate UA along the banks of the Musi River in central Hyderabad, an overview of what Buechler and Devi found in their 2003 study is still important to illustrate past agricultural production in the city.

Buechler and Devi estimated there were 250 households practicing UA along a 5km stretch of the Musi River in the heavily urbanised part of the city (between Purana Pul and Amberpet bridges) (2003: 9). This land is owned by members of the Kachi caste who were awarded the land in the seventeenth century for their services in the army of Aurangzeb who conquered Golconda fort in 1687 (Buechler and Devi, 2003: 10). 
While para grass was still the main 'crop' produced in 2003, at 65 percent of the area under cultivation it was less than the latest data which shows 95 percent of this land being used for its production. Economic returns and consideration of the labour input required helps to explain both the farmers' crop choice in 2003 and the current prevalence of para grass production along the Musi River. In 2003 one ha of para grass (which requires very little labour input until the time of harvest) brought an income of INR106,550 (US\$2197) per year. One ha of leafy vegetables (requiring relatively more time and effort) produced an income of INR51,712 (US\$1066). One hundred nonfruiting banana plants (taking up roughly 1 ha) yielded an annual income of INR29,177 (US\$601) while 100 coconut palms (equivalent to about 1 ha) brought the farmer just INR2049 (US\$42) in 2003 (Buechler and Devi, 2003: 11). ${ }^{24}$ Although these figures relate to the per hectare yield, the average size of urban farms on the banks of the Musi River in 2003 was 0.4ha (Buechler and Devi, 2003: 11) (In a more recent publication (Buechler et al., 2006: 267) the average plot size in Hyderabad is reported at $0.2 \mathrm{ha})$.

Given this scale of production, Buechler and Devi (2003: 11) found, much like other studies from around the world (van Veenhuizen and Danso, 2007: 21; Nugent, 2000: 72, 83; Vagneron, 2007; and Mkwambisi et al., 2007: 6 - 7), that UA along the Musi River was just one stream of income for participating families. In addition to other international case studies (Remenyi, 2000; Maxwell et al., 1998; Madaleno, 2000; Lado, 1990; and van Veenhuizen 2006), Buechler and Devi (2003: 11) found UA in Hyderabad to be dominated by women.

Although the transition to para grass production has been identified in the literature, there has been very little published about the industry consuming this product: the Hyderabad dairy sector. Buechler and Devi (2003: 12) have identified that dairy farmers can produce their own fodder grass for one third the price it costs to buy at the Kachiguda para grass market while more recent work (Buechler et al., 2006: 268) reports that male labourers working for eight hours a day in the para grass fields earn INR108 (US\$2.22) while women earn just INR86 (US\$1.77) for the same work.

\footnotetext{
${ }^{24}$ Note that in Buechler and Devi (2003: 11) they put these totals in Euro (€), their figures have therefore been converted into INR with a US\$ equivalent to remain consistent with the rest of the income figures used in this work.
} 
As for the scale of local milk production, the data is elementary. Preliminary studies by IWMI on dairy production in the Serilingampally municipality of western Hyderabad estimate about 15,0001 of milk to be produced daily within the municipality (IWMI, 2007a: 16). A study by IRDAS (2005 cited in IWMI, ND: 4) has estimated 100,000l of milk is produced within the city per day, making up a small percentage of the total daily demand of 1.8 million l of milk (IRDAS, 2005 cited in IWMI, ND, 4). In contrast to this figure, an interview with the marketing manager at Heritage Foods (India) Ltd. placed the local inner-city milk production at 600,000l out of a reported total of 1.9 million 1 of milk consumed daily within the city (Interview with M. Srinivas Reddy, Hyderabad: 27/5/08).

While the majority of the literature concerning UA in Hyderabad relates to that practiced along the banks of the Musi River, a small-scale survey of UA practices was conducted in 2006 in Gopanpally Tanda, Serilingampally, Hyderabad (IWMI, 2007a: 14). Under the guidance of IWMI staff, students from Roda Mistry School of Social Work surveyed a total of 76 households making up 53 percent of the community (IWMI, 2007a: 14). 84 percent of those surveyed identified agriculture as their main source of income and a total of 81 ha was found to be under cultivation by these families (IWMI, 2007a: 14-15). The main crops grown were rice paddy (36.84\%), sorghum (35.53\%) and pigeon pea (22.37\%) (IWMI, 2007a: 15). Some vegetables were also grown, with tomatoes being the dominant crop (74.5\%) (IWMI, 2007a: 15). The majority of farmers (78.9\%) grew for a combination of home consumption and sale at the market (IWMI, 2007a: 15).

In the course of the IWMI survey it was identified that the Government of Andhra Pradesh had recently procured the Gopanpally Tanda farmers' land for development of an information technology park. As a result, continuation of their farming practice would no longer be possible and increasing numbers of the community were seeking employment in non-agricultural activities (IWMI, 2007a: $15-16)$.

\section{Summary}

This chapter set out to introduce Hyderabad, the site of this thesis' fieldwork. A brief overview of the city's basic details - its location, climate, history, population, economy, governance and urban development - identified the key factors (and actors) influencing and shaping the city's current transformation. Presentation of both the incidence and efforts to eliminate economic poverty in the 
city illustrated the difficulties involved in achieving equitable development. Perhaps most starkly, however, the examples used to illustrate the current degradation of Hyderabad's local environment highlight the struggle to attain a form of development that is truly sustainable. Analysis of local government legislation along with an overview of two projects (one externally-funded and one locally-initiated) displayed some attempts being made to minimise the impact of Hyderabad's changing state on its host environment.

In concluding with an in-depth review of the literature relating to UA in Hyderabad, a clear picture of where the current work will sit within the body of the existing research has been made possible. In much the same way as the bulk of the literature in general, that associated with Hyderabad has addressed most clearly UA's positive and negative economic and environmental impacts. As already detailed in the previous chapters, the aim of this work is to take a more holistic approach to UA; one that also includes consideration of the social and cultural aspects of is practice. As such, the following chapter endeavours to investigate the potential for UA to alleviate social, cultural, environmental and economic poverties of capital. 


\section{Chapter six: Experience in the field}

What follows are the findings of my investigation into the RUAF-CFF project piloted in Surabhi Colony, Serilingampally, Hyderabad. This chapter introduces the project and presents its successes and the benefits accrued to its practitioners. The failings and limitations of UA identified in the pilot project will be presented in the next chapter where they will be used to consider UA's future and further application in the broader Hyderabad context. This chapter therefore explores the attempt of an externally funded project to introduce a community to UA with the specific aims of alleviating poverty and improving food and nutritional security.

Explanation of the findings will be on-going throughout this chapter. While semi-structured interviews provided specific information about project participants' experience, observation through wisdom of the body and work as an intern at IWMI gave insight that is vital to understanding these findings.

\section{The RUAF-CFF Pilot Project}

\section{Introduction to the project}

The Cities Farming for the Future (CFF) pilot project is funded by the Dutch government through the Directorate-General for International Cooperation (DGIS) and the International Development Resource Centre (IDRC) from Canada. It is co-ordinated globally by the RUAF Foundation which is an international network of Resource Centres on Urban Agriculture and Food Security. In South and South East Asia IWMI is the RUAF Foundation member implementing the CFF pilot project in Hyderabad and Bangalore in India and Gampaha in Sri Lanka.

The RUAF-CFF programme:

“... seeks to make a contribution to urban poverty reduction, urban food security, improved urban environmental management, empowerment of urban farmers and participatory city governance by capacity development of local stakeholders in urban agriculture and 
facilitating participatory and multi-stakeholder policy formulation and action planning on urban agriculture, including safe reuse of urban organic wastes and wastewater" (RUAF, 2008b).

In pursuing these aims the project intends to contribute towards achieving the Millennium Development Goals (MDGs) number one: “to eradicate extreme poverty and hunger" and number seven: “to ensure environmental sustainability” (IWMI, 2007a: 2; UN, 2008a).

The RUAF project runs until 2010 and the focus of the CFF phase is establishing kitchen gardens in participating families' homes. At the conclusion of the CFF phase, two pilot cities from South and South East Asia will be selected to progress into the next stage of the project which is called "From Seed to Table” (FSTT). ${ }^{25}$ This next cycle of the project focuses on improving producer capacity and establishing networks to supply local vegetable markets. It endeavours to transition from basic householder supply to a more substantial entrepreneurial business model.

For the city from the South and South East Asian programme that does not progress through to this next stage of the project it is believed that

“... the skills and knowledge gained during the [RUAF-CFF project] period will provide ample basis for the gardening activity to be carried out even after the project period" (IWMI, 2007b).

\section{Evolution of the RUAF-CFF pilot project in Hyderabad}

From its office at the ICRISAT in Patancheru, Hyderabad, IWMI is co-ordinating Hyderabad's RUAF-CFF pilot project in conjunction with the following local organisations: Andhra Pradesh Social Welfare Residential High School and Jr. College for Girls; Municipal Project Office, Serilingampally Circle, Greater Hyderabad Municipal Corporation (GHMC); Surabhi Haritha Sankalapam Committee; and the Vegetable Department, Acharya N.G. Ranga Agricultural University, Hyderabad.

\footnotetext{
${ }^{25}$ The RUAF website reports that the CFF phase of the project was set to conclude in December 2008 at which time two of the three pilot cities from South and South East Asia would progress through to the FSTT cycle of the project (RUAF, 2008b). Despite a number of emails to IWMI and regular checking of the RUAF website it is still, at time of submission of this work, uncertain which cities have progressed to the FSTT cycle of the project.
} 
Upon initiation in 2005, the RUAF-CFF pilot project undertook a Multi-stakeholder Process for Action Planning and Policy Design (MPAP) which involved discussions with local stakeholders and the analysis of four municipalities within Hyderabad to identify in which municipality the RUAFCFF project would be piloted (IWMI, 2007a: 2, 11). As one of the four municipalities considered, food supply to Serilingampally was assessed with the conclusion being drawn that the municipality was both food and nutritionally vulnerable (IWMI, 2007a: 10 - 19). In June 2007 a more thorough investigation of Surabhi Colony (located in the Serilingampally municipality) was undertaken to consider its potential for piloting the kitchen garden aspect of the RUAF-CFF project.

A socio-economic survey of Surabhi Colony was conducted and included 70 households (at this time only 80 houses were occupied and the colony's population was 300) and found the following: 61 percent of households earned less than INR4,000 (US\$82) per month ${ }^{26}$; 22.4 percent earned between INR4,000 and INR10,000 (US\$206); and 16.6 percent earned over INR10,000 per month (IWMI, 2007a: 26). For the majority of households in the colony - those earning less than INR4,000 per month - 14 percent of their monthly income was spent on fruit and vegetables and 17 percent was spent on eggs, fish and/or meat (IWMI, 2007a: 26). ${ }^{27} 57$ of the 70 households surveyed had a home garden of which over 60 percent (34 households) were comprised of mixed vegetable/fruit/flower plants (IWMI, 2007a: 25).

While issues such as water scarcity and poor soil quality were identified as potential constraints upon further UA in the Colony, the community's interest in the RUAF-CFF project saw it selected as the site for the kitchen garden pilot study. The aim of the project in Surabhi Colony was to improve households' nutritional security, reduce weekly expenditure on vegetables and, eventually, provide supplementary income for successful participating families (IWMI, 2007a: 25).

In November 2007 the project began at Surabhi Colony with training given to the 38 self-selected participating families (IWMI, 2007a: 26). This training was provided by IWMI staff in collaboration

\footnotetext{
${ }^{26}$ Note that this is the income per household in June 2007. April 2008 estimates by residents place the population of Surabhi Colony at 600 in 120 households making an average of five people per household. The poverty line used by the GHMC is INR2,000 per person per month meaning that the poverty line would be, on average, INR10,000 per household per month. In June 2007 only 16.6 percent of households in Surabhi Colony earned above this threshold.

${ }^{27}$ At 31 percent of their income, expenditure on food for the majority of people at Surabhi Colony is considerably less than the 50 - 80 percent of income poor people are said to spend on food (van Veenhuizen and Danso, 2007).
} 
with representatives of the Vegetable Department, Acharya N.G. Ranga Agricultural University and involved lessons in:

1. “Nursery bed preparation and management;

2. Field preparation;

3. Cropping calendars, inter-cropping and crop rotations;

4. Plant protection with emphasis on Integrated Pest Management (IPM);

5. Rainwater harvesting and water use efficiency;

6. Composting of crop residues and biodegradable kitchen waste;

7. Harvest and post-harvest storage” (IWMI, 2007a: 26).

A second site had been chosen to pilot a larger communal garden at Andhra Pradesh Social Welfare Residential High School and Junior College for Girls. By linking in with the Government of India's midday school meal programme the school garden was initiated with the aim of better supplying the nutritional needs of the school's 800 female boarding pupils and 25 staff (IWMI, 2007a: 26, 27). During fieldwork in Hyderabad, however, it was discovered that the principal intended to build an auditorium on the site of the school's vegetable garden plot. Although project staff continued to support the school's kitchen garden until construction of the auditorium was undertaken, it was decided not to focus research for the present work on the school garden aspect of the RUAF-CFF pilot project given the future plans for the site.

\section{Surabhi Colony}

\section{Heritage}

Surabhi Colony was established in the early 1990s (pers. comm. with Sabaa Ishaq, IWMI and Srinivasa Rao, resident of Surabhi Colony, Hyderabad: 8/5/08) when the Government of Andhra Pradesh set aside 4.5 hectares (IWMI, 2007a: 25) of land in Serilingampally Municipality (now known as Serilingampally Circle, encompassed within the jurisdictions of both HUDA and the GHMC). The Colony in Hyderabad was reserved for people whose historical roots were in Surabhi village in Kaddapaha district of Southern Andhra Pradesh (pers. comm. with Srinivasa Rao, resident of Surabhi Colony, Hyderabad: 8/5/08). The heritage of these people lay in traditional folk theatre (IWMI, 2007a: 25), however, due to declining interest in this performance Surabhi village in Kaddapaha receded as the focal point for their culture and the community dispersed throughout the 
country in search of more secure employment opportunities (pers. comm. with Srinivasa Rao, resident of Surabhi Colony, Hyderabad: 8/5/08). Surabhi Colony in Hyderabad was therefore established as the site to which the descendents of Surabhi village could converge and, hopefully, rejuvenate their cultural past (pers. comm. with Srinivasa Rao, resident of Surabhi Colony, Hyderabad: 8/5/08).

\section{Land ownership}

Discerning the exact land ownership rights in Surabhi Colony was not an easy task given that most people spoken with had a different story conveying how exactly they had acquired their land. In the document detailing their work at Surabhi Colony IWMI say that:

“... the Government of Andhra Pradesh provided them [the residents of Surabhi Colony] with land registration documents and established Surabhi Colony” (IWMI, 2007a: 25).

This, coupled with the fact that Surabhi Colony is classified as a notified slum implies that the land for the community was acquired through the "Andhra Pradesh Slum Improvement (Acquisition of Lands) Act, 1956" which provides scope for the acquisition - and subsequent designation - of land for a specific community (HUDA, 2003: 41). If land is acquired in this way it remains classified as a "notified slum" regardless of the relative state of its development (HUDA, 2003: 41). Given that 1) Surabhi Colony was specifically established for the people whose heritage lay in Surabhi village, Kaddapaha; 2) that it is a "notified slum"; and 3) that the state government provided the residents with land registration documents, it seems fair to assume that the land was acquired through the “Andhra Pradesh Slum Improvement (Acquisition of Lands) Act, 1956”.

\section{Housing and population}

The average plot size in Surabhi Colony is $117 \mathrm{~m}^{2}$. The houses have been constructed at the individuals’ own expense and are generally built to a basic, standardised design of one room with a floor area of 40m². In April 2008 locals estimated there to be 240 houses (either complete or else under construction) in the Colony, of which 120 were occupied. There is an estimated population of $600^{28}$ (notes from field trip, Hyderabad: 26/4/08).

\footnotetext{
${ }^{28}$ Note that the IWMI website places the Colony's population at 960 with an average of four people per household (http://www.iwmi.cgiar.org/southasia/ruaf/hydsc.html accessed on 12/12/08).
} 


\section{Water supply to Surabhi Colony}

Surabhi Colony’s main non-potable water supply is from a single bore well located at the eastern end of the settlement. Water is drawn by a motorised pump that supplies 51 taps (a combination of public and private) throughout the Colony. During fieldwork (March - May 2008) supply was restricted to approximately four hours per day between 6am and 10am. Unfortunately for those residents living at the opposite end of the Colony to where the bore well is located, water supply to the taps in their locale was poor. The majority of water supply was being utilised by those taps closer to the bore well meaning that by the time it reached those farthest away from the bore well it was, if running at all, a mere trickle.

In addition to the piped water supply there are five hand-pumps (four public; one private) throughout the colony that supply non-potable groundwater. These hand-pumps can be some distance from certain households and the residents are generally less inclined to use them given the effort required to withdraw the water.

Potable water is supplied by the Hyderabad Metropolitan Water Supply and Sewerage Board (HMWS\&SB). Supply was supposed to be one 50001 tanker every second day for the community’s population of approximately 600. However, during the dry summer months when the potable water supply is strained due to the increased citywide demand for delivered water, supply to Surabhi Colony decreased to two, but sometimes three, deliveries per week. 
Figure 10: Successes of the RUAF-CFF pilot project in Surabhi Colony, Hyderabad

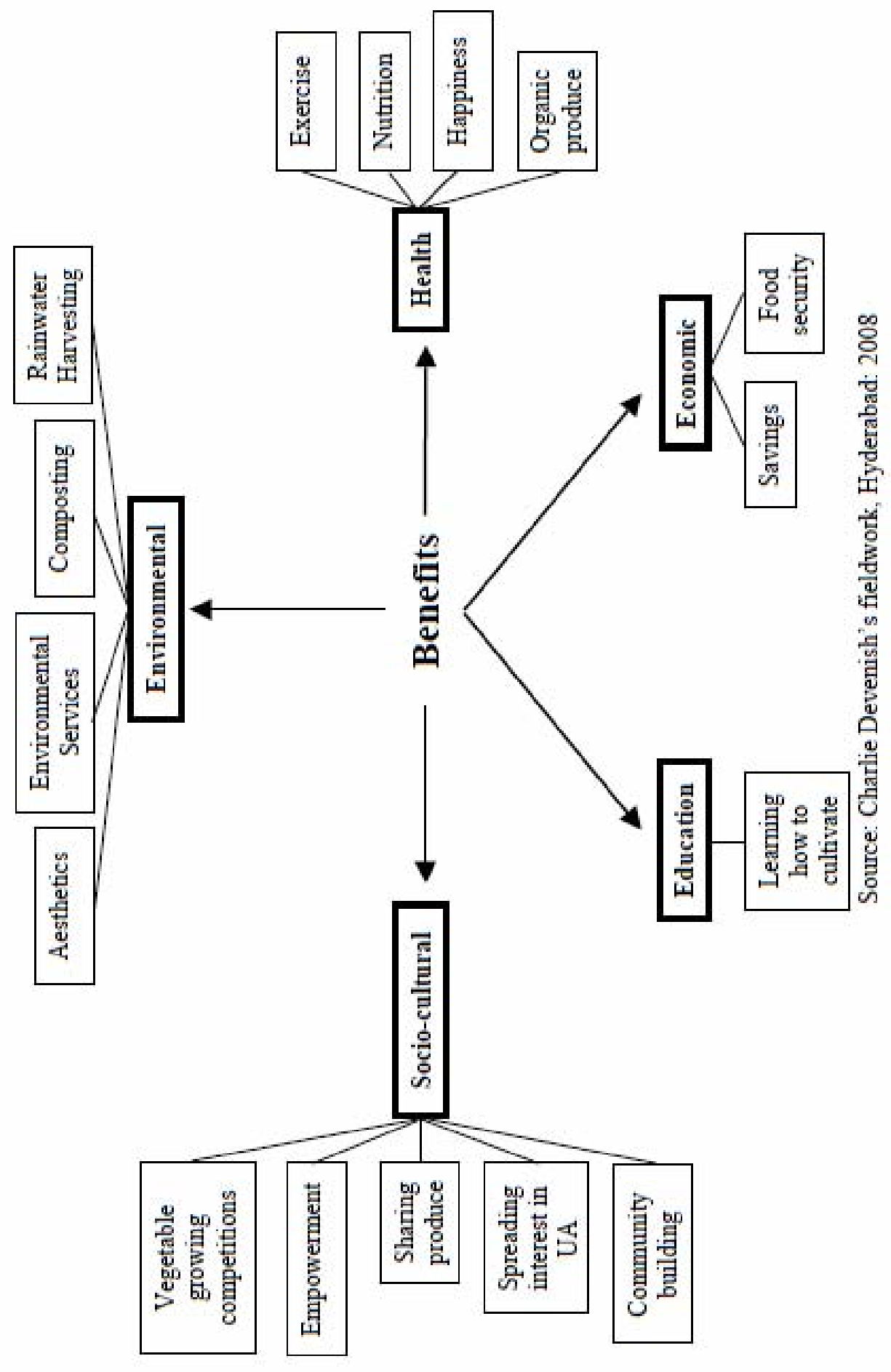




\section{Benefits and successes of the RUAF-CFF pilot project in Hyderabad}

As illustrated by Figure 10 there are environmental, socio-cultural, health-related, educational and economic benefits coming from the RUAF-CFF pilot project in Surabhi Colony. Presentation and, where necessary, discussion of these benefits follows.

\section{Environmental}

As an observer the environmental benefits of the RUAF-CFF pilot project are there to be seen, however, it is important to note that none of the project participants spoken with identified the environment as being a specific benefactor of their practice. A discussion of this issue will follow presentation of the observed benefits UA is making to the environment at Surabhi Colony.

\section{Aesthetics}

On a purely aesthetic level, establishing plant beds and growing vegetables has helped improve the otherwise somewhat harsh - and in places rather desolate - environment of Surabhi Colony. The garden of RUAF-CFF project participant Ms Venkat Laxmi (Figure 11) is a case in point - her front yard was predominantly solid clay, but, with encouragement from project staff she and her children spent two days digging over a large portion of this land to create a bed in which she later planted leafy green vegetables. 


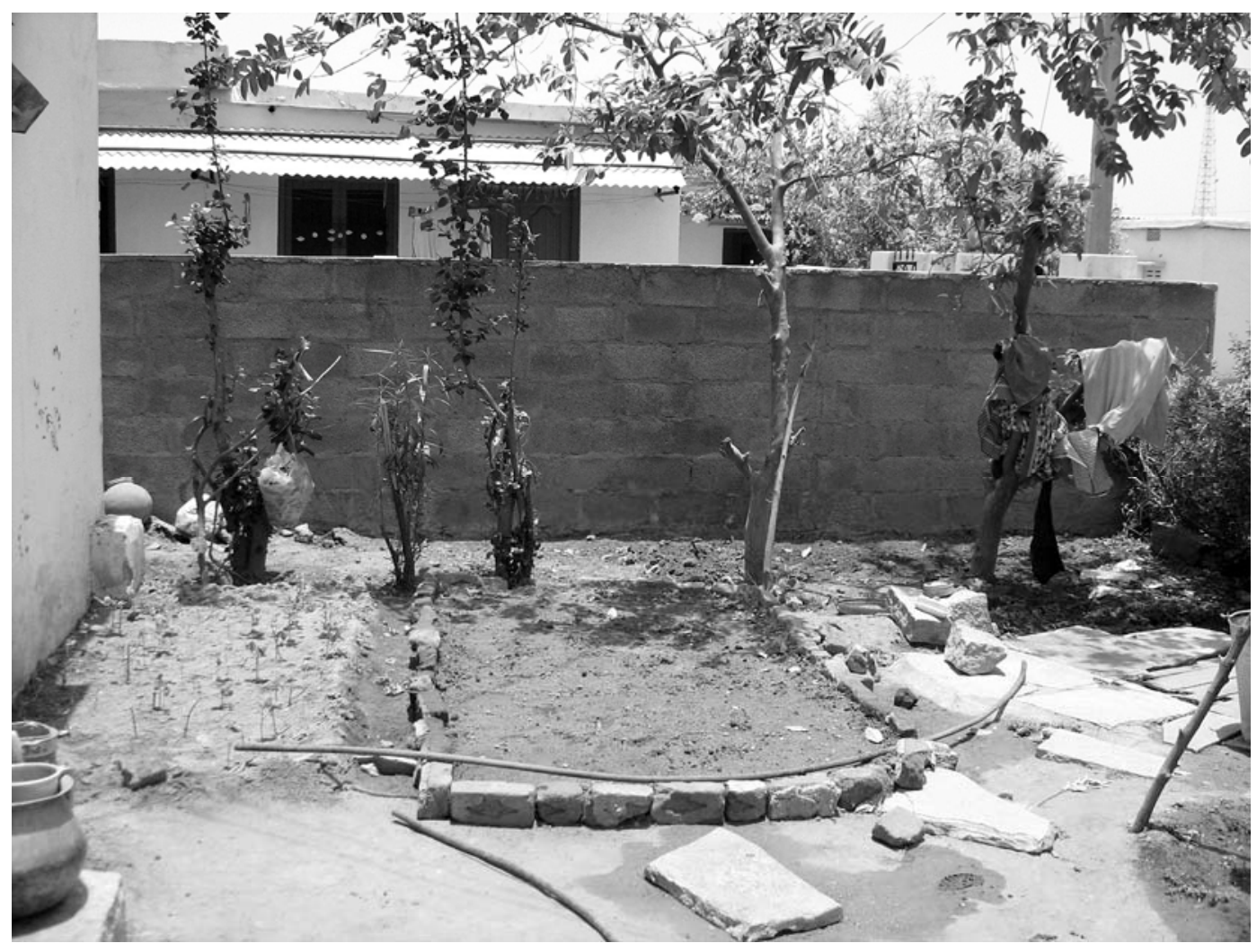

Figure 11: The newly extended garden at Venkat Laxmi’s house, Surabhi Colony, Hyderabad (Photo: Charlie Devenish, 2008)

\section{Environmental services}

The example of Venkat Laxmi's house illustrates not only the environmental-aesthetic benefits of UA but also the potential benefits to environmental services: by digging the soil and breaking its solid clay surface, Venkat Laxmi and her children improved the potential for water to be absorbed in times of rainfall. Although the exact effect of this absorption may be marginal, it could help decrease the amount of rainwater run-off to lower lying areas where it would inevitably stagnant, becoming polluted and thus a potential health hazard. In this way, it can be seen that the gardens are contributing to the improved soil moisture content and, in a very limited way, potentially recharging local groundwater supplies. 


\section{Composting}

The supply to RUAF-CFF project participants of materials, education and training for 1) composting and 2) the future installation of rainwater harvesting units was another environmental benefit of the project which, although apparent as an outsider, was not identified by the interviewees. IWMI supplied each participating family with three one foot high concrete rings to be stacked one on top of the other to form a compost bin. Training was given to the families regarding what could and should be composted and how to care for the compost. By looking at a number of these composting units throughout the Colony it was clear that the local people needed more training - some compost bins had plastic rubbish and one even contained a disused children's soft toy! However, the fact that the local people were beginning to compost at least some of their organic waste, diverting some waste from local landfills and providing a free source of fertile soil, is an environmental benefit of the project.

\section{Rainwater harvesting}

The intended construction of rainwater harvesting systems for families participating in the RUAFCFF pilot project helped spread awareness of the potential benefits from such practice. It is perhaps due to the fact that the rainwater harvesting units were not fully constructed by the time field research was complete that rainwater harvesting was not identified by project participants as a specific environmental benefit of their participation in the project. It can be said, however, that this was an environmental benefit - in the form of reduced demand on the local groundwater resource soon to be realised.

\section{Possible reasons for interviewees' omission of the environment as a benefactor of the project}

As mentioned at the beginning of this section, none of the project participants identified the environment as a specific benefactor of their participation in the RUAF-CFF pilot project. While this is a significant finding in terms of objectives two (to see if UA can re-connect practitioners with the local environment, thereby alleviating the cultural poverty present in the extinction of experience of nature) and three (to foster better environmental management to improve natural capital) of this thesis, there are a number of reasons, a few of which will be discussed presently, that could possibly explain this situation. 
First may be the way in which the questions were asked or how they were translated - from analysing the interviewee's responses it seems that they may have interpreted the line of questioning to be focused solely on their own direct benefits from growing vegetables and thus did not consider the more general benefits to the environment as a whole.

A second reason may be that the participants simply lacked knowledge about the potential positive impacts growing their own vegetables can have on the environment. This is not to imply that the participants from Surabhi Colony are environmentally ignorant, but, rather, to illustrate that as individuals we tend to concentrate on issues that are more directly applicable to - and influential on - our own lives. In a lower income community that lacks adequate water supply and sanitation, it is perhaps not surprising that, for example, the carbon sequestration potential of plants was not at the forefront of the project participants' minds. One final reason could be that the individual garden plots were considered too small and their effect too marginal to positively impact the surrounding environment.

The above reasons may explain why the participants made no mention of environmental benefits of the project. However, one could also speculate that the interviewee's omission of the environment as a benefactor of their practice indicates an element of anthropocentrism. It could be proof of the existence of an ontology of identity which has resulted in project participants' separating their sense of 'self' from the rest of the web of life. As such it may support the argument that urbanisation is indeed causing the extinction of experience of nature, thereby representing a form of cultural poverty as was argued in the first chapter of this thesis.

It must be acknowledged, however, that as attractive as this hypothesis is for the argument of this thesis, it is purely speculative. No specific research was conducted to test this hypothesis and therefore drawing such a conclusion would be a rather unfair extrapolation.

\section{Socio-cultural}

The socio-cultural benefits of the RUAF-CFF pilot project in Surabhi Colony revolve around helping to strengthen community connectedness and spreading interest in - and support of - the notion of UA. 


\section{Gardening groups in Surabhi Colony}

The RUAF-CFF pilot project instigated the establishment of the "Surabhi Haritha Sankalapam" resident home gardening committee and divided the 38 participating households into seven subgroups, each with a team leader. This helped streamline the relaying of information to, for example, inform the participants of a training day with IWMI staff and was also intended to encourage local support networks and the sharing of best practice techniques.

Despite the opinion of project participant Mrs R. Sharadha (interview with R. Sharadha, Hyderabad: 16/5/08) who chose only to take cultivation advice directly from IWMI project officers, it seems the experience of smaller, localised groups was a positive way for project participants to share knowledge (observations from IWMI Impact Assessment focus group, Hyderabad: 18/4/08).

The success of these groups may well be linked to the fact that many of the community's women also belonged to Self Help Groups (SHGs) which, as part of the urban poverty alleviation project IKP-(U) - discussed in the previous chapter - were designed to bring women in the community together to provide financial support and independence. Despite the fact that the SHGs were not officially involved in the RUAF-CFF project, the success of these groups and the relationships formed in that setting may well have flowed into the RUAF-CFF project. As such, the community's existing support networks may have helped nurture the UA sub-groups.

\section{Sharing of produce and the potential for vegetable growing competitions}

The opportunity for encouraging a community spirit through UA was further identified when project participants suggested that surplus production could be given to other, potentially poorer, members of the community (notes from IWMI focus group, Hyderabad: 11/5/08). The roots of this sentiment were evident in the actions of Mr V. Annand who, after growing a bumper crop of cucumbers, distributed the excess throughout the community (interview with Mr V. Annand, Hyderabad: 16/5/08). Mr Annand's enthusiasm for - and success with - growing vegetables extended to his suggestion that participants organise a competition to determine who could grow the biggest or gain the largest yield of particular vegetables (interview with Mr V. Annand, Hyderabad: 16/5/08). 


\section{Growing interest in Surabhi Colony}

This sort of vision for UA's potential to strengthen the community was supported by the fact that many of the non-participating families were very interested to see the progress and production of participants' gardens. Mrs Venkat Laxmi told the story that during the initial planning and consultation stages with the community, many people were sceptical of the project, believing it would be "impossible to grow vegetables under such conditions" (interview with Venkat Laxmi, Hyderabad: 16/5/08). However, on seeing the success of her garden some months later, people were becoming increasingly interested in establishing their own vegetable gardens (interview with Venkat Laxmi, Hyderabad: 16/5/08).

The spreading interest in - and awareness of - UA throughout Surabhi Colony and beyond, to the extended families of project participants, was an important success of the project. Mrs Rama Katyayani's neighbour and Mrs R. Sharadha's sister were intrigued by the project participants' gardens and sought information regarding establishing and caring for their own gardens. Similarly, Mrs Venkat Laxmi's parents and mother-in-law were interested in starting their own gardens after having seen their daughter's success. It must be pointed out that it is uncertain whether this interest was successfully converted into action.

\section{Empowerment}

After seeing his impressive groundnut (peanut) crop individuals from throughout the community sought growing advice from Mr Annand (interview with Mr V. Annand, Hyderabad: 16/5/08). The sense of purpose and ability to contribute to the family (and the community for that matter) in other, non-monetary ways, was an issue that $\mathrm{Mr} \mathrm{V}$. Annand, a retired man living with his son, greatly appreciated. Being able to help reduce the family's weekly vegetable expenditure and thus reduce the family's financial dependence on his son as the sole income-earner for the family exemplifies the potential UA has for empowering Mr V. Annand.

Furthermore, the majority of project participants were women who worked in the home. Being able to grow food and provide for the family in this manner was another way in which the project helped to empower, in particular, the women of Surabhi Colony. As Maxwell et al. (1998: 415-6) have pointed out, women most often have the role of providing food for the family but often lack control 
or access to the household's income. By growing their own vegetables women can therefore increase their contribution to the provision of food for the family.

\section{Discussion of the social benefits of the RUAF-CFF pilot project}

The community-building potential of UA is most often discussed in the literature in reference to community gardens, not private gardens (see for example Smit and Bailkey, 2006; Deelstra and Girardet, 2000). The high level of social cohesion and community support evident in the RUAFCFF pilot project may well be explained by the fact that participation in the pilot project was open to all members of the community, and therefore those that chose not to participate were still interested in the results of participation: they were undoubtedly keen to see what they could have done had they joined the project.

Another factor that may well have impacted the perceived connectedness within the community and the non-participants' interest in the project was that due to their shared cultural heritage, the residents of Surabhi Colony consider each other all part of one large family. This may have aided the dissemination of interest in - and awareness of - UA throughout the community and may also have helped to strengthen the specific UA support groups.

These two factors make it difficult to compare the community-building aspect identified in the RUAF-CFF project piloted in Surabhi Colony back to the general literature on UA because the case studies identified in the literature concern pre-existing practices, not attempts to introduce UA to a new community. ${ }^{29}$ As identified in the literature review, UA has traditionally been undertaken in response to an external 'shock' that has made people food insecure and financially vulnerable (the examples most often identified are economic and/or political crises, see: Armar-Klemesu, 2000; Maxwell et al., 1998; Maxwell, 1996; Drakakis-Smith et al., 1995; Howorth et al., 2001; IDRC, 2006; van Veenhuizen and Danso, 2007; Vagneron, 2007). The motivation for co-operation under such circumstances is therefore quite different from the situation in Surabhi Colony where the community was invited to participate in piloting the RUAF-CFF kitchen garden concept. In short,

\footnotetext{
${ }^{29}$ While other of the RUAF-CFF pilot projects from around the world are similarly introducing communities to UA anew (e.g. Ibadan, Nigeria; Bangalore, India and Bogota Colombia), no information relating to the increased community cohesion as a result of their practice has been found.
} 
the Surabhi Colony people are participating (and co-operating) out of interest in the project and its aims, not due to a specific financial or political crisis.

In saying this, however, the sharing between farmers of best-practice techniques witnessed in Surabhi Colony was shown to be similarly evident in Buechler and Devi-Mekala’s (2005) work on local innovation to counter the problems associated with wastewater irrigated agriculture in and around the Musi River in Hyderabad.

Finally, the contemporary spread of interest in community supported agriculture (CSA) and farmers' markets throughout the more-developed world (see for example Smit and Bailkey, 2006; and Fleury, 2007) is generally motivated by concern for the environment; in particular, the techniques used for production and the distance travelled - and impact caused by that transportation - before the food reaches the dining-room table (i.e. food miles). The growing community cohesion as a result of the CSA movement is therefore also different from that motivating the community-connectedness witnessed in Surabhi Colony. Given this difference and the fact that, as mentioned, the environment does not seem to be a motivation for practicing UA in Surabhi Colony, comparisons can hardly be drawn.

\section{Health}

Health related issues were some of the most readily expressed benefits of UA identified by participants of the RUAF-CFF pilot project. The nutritional benefit of growing and eating fresh, organic produce is certainly a more obvious benefit of UA that is highlighted in the literature (see Maxwell, 1995 and Buechler and Devi, 2003). The more tangential benefits of exercise and satisfaction derived from tending one's garden were issues expressed by project participants but which are not generally identified in the literature relating to UA in the developing world.

\section{Diet}

In both informal group discussions and one-on-one interviews with project participants the benefit of supplying the individual's family with fresh vegetables from the garden was clear. As pointed out by project participants Rama Katyayani and her husband Srinivasa Rao, not everyone has a refrigerator in which to store vegetables meaning that having a supply of select vegetables available 
in the garden enables access to at least some fresh produce (interview with Rama Katyayani and Srinivasa Rao, Hyderabad: 16/5/08).

While it seems that participants were not fully aware of the specific nutritional value of individual vegetables, they were clear about the importance of eating a diet that was generally full of fresh produce (observations from IWMI Impact Assessment focus group, Hyderabad: 18/4/08). The ability to provide a more nutritionally diverse and balanced diet by using the money saved by growing one's own vegetables to buy pulses, meat, oil and fruit reflects findings from the literature (see: van Veenhuizen and Danso, 2007; Nugent, 2000; Vagneron, 2007) and illustrates the project participants' more general understanding (be it cultural, biological or learned) of the need for nutritional variety. This redirecting of funds to provide a more balanced diet, coupled with the fact that project participants appreciated being able to feed their families at least some organic ${ }^{30}$ produce from their own garden further illustrates the participants' recognition of the health benefits made possible by practicing UA.

\section{Enjoyment}

What was perhaps somewhat more surprising, however, was the identification of the less tangible health benefits of exercise, happiness and satisfaction coming from growing their own vegetables. Venkat Laxmi, Rama Katyayani and Purnima were all obviously and, to my mind genuinely, happy to spend time in their gardens and enjoyed being able to provide their family with home-grown produce. Making reference to the translators, Venkat Laxmi explicitly said that she would rather be at home growing vegetables than outside the home having to work a waged job (interview with Venkat Laxmi, Hyderabad: 16/5/08).

\section{Education}

\section{Learning how to grow and care for the garden}

The most obvious educational benefit of the RUAF-CFF pilot project was teaching the local people how to grow vegetables. As identified by the situation analysis conducted by IWMI prior to the

\footnotetext{
${ }^{30}$ It is important to note that while the interviewees may not have mentioned the term 'organic' explicitly (given translation I am unsure if they used this word or not) they certainly stressed the benefit of growing food without the use of synthetic inputs such as fertilisers and pesticides.
} 
project's initiation, the people of Surabhi Colony do not come from an agricultural background. Although some of the participants do have previous experience in growing vegetables $-\mathrm{Mr} \mathrm{V}$. Annand for example had in the past grown and sold vegetables at the market - and even though the majority (60\%) of respondents to IWMI’s June 2007 socio-economic survey reported having gardens with flowers, fruit and vegetables, project participants' knowledge of vegetable growing was, for the most part, limited.

While this lack of knowledge meant some seemingly rather basic gardening practices like removing weeds were initially overlooked, the enthusiasm of some participants to learn and persevere was in my opinion admirable. Visits to Surabhi Colony were often filled with questions directed at the IWMI project staff on how to improve plant health and deter pests from preying on the plants. On subsequent visits to the community it became apparent which individuals were genuinely interested and willing to learn more about gardening.

\section{Desire to learn $=$ commitment to the project}

The difference between the appearance of some participants' plots and others was noticeable and, as could be expected, there seemed to be a correlation between a garden's appearance and the participant's commitment to the project. The case of Purnima and her neighbour is a good example. Purnima had formed specific plant beds for different vegetables, had made an effort to remove weeds and reported the following yield after five months of participation in the project: 4kg tomatoes; enough leafy green vegetables for two meals a week; 2kg eggplant; 5kg cauliflower; 5kg cabbage; a daily supply of coriander for four months; a few chillies every few days; and a handful of cucumbers, beans and lady’s fingers (okra). Contrastingly, her neighbour had planted tomato plants in a very ad hoc way: no beds were made and it looked as though the seeds had simply been scattered over the empty space behind her house. While no yield was recorded for this participant, it was clear that production from her garden was not as diverse as that of Purnima.

Continued failure to implement IWMI staff's advice concerning composting techniques - that, for example, plastic was not to be placed in the compost bin - often equated to a similar disdain for basic guidance on cultivation practice. Recognition of a general divergence into two groups - those that wanted to learn and those that did not - resulted in more concentrated support and training being given by IWMI staff to those participants that were genuinely interested. 
For these people that were committed to the practice, agricultural education was highlighted as a specific benefit of the project. However, in saying this, it must be noted that a genuine interest in learning how to grow vegetables was identified by the interviewees as a motivation for joining the project in the first place. As such, a generally well-maintained garden was evidence of this interest.

Another story of Mrs Venkat Laxmi’s gardening experience illustrates her genuine, albeit perhaps over zealous, commitment to the project and her garden's success. When confronted by the problem of a pig routing through her newly planted leafy green vegetable bed at night, Mrs Venkat Laxmi took to protecting her garden by laying a live wire - connected to the overhead power lines - around the perimeter of her garden! While buoyed by her obvious commitment to the project, IWMI staff were quick to advise Mrs Venkat Laxmi of the dangers of such practice and encouraged her to seek another solution, one without potentially fatal consequences!

Increased participant knowledge relating to growing calendars and production techniques could quite easily be extrapolated to show an example of counteracting the extinction of experience of nature. However, as this was not mentioned - let alone even signalled at - by any of the interviewees, it would be wrong to interpret their increased agricultural / environmental knowledge as proof of overcoming the extinction of experience of nature. In saying this, however, as the interviewer I must take some responsibility for failing to more fully explore this issue. I had considered a line of questioning that would investigate the theory behind the extinction of experience but felt once in the field that given the local context, it may be interpreted as arrogant, potentially patronising and likely evidence of an overly academic (and perhaps West-centric) approach to the work. Regardless of these concerns however, it is regrettable that the issue of UA and the extinction of experience was not further explored.

\section{Economic}

In contrast to that just mentioned, the economic benefits of UA were the most easily accessible and readily available. Economic data is quantifiable and, as an indicator of the project's impact on participant's daily lives, it is definitive. However, in saying this, it is also data that is perhaps the most politicised. As has been discussed in the research methods (Chapter three), the project 
participants may have modified the statistics regarding the economic impact of the project depending on what they thought I, as the researcher, may 'want' to hear. ${ }^{31}$ In saying this, however, it would be immoral and obstructive to consciously ignore the data with which interviewees provided me: they gave this information willingly and in most cases it was expressed as the most important outcome of their participation in the project. As detailed in Chapter three therefore, the presentation here of quantitative data must be viewed as information that is indicative, rather than explicit, of UA's impact.

\section{Economic savings from UA}

The interviewees all identified savings in their weekly vegetable expenditure as a result of growing their own vegetables. Mr V. Annand estimated that by growing his own vegetables, savings of up to 25 percent of his family's weekly vegetable expenditure could be made (interview with $\mathrm{Mr} \mathrm{V}$. Annand, Hyderabad: 16/5/08). Mrs R. Sharadha noted that the estimated INR50 (US\$1.03) she saved per week by growing her own leafy green vegetables could be put towards other purposes, like, for example, funding the construction of her new home. ${ }^{32}$ Purnima stated that her monthly savings were INR200 (US\$4.12), an amount that represents 2.5 percent of her household's monthly income. These various findings should be considered in reference to RUAF data (2008a) which suggests that UA can bring practitioners savings of 20 percent on weekly food expenditure. Howorth et al. (2001: 287) report a more conservative saving of ten percent in Dar es Salaam, Tanzania.

Mr V. Annand also identified the entrepreneurial potential of UA. He stated that if the community’s water scarcity issues were solved, he could grow enough extra vegetables to sell at the market (interview with Mr V. Annand, Hyderabad: 16/5/08). This point, already touched on under the “Health” subheading of this chapter, illustrates the employment and empowerment potential of UA.

\footnotetext{
${ }^{31}$ On this point it is important to note that data has recently been posted on the Hyderabad page of the RUAF website which says that on average, participants of the RUAF-CFF pilot project at Surabhi Colony have yielded 3.8kg of vegetables per household per month, equating to an average saving of INR84 (US\$1.73) per household per month (RUAF, 2009c). This data should be kept in mind when considering the following findings of the present research. The difference between the two data sets may be evidence of the very situation suggested in the text.

${ }^{32}$ Although INR50 (roughly US\$1) may seem a negligible amount to a reader living in a Western country, it must be put in context. A cup of tea on the street costs between INR3 (US\$0.06) and INR5 (US\$0.1) while the average daily wage for a male worker cutting para grass in the field is INR107 (US\$2.22) (Buechler et al., 2006: 286).
} 


\section{Food security}

While such anecdotes illustrate the purely economic potential of UA, the more tangential economic issue of food security was identified by Mrs Rama Katyayani and Mr Srinivasa Rao. They stated that by growing their own produce they have their own supply of fresh vegetables and it therefore no longer matters so much what the price of vegetables is at the market (interview with Rama Katyayani and Srinivasa Rao, Hyderabad: 16/5/08). As such, they identified the value of being free from the market's fluctuations.

As indicated by the literature review (Chapter four), issues of food security and a certain amount of freedom from the market are commonly cited attributes of UA. While improved food security is an aim of the RUAF-CFF pilot project and an issue identified by Mrs Rama Katyayani and $\mathrm{Mr}$ Srinivasa Rao, it is too early to draw a conclusion as to whether the project has substantially or sustainably improved food security. As a pilot project the RUAF-CFF project was simply scoping UA in Hyderabad. The longer term effects on food security will only be perceptible further down the track and will depend on whether the project participants maintain their practice.

\section{Summary}

The information and attitudes gained from interviews with project participants was certainly encouraging and indicates the potential UA has for improving certain aspects of practitioners' lives. While the economic benefits of the project were small, they were not insignificant and, as such, they signal the potential UA has for alleviating economic poverty and improving food security.

It is also interesting to note the non-economic, more qualitative benefits identified by participants and myself as an observer of the project. As issues which have not been covered quite so thoroughly in the literature relating to UA, they are findings of particular value. The strengthening of community bonds through participation in the RUAF-CFF pilot project is evidence of UA's potential to foster social capital, thereby alleviating the poverty caused by the breakdown of community discussed in the first chapter. Furthermore, the shared-learning and support networks fostered within the community indicate the potential longer-term sustainability of the initiative meaning that the practice of UA may continue after the specific project concludes. 
The empowerment and health benefits accrued to the practitioners of UA fit with the literature. Although these particular issues were not discussed within the social-cultural-environmentaleconomic framework presented in the first chapter of this work, they are, nonetheless, positive results and illustrate the accomplishment of two of the RUAF-CFF pilot project's aims.

The issues relating to cultural and environmental poverty as they were discussed in terms of the extinction of experience and the degradation of natural capital are especially interesting. While the absence of any mention of the environment by project participants may indicate a dissociation from their surrounding environment and the existence of an ontology of identity, the gardening-related knowledge gained and identified by some of the interviewees could just as easily be interpreted as evidence of the counteraction of the extinction of experience and an association with the immediate environment. As discussed in the body of this chapter, it is unfortunate that these issues were not more thoroughly explored in the present research, however, the findings so far indicate that this could be a valuable field for further study.

While this chapter has detailed the benefits and successes of the RUAF-CFF pilot project at Surabhi Colony, there are a number of issues restricting the fuller realisation of UA's potential both at the project level and at the broader city-wide level. Presentation and discussion of these limitations is essential to gain a complete picture of UA in Hyderabad, and, ultimately, to assess UA's ability to sustainably alleviate the poverties of capital presented in Chapter one. 


\section{Chapter seven: Future prospects of and for UA in Hyderabad}

There is, in any work, the desire to have a 'happy ending'. Were this to be the case in the present work, I would have concluded after the previous chapter. However, to do this would be misleading. There are, as they say, two sides to every story. It is to that 'other side', the failings of, and limitations to, UA that we must now focus our attention.

This chapter identifies three lessons learned from the RUAF-CFF pilot project which, when applied to the Hyderabad setting, illustrate why I think that UA will not become more widely used as a method of poverty alleviation and sustainable development within the city. The case study at Surabhi Colony highlighted that: 1) it is difficult to artificially create a culture supportive of UA; 2) a secure supply of water is central to UA's success; and 3) UA requires institutional support if it is to be successful in the long term. As it will be shown, these three issues, proven to limit UA in Surabhi Colony, similarly apply to the greater Hyderabad setting, and, as such, undermine UA's potential future and further spread throughout the city.

Following presentation of these lessons and their application to the wider Hyderabad setting, the thesis will conclude with a chapter (eight) that takes a step back from the site of fieldwork to consider UA's more general use as a form of poverty alleviation within the framework of sustainable development described in Chapter one. In this way, the final chapter will provide a summation of the efficacy of UA to remove the barriers that obstruct the streams of income / benefit that flow from the four capitals required to create and sustain well-being.

\section{Lesson One: It is difficult to artificially create a culture supportive of UA}

When asked the major issues facing their community, people from Surabhi Colony responded that water and sanitation were the main problems. In comparison, the main motivation for the RUAFCFF pilot project as it was identified by IWMI was to address the region’s “... food and nutritional 
vulnerability ...” (IWMI, 2007a: 19; IWMI, 2007b). It must be noted that the RUAF-CFF project does seek to:

“... make a contribution to ... improved urban environmental management ... and action planning on urban agriculture, including safe reuse of urban organic wastes and wastewater" (RUAF, 2008b).

Although these aims signal the opportunity for the project to address Surabhi Colony's water and sanitation problems, the reality is somewhat different. As evidenced by their absence from the previous chapter's discussion of the project's benefits, UA is making little positive impact at all on the community's main concerns of water and sanitation. Rather, its benefits have centred on the enjoyment gained, knowledge learned, connections formed, and economic savings made, by individuals' and their families' participation in the project.

While such outcomes should not be disregarded, the point is that they do not impact the specific problems afflicting the community. Although both the rainwater harvesting and composting initiatives of the RUAF-CFF pilot project have the potential to improve water and sanitation in the community, observations and findings during fieldwork indicate that UA is in fact exacerbating water scarcity in Surabhi Colony. Discussions with project participants uncovered that a number of the community's members felt some animosity towards participants of the RUAF-CFF pilot project because the watering of their gardens was only adding to the community's water worries.

This issue not only illustrates the importance of ensuring security of supply of inputs for UA's success - an issue that will be returned to in Lesson Two - but it also highlights the point that externally designed and implemented development projects must address the community's specific, self-identified needs. No matter how good a project may be in theory, if it does not provide solutions to the local people's most pressing issues, then its success will undoubtedly be limited.

I think that this incongruity between what the local people identified as their needs and what IWMI and the RUAF-CFF pilot project sought to solve contributed to the initial high rate of attrition from the project and many of the participants' subsequent low level of commitment. Of the 80 household representatives that attended the first training session held by project staff, only 38 chose to take part in the pilot project (field notes, Hyderabad: 26/4/08). Of those 38 participating families, less than half have been dedicated and active participants. An informal account by one of the IWMI project 
staff after six months of the project reported that only six household's gardens were in good condition, ten were of an average standard and the remaining 22 were somewhat disorderly (observations from the field, Hyderabad: 18/4/08).

While there are certainly other factors influencing the success of the pilot project - water scarcity the most important among them - the fact that UA does not explicitly address the community's own identified problems is, I believe, the main factor that influenced the community members' decision not to participate.

It was perhaps with this point in mind that Gisèle Yasmeen (2001) opined in her appraisal of UA in India that:

“... all planned interventions need to think in terms of capacity-building rather than starting a new set of activities" (2001: 41).

The Surabhi Colony experience is a prime example of the rationale behind Yasmeen's evaluation: that it is very difficult for an external actor to artificially create a pro-UA ethic within a community. As it has been shown, this is especially the case if UA does not provide a solution to the problems specifically affecting that community.

It is with this lesson in mind that I will now consider the likelihood of UA spreading more widely throughout Hyderabad.

As it was identified in the literature review (Chapter four), UA has most commonly come about in cities of the developing world as a response to significant economic and/or political crises or 'shocks'. As central as these factors have been to the success of UA in other cities, they are not present in Hyderabad. In fact, it could be argued that Hyderabad is currently stable in terms of both its economy and politics.

As detailed in Chapter five, Hyderabad's economy is growing at a rate faster than that of the rest of the state (Dev, 2007: 33). In relation to the rest of India, Andhra Pradesh recorded a level of growth in Gross State Domestic Product (GSDP) that was 1.64 percent higher than the rest of the country (CESS, 2008: 34), a statistic that likely contributed to the state's per capita income being higher than 
the all-India average (The Hindu, 20/2/2007). Such statistics are, I believe, evidence of a certain amount of economic stability.

In respect of Hyderabad's political condition, I would say with some confidence that the city is currently free from any obvious or imminent crises the magnitude of which have been shown to catalyse UA in other cities of the developing world. While I do not intend to make an in-depth analysis of Hyderabad's or India's political institutions, brief reference to work conducted by Transparency International (TI) will suffice in illustrating the city’s, and countries' political bodies’ credentials. TI’s India Corruption Study 2005 ranked Andhra Pradesh the fourth least corrupt state in the country, making special mention of the state's efforts to improve its governance (TI, 2005: 182 - 184). Meanwhile, India was ranked 85 out of the 180 countries assessed in TI’s Corruption Perception Index 2008 (TI, 2008). Although this data is not necessarily proof of Hyderabad's or India's political stability, it could be used as a proxy for interpreting the efficacy of the country’s democratic system and, as such, it demonstrates Hyderabad’s relative political stability.

The point of the above details is to illustrate the absence from Hyderabad of historically proven catalysts of, and motivations for, UA in other cities of the developing world: economic and political crises. This factor, coupled with firsthand experience from Surabhi Colony intends to show that without clear reasons for practicing UA - namely that it will bring solutions to local problems - it is unlikely that the citizens of Hyderabad will take up the practice.

In saying this, however, reference must be made to a point raised in the literature review: that UA is becoming an increasingly common coping mechanism utilised by the internationally growing number of 'urban poor'. This could be seen as reason for the future and further spread of UA in Hyderabad. Indeed, there are an estimated two million people, almost one third of the city's population, living below the poverty line (GHMC, 2008b: No page). While such statistics point toward the opportunity for UA to become more widespread throughout the city, the following two lessons detail practical limitations that illustrate why I think that this is unlikely. 


\section{Lesson Two: Security of water supply is central to UA's success}

As raised in the previous section of this chapter, water scarcity is a major factor negatively impacting the RUAF-CFF pilot project. While it is arguable as to whether this issue determined community members' desires to participate in the project in the first place, it is clear that for those who did choose to participate, water scarcity soon became a limitation upon their practice.

Water scarcity was identified as a potential constraint upon the project by IWMI staff as early as December 2007 (IWMI, 2007a). Rainwater harvesting was therefore included as a specific aspect of the project intended to deal with this issue (IWMI, 2007a: 26). It is due to such early recognition of the problem and its proposed solution that makes it all the more curious that rainwater harvesting units were still not installed a week out from the predicted arrival of the monsoon.

Every year the Southwest monsoon arrives in Hyderabad in early June - the Indian Meteorological Department (2008b) puts its arrival in the city at June 5. This is when the majority of rain falls in the city: on average $703.5 \mathrm{~mm}$ out of an average annual total of $804.5 \mathrm{~mm}$ fall during the months June to October inclusively (Indian Meteorological Department, 2008a). Despite this well-known situation however, when I finished my internship with IWMI at the end of May the majority of the approximately twenty 5001 water tanks being stored beside the IWMI office since I had arrived there in mid-April remained just there: in storage! With the monsoon literally days away, the community's potential for harvesting much-needed rainwater was yet to be realised. While a handful of households had received their water tanks, construction of their rainwater harvesting systems still appeared some time off.

It had been assumed by project staff that rainwater could simply be captured on household rooftops and directed via a down-pipe to the water tank. During a visit to Surabhi Colony on 30 May 2008, however, it was realised by project staff that not all of the project participants' rooftops would allow for such ease of collection. Furthermore, there is some contention as to whether installation of 5001 water tanks would supply enough water for the project participants' needs in any case. Given the abovementioned rainfall patterns in Hyderabad - that the monsoonal rains end in October - it is

highly unlikely that a $500 \mathrm{l}$ tank would provide enough stored water to last into the dry, water scarce summer months of March, April and May. 
Such last minute planning for what was well known to be a significant factor determining the project's success is not conducive to creating an effective project and neither is it likely to help retain a group of committed participants. It should come as little surprise therefore that water scarcity was repeatedly identified by project participants as the main barrier to their practice. Furthermore, as already mentioned, the increased usage of the already scarce water supply by project participants was beginning to cause some underlying tension within the community.

For those project participants living farthest away from the bore well - meaning that water barely reached the taps in their locale - fetching extra water for their gardens from operational taps became an increasingly time consuming task. At the time of interview, $\mathrm{Mr} \mathrm{V}$. Annand, one of the most enthusiastic gardeners who was interested in eventually growing surplus vegetables to sell at the market, was having to make a ten minute round trip to collect a single vessel of water. Watering his vegetable garden therefore required extra trips on top of those he already had to make to meet his family’s basic domestic water needs.

The inadequate water supply not only increased the amount of time and effort spent collecting water per day, but undermined Mr V. Annand's desire to grow extra vegetables to sell at the local market. Such a situation does not inspire hope for the planned next stage of the RUAF project - "From Seed to Table” - which has the explicit aim of improving producer capacity and establishing networks to supply local vegetable markets. Mr V. Annand commented that unless the water shortage situation was resolved, he would be unable to grow the amount of vegetables necessary to warrant supplying the market (interview with Mr V. Annand, Hyderabad: 16/5/08).

Another project participant, Purnima, had a similar experience. Although it was not possible to get a definitive answer regarding her water collection and use habits - varying responses were given on different days of consultation - the general point was that water scarcity was a major issue that needed to be addressed if she was to continue growing her own vegetables in the future.

While such findings illustrate the magnitude of the issue, it must be kept in mind that the interviews were conducted at the height of summer when water scarcity was at its most acute. Within a matter of weeks of these interviews the monsoon was predicted to arrive at which time water scarcity may 
well have become a distant memory for project participants. Regardless of this point, however, the fact of the matter is that peak summer water scarcity proved to be a major barrier to the project's success. Unless it is solved in a long-term, sustainable way, it will continue to be a limitation upon UA in Surabhi Colony.

A final point to be made regarding water is the construction of a large new government housing development immediately adjacent to Surabhi Colony (Figure 12). A member of Surabhi Colony said that 20 buildings were being constructed to house an estimated 5000 people (field notes, Hyderabad: 8/5/08). While this housing development is to be supplied piped water from the Krishna Water Supply Project (further details of this project follow), the covering with concrete and asphalt of what had until construction began been barren land nearby to Surabhi Colony will undoubtedly have a negative effect on the recharge of local groundwater reserves (for a discussion of this issue in Hyderabad see Ramachandraiah and Prasad, 2004: 7). Keeping in mind that Surabhi Colony’s main water supply comes from bore wells that tap the local groundwater, the future water situation for the Colony's population, let alone for UA, does not look promising. 


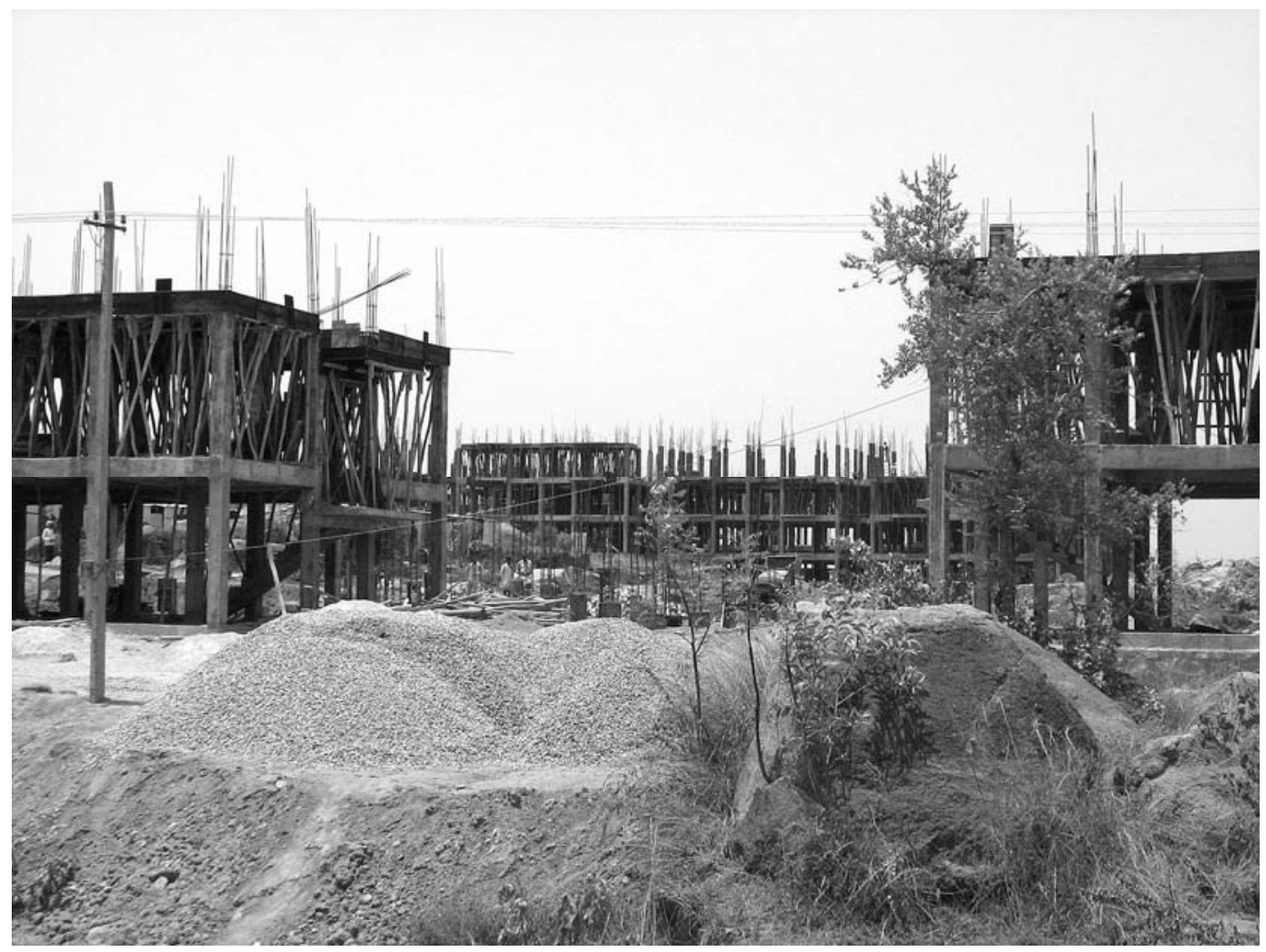

Figure 12: Construction beside Surabhi Colony, Hyderabad (Photo: Charlie Devenish, 2008)

As detailed in Chapter five, Hyderabad is characterised by water scarcity (see Ramachandraiah and Prasad, 2004; MCH, 2003; Asadil et al., 2007). The declining quality and quantity of the region’s fresh water resource is already having a considerable impact on the city's development. Despite large scale projects to ameliorate this situation however, water scarcity is only set to continue in the future. As will be explained, this situation of water scarcity in Hyderabad means that were UA to spread more widely throughout the city, practitioners would likely encounter problems similar to those already being experienced in Surabhi Colony.

HUDA's upper prediction for Hyderabad's 2020 population is 13.643 million (HUDA, 2006: 67). Based on a 'desired' daily water allowance of 150 litres per capita per day (lpcd), this amounts to a total citywide demand of almost 2050 million litres per day (Mld) in 2020 (HUDA, 2006: 67). 
In 2002, the total water supply to the HUDA-governed area was 735Mld (HUDA, 2006: 67). This means that a further 1315Mld must be made available to meet the demand projected for Hyderabad by 2020 (HUDA, 2006: 67). It is anticipated that once finished, the three-phase Krishna Water Supply Project which spans the next two decades will supply a further 1230Mld to the HUDA region thereby increasing the total supply within the HUDA area to 1965Mld. However, this is still 85Mld short of the total demand (2050Mld) HUDA have projected for the city in 2020. This means that the population's daily water allowance will decrease from the desired 150lpcd to 144lpcd. ${ }^{33}$ Although this may not seem like a lot, the point is that the Krishna Water Supply Project is a very large and expensive initiative - it is budgeted to cost INR10 billion (US\$206 million) (Ramachandraiah and Prasad, 2004: 11) - intended to help solve the city's water scarcity problems. If the scheme will not meet the desired water supply to the city's population in 2020, what does this mean for Hyderabad's citizens in 2030 and beyond?

This projected deficit in Hyderabad's water supply, coupled with HUDA’s admission that:

"It is however natural that the cost of making Krishna Water available at Hyderabad after treatment and distribution will be very high” (HUDA, 2006: 68),

illustrates that Hyderabad's population will likely continue to face water supply issues even with completion of the Krishna Water Supply Project.

While this situation has obvious negative impacts on the domestic use of water for citizens of Hyderabad, it is even more concerning for the potential future and further practice of UA in the city. As noted in Chapter four, there is a vast literature relating to the potential for UA to utilise cities' wastewater, and, as detailed in Chapter five, wastewater is already being used for irrigating UA along the Musi River in Hyderabad. With the predicted shortfall of fresh water availability in Hyderabad, wastewater seems a likely alternative water source for anyone intending to continue, or take up anew, UA in Hyderabad in the future. However, as previously discussed (Chapter five), the level of pollution of the city's wastewater - only 3 percent of wastewater is given any treatment (Buechler and Scott, 2006: 6; Buechler and Devi-Mekala, 2005: 411) - is already forcing urban

\footnotetext{
${ }^{33}$ Note that: "The Urban Development Plans Formulation and Implementation (UDPFI) Guidelines suggest for large metropolitan cities a domestic standard of 135lpcd as the minimum and 150-200lpcd as the desirable norm" (HUDA, 2006: 67). The domestic standard of 135lpcd is considered to be lower than commercial and industrial standards meaning that as a city with considerable industry, the desired water supply for Hyderabad would work out to an overall average higher than the 135lpcd, hence the 150-200lpcd 'desirable norm'.
} 
farmers to move away from vegetable production and towards the production of fodder for the dairy industry (Buechler and Devi in van Veenhuizen, 2006: 269; Buechler and Devi-Mekala, 2005: 419).

This leaves the future of UA in Hyderabad in a precarious position: with a lack of available fresh water, urban farmers are being forced to use wastewater for irrigation, however, due to a lack of adequate infrastructure to treat this wastewater, farmers are having to change the type of crops they grow to reduce the health risks to themselves and the consumers of their produce (Buechler et al., 2006: 267). It appears that if vegetable production is to become viable in Hyderabad, a concerted effort to improve the city's sewerage and sanitation infrastructure will have to be initiated immediately so that practitioners of UA can safely reuse the city's wastewater.

Another option that has already been mentioned in reference to Surabhi Colony is rainwater harvesting. In considering this alternative for Hyderabad in general, however, one must note Chapter five's detailing of the difficulties city authorities encountered in enforcing Article 18 of the “Andhra Pradesh Water, Land \& Trees Act, 2002” which concerns the compulsory harvesting of rainwater. The poor level of compliance (a fact that is 'typical' of the developing world according to Hubbard and Onumah, 2001 and Asomani-Boateng, 2002) with this legislation may well signal the challenges involved in using rainwater harvesting as a way of addressing the city's water scarcity issues. In saying this, however, rainwater harvesting is still an option that could be undertaken on a voluntary basis by practitioners of UA. As such, rainwater harvesting could be a way of overcoming the lack of suitably clean and available water for irrigating agriculture in Hyderabad.

Having identified the precariousness of, and a potential solution to, Hyderabad's water scarcity and the implications this has for UA in the city, it is necessary to determine if once such practicalities were solved, UA would ever even become an officially sanctioned practice used for sustainable poverty alleviation within the city.

\section{Lesson Three: To be successful, UA requires institutional support}

IWMI's limited success in engaging, co-operating and maintaining an ongoing relationship with other organisations and local government departments working on similar issues as was witnessed in 
relation to the RUAF-CFF pilot project undermined the long term success and sustainability of the project. Without local institutional support coupled with a certain sense of ownership by the wider community, the project runs the risk of collapsing once IWMI withdraws from Surabhi Colony.

A number of examples illustrate this point. The World Vegetable Centre (AVRDC) is running a project from their office at ICRISAT in Hyderabad to determine the most nutritionally balanced and year-round productive vegetables to grow in kitchen gardens (pers. comm. with an official at AVRDC, Hyderabad: 26/5/08). Despite the fact that the AVRDC and IWMI work at the same research institute and that the AVRDC's trial field is a matter of kilometres from Surabhi Colony meaning that growing conditions are similar, IWMI has not sought any input from the AVRDC to help the RUAF-CFF pilot project (observations at IWMI, 27/5/08).

While this situation could be explained away by the fact that both IWMI and the AVRDC are competing for similar (and small) funding opportunities, IWMI's limited integration with the local governing authorities of Hyderabad seems to my mind, less excusable. Not only does it put in doubt the long term sustainability of the RUAF-CFF project, but it jeopardises potential future support for UA in the city.

In a meeting at the GHMC's Urban Community Development wing it was discovered that a high ranking official in the Urban Poverty Alleviation and Livelihoods Cell knew nothing of the RUAFCFF pilot project. While one could not expect IWMI project staff to be in contact with all related local government officials, it seems fair to assume that the team working specifically on urban poverty alleviation and livelihoods in Hyderabad would be an important contact to have made and maintained.

Another example of a potential missed opportunity was IWMI's lack of communication with an official at the GHMC who was informed about and supportive of UA. When asked in an interview how to push UA up the political agenda in Hyderabad, this official believed it was IWMI's role as the co-ordinator of the project. In subsequent discussions with IWMI project staff however, it was discovered that they believed it was the role of local government officials to promote UA in the GHMC and HUDA. The lack of communication between IWMI and this official of the GHMC led 
to a situation in which no one was providing the local authorities with the impetus to create policy to support UA in the city.

On this point I believe that IWMI must take responsibility. In their concept document IWMI (2007a) have explicitly stated:

“... the need for a supportive and favourable policy environment for UPA [Urban and Periurban Agriculture] that will facilitate the integration of UPA into urban planning policies. In addition to this, both government and non-government institutions often lack the capacity and coordination to support UPA farmers which could be addressed if suitable policies and directives are in place” (IWMI, 2007a: 21).

Having identified this point and being a leading proponent of UA in Hyderabad, one could assume it to be IWMI’s role to encourage local government support for its practice.

Finally, on the broader issue of food security and poverty alleviation strategies it is interesting to note that an event was held by the Urban Poverty Alleviation and Livelihood Cell of the GHMC on 3 April 2008 at NTR Stadium in Hyderabad. At this meeting the Indira Kranthi Patham Urban (IKP(U)) project (detailed in Chapter five) was launched with a mission:

”To enable the [u]rban [p]oor, particularly the poorest of the poor, to come out of poverty and vulnerability in a sustainable manner and improve their quality of life in urban areas” (GHMC, 2008b: No Page).

Not only did no IWMI representative attend the launch of this project, but evidently none of them even knew about the event as they were all eager to see the document relating to IKP-(U) that I had acquired on a visit to the GHMC. This was a very unfortunate situation, especially when one reads the IKP-(U) method for addressing food security:

"To address the issue of malnutrition and food security for [u]rban [p]oor [f]amilies, provision has been made to enable SHGs [Self Help Groups] to procure the 5 essential food commodities viz rice, dal [lentils], mirchi [chilli], tamarind \& oil at cheaper rates in bulk for distribution among themselves” (GHMC, 2008b: No Page).

Given that the underlying ethos of the RUAF-CFF project is that growing one's own food improves one's own and one's family's food security, the IKP-(U) approach would likely be seen by IWMI as the co-ordinator of the RUAF-CFF pilot project as a short-term, unsustainable approach to solving 
food insecurity. Surely it would have been a good opportunity to promote UA as a longer-term, more sustainable approach to food security for the city's poor? However, given that the IKP-(U) project launch took place without any presence from $\mathrm{IWMI}^{34}$, it seems the chance for incorporating UA within the Urban Poverty Alleviation and Livelihood Cell's approach to food security went begging.

The apparent lack of integration with the GHMC and HUDA seem to have limited both the immediate and lasting success of not only the RUAF-CFF pilot project, but UA in the city in general. Greater and sustained involvement of the local authorities from an early stage could have helped to improve the chances of UA's continuation and spread after IWMI withdraw from Surabhi Colony. Furthermore, better involvement of local government officials, by, if nothing more than an update of the pilot project's progress to the relevant officials, could have in my opinion, increased the potential to create legislation that would have a direct affect on the future of UA in the city. As will be explained presently, the failure to more widely promote UA as a practice that benefits not only participants, but also the wider community (including non-human species), means that the opportunity to formulate policy supportive of its practice may well have passed indefinitely. ${ }^{35}$

This research conducted a number of interviews and discussions with local government officials in Hyderabad's governing institutions and encountered a lack of information about and awareness of UA. Misperceptions about its practice and scope, as well as a general disdain for its presence were common amongst these officials. As already indicated in Chapter five, and as will be elaborated upon here, recent (April 2008) approval of the city's development plan, including land-use specifications to 2020, makes the future prospect of official support for UA as a strategy to alleviate poverty in Hyderabad seem to me unlikely.

\footnotetext{
${ }^{34}$ Since returning to New Zealand I have written a number of emails requesting clarification of this point, however, I am yet to receive a reply from IWMI officials. Given that IWMI staff did not know about the launch of IKP-(U), I am inclined to think that they did not have any input to the project's formulation.

${ }^{35}$ It must be highlighted that it was recently (16/2/09) seen by the researcher on the RUAF-CFF website (RUAF, 2009c) that the GHMC have purportedly: "expressed interest in exploring avenues to include urban agriculture as a part of the city greening programme "Greener Hyderabad" ... [and that] ... GHMC is keen to pilot test the allotment garden concept in some of the open spaces close to low income communities ... [and that] ... GHMC also expressed interest to develop a city strategic agenda on urban agriculture." While such information seems to counter this work's assertions, I would hasten to add that while I do not know the exact date this information was gained by IWMI, it was certainly well after the conclusion of my field research (31/5/08) meaning that this work's findings and conclusions are still valid for the period of research. Furthermore, I would stress that this is a re-presentation of what are said to be the GHMC's intentions, as such they may not in fact eventuate. They are, after all, only "expressions of interest". They are nonetheless encouraging and progress on this matter will be watched with some interest.
} 
None of the following high ranking officials at the GHMC or HUDA had heard of UA, let alone the fact that there was a project being piloted in the city to explore its potential use for reducing poverty and improving food security for the city's poor: the Additional Commissioner of Works; the Additional Commissioner of Parks; the Chief Horticulturalist; the Chief of Urban Forestry and; the Project Officer for Urban Poverty Alleviation and Livelihoods.

For the majority of those interviewees that had either heard of UA or were willing to entertain the idea, it was ultimately dismissed as being unrealistic in Hyderabad. It is important to note here the likeness of the responses I received in interviews with those found in the literature. Gopal Kishan Rao, manager of NTR Gardens, a 13 ha park situated in the city centre, thought that UA was a 'crazy' idea (interview with Gopal Kishan Rao, Hyderabad: 25/3/08). On this point note that Maxwell (1995: 1669), IDRC (2006: 26), Drakakis-Smith et al. (1995: 187), and UNDP (1996: 3, 212) have encountered institutional opinions of UA that have characterized it as a "backward" practice that harks back to "pre-modern” times.

Meanwhile, Chief Horticulturalist at the GHMC, Mr P. Konda Reddy, believed that no one in the city would be interested in growing their own vegetables because the quantity produced would be negligible (interview with P. Konda Reddy, Hyderabad: 26/3/08). Maxwell (1996) found similar attitudes in his research conducted in Africa. Mr Reddy also raised the issue of security, questioning how one would assure that produce was not stolen (interview with P. Konda Reddy, Hyderabad: 26/3/08) (note that this issue was found to be a considerable problem for farmers in Kano, Nigeria see: Lynch et al., 2001).

On the idea of community gardens Mr Reddy said that there was not enough space within the city, however, he then went on to say that the GHMC was planning to create an extra 750 parks within the city in the coming two to three years. With an area of between 1000 and 3000 sq. m, these parks are to be landscaped with ornamental plants and lawns designed to provide the citizens of Hyderabad with well maintained recreational areas (interview with P. Konda Reddy, Hyderabad: 26/3/08).

Of the interviews conducted, only Mr Shorey, the recently retired lead author of the city's development plan (HUDA, 2003) was in a position to talk informatively about the prospect of UA 
being used as a poverty alleviation strategy more widely throughout the city. ${ }^{36} \mathrm{Mr}$ Shorey had heard of UA and had acknowledged its worth in the cityscape. He believed that UA's main use was as a "lung space" for the city and said that it could potentially be used as a temporary practice on land that was in transition from one "permanent" land use to another (interview with Mr P. Shorey, Hyderabad: 31/3/08). Mr Shorey cited the potential pollution caused by fertilisers leaching from UA as the main reason it was not included as an officially sanctioned land use in the city's development plan (HUDA, 2003).

Such findings give credence to the following words from Armar-Klemesu (2000: 113):

"Generally, the nature and success of any intervention aimed at developing urban agriculture in any city will, to a large extent, depend on the awareness and, above all, the political will of personalities holding various positions in the city administration."

IWMI must take some responsibility for the lack of awareness about UA in the city's institutions, however, political will is a completely different story and one that is far more difficult to influence. On this issue it is important to consider the lag in institutions as those people in decision-making positions may be more sympathetic to ideas and approaches to development that may be, in the current context, considered outdated. My experience of HUDA and the GHMC is that those people in more powerful positions tend to be both male and more mature meaning that they may not be as informed about - or as interested in - contemporary ideas about sustainable development. My suggestion is that such officials may have a certain attachment to ideas that were 'cutting-edge' when they were at university some years ago. This situation may help explain what appears to me to be an approach to the city's development that resembles modernisation theory (see Berthoud, 1992; and Preston, 1996). I must stress that this is purely speculative and it is just one theory that attempts to explain what I encountered and interpreted as a lack of political will regarding UA in Hyderabad.

In saying this however, it is never too late for supportive policy to be created. It has recently been reported by RUAF that the GHMC have "expressed interest” in UA in Hyderabad (RUAF, 2009c) and in Pune, India, the municipal corporation there recently passed a law and set about acquiring 1.2

\footnotetext{
${ }^{36}$ Interviews with the Chief City Planner, Purushotham Reddy, one member of the Urban Community Development Department, and a representative from the Serilingampally Municipal Office revealed that while they had heard of UA, they were not in a position to discuss its prospects as an official land use within the city.
} 
ha of land to facilitate UA in that city (see Times of India, 8/4/08). The point however, is that given my experience of Hyderabad's institutions and their officials' attitudes, I believe it remains unlikely that legislation supporting UA will in fact come about in the near future. ${ }^{37}$ In addition to my own experiences, reference to the city development plan (HUDA, 2003) will illustrate the path of development Hyderabad's city planners intend the city to take. As such, it will provide further evidence to support my assertion that it is unlikely UA will become a sight common within Hyderabad. $^{38}$

As already highlighted in Chapter five (and summarised in Table 3 below), the plan defining Hyderabad's future development sets out a reduction in the amount of land 'not built-on' within the city from the 2000 amount of 71.18 percent to a projected 43.32 percent by 2020 (HUDA, 2003: 80, 100). As a result, the ratio of people to 'land not built-on' will increase from the 2000/01 level of 4629 people per sq. $\mathrm{km}$ to a figure ranging between 14,237 and 16,589 people per sq. $\mathrm{km}$ in $2020 / 21 .^{39}$

\footnotetext{
${ }^{37}$ Again, it must be stressed that the purported 'expressions of interest' regarding GHMC's support of UA in Hyderabad is both encouraging and unexpected. I would reiterate the tentativeness of such information - both its source and the prospect of it coming to fruition - preferring instead to maintain the opinion I formed as a result of my own fieldwork. As I have stressed, the findings of the present study are based on my investigation of UA in Hyderabad in March, April and May 2008, they are, as such, tied to that context. It is simply not feasible in writing this thesis to remain up-to-date with all of the change taking place in Hyderabad and within its governing institutions. As such, the information reported on the RUAF website cannot be corroborated.

${ }^{38}$ Note that while the RUAF-CFF project in Pikine, Senegal has managed to get UA included as a land use within that city's urban zonal planning, the delay in fully integrating UA within the city's development plan and lax enforcement of regulations supporting UA has meant that despite the law changes, land on which UA is currently being practiced continues to be encroached upon by urban development. This example illustrates the slow and uncertain future UA faces in the process of gaining institutional support.

${ }^{39}$ The figure for 2020/21 varies depending on the population projections used. HUDA estimate a population of between 11.5 and 13.4 million people living in Hyderabad in 2020/21 (HUDA, 2003: 73).
} 
Table 3: Past and future land use in the HUDA jurisdiction (summarised version of the same table used in Chapter 5)

\begin{tabular}{|l|r|r|r|r|}
\hline Broad land use group & \multicolumn{2}{|l|}{$\begin{array}{l}\text { Land use in the HUDA } \\
\text { jurisdiction as at 2000* (2001 } \\
\text { Population: approx. } \\
\text { 6.1million) }\end{array}$} & \multicolumn{2}{l|}{$\begin{array}{l}\text { Proposed land use in the } \\
\text { HUDA jurisdiction for } \\
\text { 2020 (Projected 2021 } \\
\text { population 11.5 - 13.4 } \\
\text { million) }\end{array}$} \\
\cline { 2 - 6 } & Sq. km & \% of total & Sq. km & \% of total \\
\hline $\begin{array}{l}\text { Sub-totals for land } \\
\text { built-on' }\end{array}$ & 537.3 & $28.82 \%$ & 1057.1 & $56.68 \%$ \\
\hline $\begin{array}{l}\text { Sub-totals for land 'not } \\
\text { built-on' }\end{array}$ & 1327.57 & $71.18 \%$ & $\mathbf{8 0 7 . 7 7}$ & $43.32 \%$ \\
\hline Total & 1864.87 & 100 & 1864.87 & 100 \\
\hline
\end{tabular}

* This data is made up of land use information provided by NRSA satellite images for $1692.27 \mathrm{sq}$. $\mathrm{km}$ of the total (1864.87 sq. km) HUDA area (HUDA, 2003: 100). Data pertaining to the remaining 172.6 sq. km of land under the HUDA jurisdiction is based on that given by the Municipal Corporation of Hyderabad (MCH) and relates to the district of the city referred to as the MCH (HUDA, 2003: 80).

Source: HUDA (2003)

As the amount of land 'not built-on' decreases and the population increases, demand (both human and non-human) for that shrinking amount of publicly accessible open space will become acute. As just one of many potential land-uses vying for utilisation of that land, UA's chances of spreading into the city's publicly owned, open spaces is, to my mind, slim. This issue raises three points, the first of which will be addressed presently while the remaining two will be considered in the next chapter (eight). First is that the city development plan illustrates the attitude of the city's planners and the vision of the city they intend to create. Second is the tension between densification and urban sprawl and the impact this has on UA's merit and prospects in the cityscape in general. Third and finally is the notion that if UA is to be used as an officially sanctioned poverty alleviation strategy, then it must provide a considerable return so as to make it a worthwhile use of increasingly expensive, not to mention contested, publicly owned urban land. 
The planned reduction in the amount of 'open space', or, land that is 'not built-on', within Hyderabad city has come almost exclusively from the conversion of land classified as "conservation / agriculture”. While this is to be expected as the city grows, what is perhaps more concerning and indicative of the city planners' attitude to Hyderabad's development is the point that despite a projected human population of between 11.5 and 13.4 million in 2021, there is no plan to increase the amount of land designated as 'forests' and only a small increase in the city's water bodies from 4.98 percent of the city's total land-use in 2000 to 5.58 percent in 2020 (HUDA, 2003: 80, 100). This is especially concerning given that as the population grows, there will be increasing demand placed upon the city’s already scarce natural resources.

In terms of forested land, the plan not to increase the amount of land covered by trees is cause for concern given the current need for the increase globally in sequestration of carbon dioxide. Perhaps more relevant to the specific context of Hyderabad however, this situation contradicts the GHMC's project Greater Hyderabad, Greener Hyderabad (GHMC, 2008a) which highlights the local climateregulating effect of trees as a specific reason for the afforestation aspect of the project. Despite the best efforts of both the GHMC and HUDA to afforest Hyderabad (discussed in Chapter five), implementation of the city's development plan will bring with it a net decrease in the ratio of land covered by trees to that covered with roads and buildings. This has obvious consequences for the inhabitants (human and non-human) of Hyderabad. Not only will it undermine the environmental services provided by trees, but it will limit the flora and fauna living in and enjoyed by inhabitants of the region.

Such details are, I believe, representative of the city planners' attitude to development and illustrate the relative lack of attention being paid to environmentally sustainable development. As such it signals the probable further degradation of the city's natural capital with concomitant consequences for the citizen's experience of 'nature'. The central government's “Special Economic Zones (SEZ) Act, 2005” is yet more evidence of this approach to development. The Act encourages the conglomeration and conversion of vast tracts of agricultural land to sites dedicated to producing goods for export. Through a host of incentives, including tax exemptions (for more details see Department of Commerce, 2008), SEZs are being hailed by India’s Department of Commerce as facilitating:

“(a) generation of additional economic activity; 
(b) promotion of exports of goods and services;

(c) promotion of investment from domestic and foreign sources;

(d) creation of employment opportunities;

(e) development of infrastructure facilities" (Department of Commerce, 2008).

The effect this legislation is having on Hyderabad's development and its environment is considerable. The Act has been used to acquire land and draw up plans for the construction of a number of developments, the names and basic details of which follow: "Pentagon: The IT \& Commercial HUB" which is 81 ha designed to house IT organisations and Multi-National Corporations (HUDA, 2008e); “Giga City - The IT \& Knowledge Destination” which aspires to be an 809 ha "... hotbed for the IT industry, Educational Institutions etc." (HUDA, 2008f); "Elixir City - The fountain of life”, an 81 ha medical 'city' (HUDA, 2008g); "HUDA Menfer - The Beautiful City”, an 81 ha 'township' that will comprise “... villas built as per international standards and modern amenities like a clubhouse, health club, tennis courts etc." (HUDA, 2008h); and "Regal Broadway - The Hotel Corridor” 61 ha designed for: “... a cluster of hotels with international standards catering to a varied segment of audience ...” (HUDA, 2008i).

While it is not my intention to judge the changing face of Hyderabad, the above examples have been used to illustrate what I see as evidence of the city's and its citizens' desire to 'modernise', industrialise, 'technologise' and mechanise. In so doing, there appears a desire to break ties with their country's agricultural heritage. Presence of such sentiments have proved a barrier to UA in other cities of the developing world (Maxwell, 1995 and 1996; IDRC, 2006; Drakakis-Smith et al., 1995; Binns and Lynch, 1998; and Asomani-Boateng, 2002), and may explain why UA has received little attention or interest in the halls of Hyderabad's governing institutions.

\section{Summary}

This chapter has taken three lessons learned from the RUAF-CFF pilot project and applied them to the wider Hyderabad context as a means of gauging the potential future and further spread of UA throughout the city. Although as individual issues they are not necessarily insurmountable, when 
considered in their entirety they do, I believe, constitute strong reason for doubting UA's future use as a more widespread method of poverty alleviation and sustainable development within Hyderabad.

As illustrated by lessons one and two, not only is there an absence of political and/or economic crisis the like of which have been shown to catalyse UA in other cities of the developing world, but, UA is likely to exacerbate, not ameliorate, the main issue facing Hyderabad and its citizens: water scarcity. This negative relationship between UA and the city's water situation is, I believe, a factor contributing to the absence of a strong culture supporting and advocating UA in the city.

In terms of UA's poverty alleviation potential the practicalities identified in lessons one (that it is difficult to artificially create a pro-UA culture) and two (that a secure water supply is essential for UA's success) become somewhat irrelevant if, as I have illustrated in relation to lesson three, the civic authorities are not supportive of UA's practice. While the fact that the city officials are largely uninformed about UA may go some way to explaining their attitude to its practice, the city's development plan is, I believe, evidence of an approach to development that means UA will be unlikely to gain wider support within the city's governing bodies.

With these issues and experiences of UA in Hyderabad in mind, the following chapter will conclude the thesis with a more general appraisal of UA's efficacy and worth as a practice intended to alleviate the diverse forms of poverty discussed in Chapter one of this work. 


\title{
Chapter 8: Final Discussion and Conclusion
}

\author{
"Hope is an instinct only the reasoning human mind can kill" \\ Graham Greene, Power and the Glory (1940: 171)
}

To reiterate Robert Chambers' notion of development with which this thesis began, one could say that while it is inevitable and necessary that Hyderabad develop and change, the critical point is the form that this development / change takes. Although this work has arrived at a conclusion that doubts UA's future and further use as a method for shaping Hyderabad's development and alleviating the citizen's poverty, it is not to say that UA is a bad idea per se. Similarly, just because there are factors limiting UA's further spread throughout the city, it does not mean that Hyderabad itself cannot develop in other, potentially as - or more - sustainable ways as that offered by UA. As such, perhaps more than anything else, this case study has illustrated the context specificity of UA in particular and development in general. There is, as they say, no such thing as a single solution to the world's (or cities') problems.

\section{The need for a literature that is critical}

In 1998 Ellis and Sumberg opined that there was at that time a relative dearth of work critically assessing UA. Indeed, as they argued, much of the literature was tinged with a sense of advocacy as its supporters were trying to garner both financial and political support for its practice. Ten years on from their work, I believe that while there is a certain amount more willingness to critique UA, there still remains an element of promotion evident in many of the publications relating to UA. While such an approach may have altruistic motives, I would support Lynch et al. (2001) in cautioning that it has the potential to be very destructive of both the cause that intends to further the use of UA as a method of 'development' and the work of 'development' in general. As Chambers (1997: 76) has pointed out:

"Self-deception and mutual deception sustain myths ..." 
As practitioners of development therefore, we must by aware of the unintended impacts of our work. Central to this is acknowledging the limitations of the practices in which we believe. In reference to UA this means understanding that it is not a solution to all communities' problems in all settings. It is for this reason that we need a literature based on critical examination and objectivity, not advocacy.

Characterising UA in a way that it is a 'cure-all' - as advocates (myself included) have the tendency to do - obfuscates the point that it is just one of many options available for alleviating the various manifestations of urban poverty. As van Veenhuizen and Danso (2007) Binns and Lynch (1998) and Nugent (2000) have illustrated, UA is often just one of a host of strategies taken to improve families' livelihoods. As the SLA illustrates, a truly sustainable lifestyle requires a number of different 'income streams'. Fully understanding the limits of different poverty alleviation strategies and the importance context plays in these strategies' success is vital if we are to transition to an approach to development that solves our society's (and Earth's) problems in a holistic and sustainable manner.

This is quite some demand, yet one that requires a sincere effort to be humble; to acknowledge the scope and reach of the methods of development in which we believe. In short, it requires a shift from advocacy to openness; from talking to listening.

The reason for which I stress this point is that it became apparent in the process of researching and writing this thesis that there is a clear difference between the ideals implicit to the theory of UA and the reality of UA in practice. Recognising this disjuncture is central if it is to be overcome. So, while I still believe that UA has much to offer cities of the developing world, it is vitally important that in our support of the concept we are open and honest about what it cannot achieve.

Given this situation I think it is necessary to elaborate upon some of the subconscious, preconceived ideas that I took into this research and how, at this point in the work they have been, if not dispelled, then certainly challenged.

\section{UA as a poverty alleviation strategy}

As much as the aim of this thesis was to move away from the predominant, econo-centric way of thinking about and theorising poverty and development, it became obvious during fieldwork that this 
remains the principal factor guiding the governing institutions of Hyderabad. On this issue I would hasten to add two points: 1) that I do not think this situation is necessarily unique to Hyderabad; and 2) that I appreciate the economy certainly is a very important factor to be considered in making decisions about cities' development. My point, however, is that until we (and I mean this as a global 'we') come to a point of valuing/assessing the non-material costs and benefits of our actions in a way that they are more fairly - and consistently - compared with those ascribed to material (often economic) costs and benefits, practices like UA will in my view, continue to be given unrealistic, and generally poor evaluations by civic authorities.

In saying this, I do not mean to imply that governments and their officials lack the intelligence or capability to see the importance of non-material social, cultural and environmental benefits stemming from practices like UA. This is of course the very aim of 'sustainable development', an approach that is rapidly gaining interest and support throughout the world. Indeed, the use of accounting techniques like triple-bottom-line reporting which encompasses economic, ecological and social criteria is becoming more common as individuals and businesses seek to construct a more complete picture of their work and its impacts. The advent of disciplines like environmental and ecological economics (see Harris, 2006; Daly and Farley, 2006) has encouraged the creation of more holistic indicators like the Genuine Progress Indicator (GPI). Unlike the standard accounting of Gross Domestic Product (GDP), the GPI subtracts 'defensive expenditures' ${ }^{40}$ in an effort to make a more realistic appraisal of the costs borne by, and benefits accrued to, Earth and all its inhabitants by humanity's actions (Harris, 2006: 159). Similarly, the principle behind the Gross International Happiness Project which endeavours to track happiness apace more common measures like GDP and per capita income is promising for a future that necessitates holistic, sustainable development (see Gross International Happiness, 2008; and Ura, 2008).

Conceptualising development through frameworks like those detailed above and that used in this thesis represent the direction in which we can, and I believe must, continue to evolve. Similarly, I would add that the future success of UA - and other sustainable development techniques for that matter - is contingent upon the genuine, wholehearted utilisation of such approaches.

\footnotetext{
${ }^{40}$ Defensive expenditures are costs that have a net negative effect on society, for example, cleaning up pollution or solving crime (Harris, 2006: 159).
} 


\section{UA and urban design}

The dilemma for UA, however, is that although such progress is being made in terms of the way we measure, and give credence to, the non-material aspects of society and development (i.e. the areas in which UA excels), there remain institutionally-ingrained barriers to UA. Not only do misperceptions about its practice abound, such as that it is 'pre-modern', 'backward', and of 'marginal value', but, as Maxwell (1996), De Bon (2003), Midmore and Jansen (2003) and Moustier (2007) have pointed out, UA is often seen as being in direct competition with other, potentially more financially profitable uses of urban land. ${ }^{41}$ Not only does this situation act to feed, and ostensibly validate, civic authorities' aversion to UA, but, ultimately, it serves to undermine UA's opportunity for being used as a poverty alleviation strategy because such perceptions prevent the formulation of policy necessary for supporting UA’s practice.

As detailed in Chapter four, the fact that the poor generally lack secure access to land means that if UA is to be used for alleviating urban poverty, then it will either need to be decriminalised (as Ellis and Sumberg (1998) have argued), or else land will have to be specifically set aside for its practice. This issue raises a number of points. First, allowing UA's presence - be it through decriminalisation or designating land for its practice - within cities that are attempting to 'develop' seems counterintuitive for city planners that are intent on building 'modern' cities. As illustrated by the case study of Hyderabad, reinserting agriculture - a practice reminiscent of the countries' 'pre-modern' era within a city that is rapidly urbanising and modernising does not suit the city planners' (nor many of the citizens') ideal of 'progress' and 'development'.

Second, in respect of land being designated for UA's explicit practice in cities of the developing world, the following quote from Miller (2005) is, I believe, also relevant to UA:

“Expenditures on open spaces and greenways are too often viewed as a luxury, subordinated to more pressing socioeconomic concerns and typically the first items to be eliminated from municipal budgets” (Miller, 2005: 431).

\footnotetext{
${ }^{41}$ This situation implies the opportunity cost of urban land. Opportunity cost means the "...next-highest-valued alternative of that resource" (Henderson, 2008). In respect of UA this implies the value/benefit forfeited by utilising a certain piece of land for UA as opposed to the next best option for that land. As a practice that brings, relatively speaking, marginal economic benefit, UA will likely compare (in economic terms) unfavourably with other uses for that same piece of land.
} 
Finally, if we are to evaluate UA critically and comprehensively within the wider realm of sustainable development, then consideration of its merit in respect of the city planning dilemma of densification versus urban sprawl is necessary. This issue gives rise to the following questions: do we want cities that have a relative abundance of open space in which competition for that land is less fierce, thereby meaning that the urban poor have greater chance of gaining access to land on which they can practice UA? Or, do we want more compact, densely built cities in which the opportunity cost of that land may make setting it aside for the city's poor to practice UA an (economically) inefficient use of that land?

Balancing the various factors influencing sustainable urban design is not an easy task. While the desire for, say, cities designed to reduce distances citizens have to commute to work may encourage urban densification, this may come at the expense of open green space and thus the city's ability to provide environmental services like the sequestration of carbon dioxide and/or groundwater recharge. As this example illustrates, it depends on how one conceptualises urban poverty as to the conclusions one will draw: in the first example the aim of densification may be to alleviate a poverty of free time that is created by increased distances and time spent commuting in geographically dispersed cities. In the second example the aim may be to overcome environmental poverty caused by degradation of the local environment and the services it provides. Consideration of this issue also implicates the theory of the extinction of experience of nature.

\section{UA and the extinction of experience}

As argued in the first chapter, urbanisation is causing urban dwellers' increased disconnection from nature. While this work unfortunately failed to investigate more fully the capacity for UA to be used as a way of counteracting the extinction of experience, it has still given rise to a number of questions concerning this issue. For example: does UA help alleviate poverty as it is present in the spread of the extinction of experience resulting from urbanisation, or does UA create a form of 'nature' that is so controlled (and contrived) that the essence of 'nature' - its freedom from humanity's control (c.f. White, 1967) - is lost?

Indeed, it has been suggested that parks and playgrounds are inadequate at counteracting the extinction of experience of nature (Nabhan and Trimble, 1994, cited in Miller, 2005: 431). As Miller 
has pointed out in reference to the "park connector network" of Singapore, green space in urban areas does not necessarily mean an improved habitat for native species (Briffet et al., 2000 and Sodhi et al., 1999 cited in Miller, 2005: 432). The same rationale must be, I believe, applied to UA: just because UA may increase the amount of green space in cities, it does not necessarily equate to an improved urban environment.

In much the same way that one must not assume that more green space means a better urban environment, one must not link the increased presence of UA with a necessarily more ecologically literate society. In saying this however, it is important to reiterate Dunn et al.'s (2006) hypothesis mentioned in Chapter four: that given urban areas relative dearth of 'nature' it may be worthwhile encouraging city dwellers' protection of what little 'nature' exists within the city, regardless of its ecological merit. Dunn et al. (2006) propose that such an approach may help foster proenvironmental attitudes amongst the increasingly nature-starved populations of many of the world's cities. Whether UA has the potential to successfully fulfil this role remains to be seen. As detailed by this work, the environment was conspicuous in its absence in discussions with practitioners about UA's benefits and benefactors. However, in saying this, I would stress that further research is required before any conclusions can be drawn regarding UA's ability to address the extinction of experience.

\section{Conclusion}

With such conflicting issues and considerations left circling my mind I am left pondering how, and if UA will and/or should become an activity more widely practiced within cities of the developing world. As this thesis has illustrated, UA has many varied attributes and benefits to offer its practitioners. At the same time however, a multitude of contextually-specific factors were highlighted as being in need of further consideration should UA be successfully employed and utilised as a tool intended to inspire 'good change' in the developing world.

As a result, it is on this idea of 'good change' that I think the literature and UA's supporters must focus their attention. The inherently econo-centric connotations of the term 'poverty' mean that no matter how diverse a definition one uses and regardless of how holistic a framework used to apply the term, there remains an implicit focus in the concept of 'poverty' to the reduction of economic 
poorness. The point is that due to UA's relatively limited ability to alleviate economic poverty, I think that continuing to promote it as a practice for poverty alleviation - be it social, cultural, environmental or economic poverty - does more harm than good to the cause. In short, it takes away from the non-economic attributes of its practice. Framing UA as a method that inspires 'good change' may, as a result, help construct a literature that is more realistic about UA's non-material attributes, which, as this thesis has shown, centre around the enjoyment, exercise, community connectedness, education and the like gained by practitioners of UA.

Given this situation, I can now see that the underlying assumption of this work - that UA can be used to alleviate social, cultural, environmental and economic forms of poverty - was not only unrealistic, but potentially destructive of the cause of UA as a method of development. However, such an assumption is not necessarily unique to this study. It is representative of an approach very similar to that which underpins not only the RUAF-CFF pilot project, but many a development project in general: that by providing a community with all the necessary training and equipment, they will be enabled to 'develop', thereby alleviating the many and varied localised manifestations of 'poverty'. Such an approach leads to forms of development that:

"... apply blueprint approaches, which work with controllable and predictable things, to processes with uncontrollable and unpredictable people" (Chambers, 1997: 189 - 190).

Existence of such an assumption represents a certain level of reductionism which could be interpreted as evidence of an ontology of identity: a way of being that fails to fully appreciate or understand the complexity of life's interconnectivity. Realisation of this state obviously confronts the philosophical aspirations of this very work. In Chapter two I argued that the cause of our current state of poverty as it has manifested itself in the social, cultural, environmental and economic poverties detailed in Chapter one is as much ethical as it is physical. The philosophical aim of this work had been to illustrate how a shift in one's ontology - to one that is based on difference - was key to unlocking a form of 'development' that is inherently more holistic. Fully understanding the complexity of this demand has, in the process of this study, become clear. Perhaps most importantly however, it has illustrated the fact that sustainability requires a lifelong commitment. As such, it is the ultimate 'work in progress', the quest for which we must not lose hope. 


\section{References}

\section{Books and Articles}

Adams, W. M. (2009) Green Development: Environment and sustainability in a developing world: Third Edition Routledge, New York.

Agrawal, M; Singh, B; Rajput, M; Marshall, F; Bell, J.N.B. (2003) "Effect of air pollution on periurban agriculture: a case study” in Environmental Pollution 126 pp. 323 - 329.

Amarasinghe, U. A.; Shah, T.; Turral, H.; Anand, B. K. 2007. India's water future to 2025-2050: Business-as-usual scenario and deviations. International Water Management Institute Research Report 123, Colombo, Sri Lanka.

Amerasinghe, Priyanie; Devenish, Charles; and Suleman, K.B. (2008) "Rainwater Harvesting Potential for Urban Agriculture in Hyderabad” in Urban Agriculture Magazine 20 pp. 34 36.

Appiah, Kwame Anthony (2006) Cosmopolitanism: Ethics in a world of strangers W. W. Norton and Company, New York.

Armar-Klemesu, Margaret “Urban Agriculture and Food Security, Nutrition and Health” pp 99 - 117 in Bakker, N.; Dubbeling, M.; Guendel, S.; Sabel Koschella, U.; and de Zeeuw, H. (eds.) (2000) Growing Cities, Growing Food, Urban Agriculture on the Policy Agenda. DSE, Feldafing Germany

Asadi, S.S.; Vuppala, Padmaja; Reddy, M. Anji (2007) "Remote Sensing and GIS Techniques for Evaluation of Groundwater Quality in Municipal Corporation of Hyderabad (Zone-V), India” in International Journal of Environmental Research and Public Health 4(1), pp. 45 - 52.

Ashebir, Dereje; Pasquini, Margaret; and Bihon, Wubetu (2007) "Urban agriculture in Mekelle, Tijray State, Ethiopia: Principal characteristics, opportunities and constraints for further research and development” in Cities 24(3) pp. 218 - 228.

Asomani-Boateng, Raymond (2002) "Urban cultivation in Accra: an examination of the nature, practices, problems, potentials and urban planning implications” in Habitat International 26 pp. $591-607$.

Bailkey, Martin; Wilbers, Joanna; van Veenhuizen, Rene (2007) “Building communities through Urban Agriculture” in Urban Agriculture Magazine 18 pp. 1 - 6. 
Baldwin, Elaine; Longhurst, Brian; McCracken, Scott; Ogborn, Miles; and Smith, Greg (1999) Introducing Cultural Studies Prentice Hall Europe, London.

Bakker, N.; Dubbeling, M.; Guendel, S.; Sabel Koschella, U.; and de Zeeuw, H. (eds.) (2000) Growing Cities, Growing Food, Urban Agriculture on the Policy Agenda. DSE, Feldafing Germany

BBC, (5/4/2008) "Food riots turn deadly in Haiti" Available at: http://news.bbc.co.uk/2/hi/americas/7331921.stm (accessed on 9/1/09).

Bedford, Tracey and Burgess, Jacquelin "The Focus-Group Experience” in Limb, Melanie and Dwyer, Claire (eds.) (2001) Qualitative Methodologies for Geographers: Issues and Debates Arnold Publishers, London.

Berthoud, Gérald "Market” in Sachs, Wolfgang (ed.) (1992) The Development Dictionary: A Guide to Knowledge as Power Zed Books Ltd., London.

Bhatt, S. C. (Ed.) (1998) The Encyclopaedic District Gazetters of India, Volume 1 Gyan Publishing House, New Delhi.

Binns, Tony and Lynch, Kenneth (1998) "Feeding Africa's growing cities into the $21^{\text {st }}$ Century: The potential of urban agriculture” in Journal of International Development 10 pp. 777 - 793.

Briffet, C. et al. "The planning and ecology of green corridor networks in tropical urban settlements: a case study” pp. 411 - 426 in Craig, J. et al. (eds.) (2000) Nature Conservation 5: Managing the Matrix Beatty and Sons, Surrey.

Brockington, Dan and Sullivan, Sian "Qualitative Research” in Scheyvens, Regina and Storey, Donovan (2003) Development Fieldwork: A Practical Guide Sage Publications, London.

Buechler, Stephanie "A Sustainable Livelihoods Approach for Action Research on Wastewater Use in Agriculture” in Scott, C.A; Faruqui, N.I.; and Raschid-Sally, L. (eds.) (2004) Wastewater Use in Irrigated Agriculture: Confronting the Livelihood and Environmental Realities CAB International, Wallingford.

Buechler, Stephanie and Devi, Gayathri, (2003) Household Food Security and Wastewaterdependent Livelihood Activities Along the Musi River in Andhra Pradesh, India Report submitted to the World Health Organisation, Geneva, Switzerland.

Buechler, Stephanie and Devi-Mekala, Gayathri (2005) "Local Responses to Water Resource Degradation in India: Groundwater Farmer Innovations and the Reversal of Knowledge Flows” in The Journal of Environment and Development 14 pp. 410 - 438. 
Buechler, Stephanie; Devi-Mekala, Gayathri; and Keraita, Ben "Wastewater use for Urban and Periurban Agriculture” pp. 243 - 273 in van Veenhuizen, Rene (ed.) (2006) Cities Farming for the Future: Urban Agriculture for Green and Productive Cities RUAF Foundation, International Development Research Centre, International Institute of Rural Reconstruction, Philippines.

Buechler, Stephanie and Scott, Christopher (2006) "Wastewater as a Controversial, Contaminated yet Coveted Resource in South Asia” Occasional Paper for the Human Development Report, 2006 United Nations Development Programme.

Burckhardt, Jacob (1981). The Civilisation of the Italian Renaissance in Italy (Second Edition) Phaidon, Oxford.

Capra, Fritjof (1997) The Web of Life: A New Synthesis of Mind and Matter Flamingo, London.

Cencosad (1994) Urban Market Gardens in Accra Centre for Community Studies, Action and Development and the Mega Cities Project Accra, Ghana.

Centre for Economic and Social Studies (CESS) (2008) Human Development Report 2007: Andhra

Pradesh Available at: http://www.aponline.gov.in/apportal/Human-Development.html (accessed on 18/10/08).

Chambers, Robert (1997) Whose Reality counts: Putting the first last Intermediate Technology Publications, London.

Chambers, Robert (1993) Challenging the Professions: Frontiers for Rural Development Intermediate Technology Publications, Ltd., London.

Chambers, R and Conway, D (1992) Sustainable Rural Livelihoods: Practical Concepts for the $21^{\text {st }}$ Century University of Sussex, Institute for Development Studies, Brighton.

Churchill, W.S. (1948) The Gathering Storm Houghton Mifflin Company, Cambridge, Massachusetts.

Crews, T.E. and Peoples, M.B. (2004) "Legume versus fertilizer sources of nitrogen: ecological tradeoffs” in Agriculture, Ecosystems and Environment 102, pp. 279 - 297.

Crotty, Michael (1998) The Foundations of Social Research: Meaning and perspective in the research process Allen \& Unwin, St Leonards, Australia.

Daly, H.E. (1973) Towards a Steady-State Economy W.H. Freeman and Company, San Francisco.

Danso, George; Drechsel, Pay; Wiafe-Antwi, T.; and Gyiele, L. (2002) “Income of Farming Systems around Kumasi, Ghana” in Urban Agriculture Magazine 7 pp. 5 - 6. 
De Bon, Hubert "Urban Horticulture and peri-urban horticulture in Africa and Asia: characterization of the systems and issues of sustainability” in ETC-RUAF, (2003) Annotated Bibliography on Urban Agriculture Available at: www.ruaf.org/node/700 (accessed on 16/9/08).

Deccan Chronicle (31/3/08) “HMDA to replace Huda in 10 days” p. 5.

Deelstra, Tjeerd and Girardet, Herbert "Urban Agriculture and Sustainable Cities" pp. 43 - 65 in Bakker, N.; Dubbeling, M.; Guendel, S.; Sabel Koschella, U.; and de Zeeuw, H. (eds.) (2000) Growing Cities, Growing Food, Urban Agriculture on the Policy Agenda. DSE, Feldafing Germany.

de Lopez, T. T. (2001) "Stakeholder Management for Conservation Projects: A Case Study of Ream National Park, Cambodia." Environmental Management 28(1) 47 - 60.

Denzin, Norman K. and Lincoln, Yvonna S. (2000) Handbook of Qualitative Research, Second Edition Sage Publications, Inc., Thousand Oaks.

Department for International Development (DfID) (1999) Sustainable Livelihoods Guidance Sheets "Introduction: 2.1" Available at: http://www.nssd.net/references/SustLiveli/DFIDapproach.htm\#Guidance (accessed on 11/2/09).

Department for International Development (DfID) (2008) http://www.dfid.gov.uk/pubs/files/mdgfactsheets/slumdwellers-factsheet.pdf accessed on 13/10/08.

Department of Commerce (Government of India)

http://www.sezindia.nic.in/HTMLS/about.htm (accessed on 11/12/08).

de Rivero, Oswaldo (2001) The Myth of Development: The non-viable economics of the $21^{\text {st }}$ Century Zed Books Ltd., London.

Dev, S. Mahendra (2007) Inclusive Growth in Andhra Pradesh: Challenges in Agriculture, Poverty, Social Sector and Regional Disparities Working Paper Number 71 for the Centre for Economic and Social Studies, Hyderabad, India.

Diamond, Jared (2005) Collapse: How Societies Choose to Fail or Survive Penguin, London.

Dove, Lesley (2004) "Providing environmental services to the poor in Andhra Pradesh: developing strategic decision-making” in Environment and Urbanisation 16(1) pp. 95 - 106.

Drakakis-Smith, David; Bowyer-Bower, Tanya; and Tevera, Dan (1995) "Urban Poverty and Urban Agriculture: An Overview of the Linkages in Harare” in Habitat International 19(2) pp. 183 $-193$. 
Drechsel, Pay and Kunze, Dagmar (2001) Waste Composting for Urban and Peri-Urban Agriculture: Closing the Rural-Urban Nutrient Cycle in Sub-Saharan Africa CABI Publishing.

Drechsel, P.; Graefe, S.; Sonou, M; and Cofie, O.O. (2006) Informal irrigation in urban West Africa: An overview International Water Management Institute Research Report 102, Colombo, Sri Lanka.

Drechsel, P.; Keraita, B.; Amoah, P.; Abaidoo, R.C.; Raschid-Sally, L.; and Bahri, A. (2008) "Reducing health risks from wastewater use in urban and peri-urban sub-Saharan Africa: Applying the 2006 WHO guidelines” in Water Science and Technology 57(9) pp. 1461 1466.

Dunn, Robert R.; Gavin, Michael C.; Snachez, Monica C.; and Solomon, Jennifer N. (2006) “The Pigeon Paradox: Dependence of Global Conservation on Urban Nature” in Conservation Biology 20(6) pp. 1814 - 1816.

Ellis, Frank and Sumberg, James (1998) “Food Production, Urban Areas and Policy Responses” in World Development 26(2) pp. 213 - 225.

Ensink, Jeroen H.J.; van der Hoek, Wim; Matsuno, Yutaka; Munir, Safraz and Aslam, M. Rizwan (2002) “Use of Untreated Wastewater in Peri-urban Agriculture in Pakistan: Risks and Opportunities” Research Report 64 for the International Water Management Institute, Colombo, Sri Lanka.

Environmental Protection Training and Research Institute (EPTRI) (2004) State of Environment Report for Andhra Pradesh Available at: http://envis-soe.ap.nic.in/pubs.html (accessed on 9/8/08).

Escobar, Arturo (1995) Encountering Development: The Making and Unmaking of the Third World Princeton University Press, Princeton, New Jersey.

Esteva, Gustavo “Development” in Sachs, Wolfgang (ed.) (1992) The Development Dictionary: A Guide to Knowledge as Power Zed Books Ltd., London.

ETC-RUAF (2003) Annotated Bibliography on Urban Agriculture Available at: www.ruaf.org/node/700 (accessed on 16/9/08).

Evans, Alex (2008) Rising Food Prices: Drivers and Implications for Development Chatham House Briefing $\quad$ Paper Available at: http://www.chathamhouse.org.uk/files/11422_bp0408food.pdf (accessed on 9/1/09). 
Featherstone, Mike (ed.) (1991) Global Culture: Nationalism, Globalisation and Modernity Sage Publications, London.

Fleury, André (2007) “Community Supported Agriculture: French approaches” in Urban Agriculture Magazine 18 pp. 19 - 21.

Food and Agriculture Organisation (FAO) (2003) Trade Reforms and Food Security: Conceptualising the Available at: http://www.fao.org/DOCREP/005/Y4671E/y4671e06.htm (accessed on 9/1/09)

Food and Agriculture Organisation (FAO) (2002a) “Urban Food Security” Available at: http://www.fao.org/ag/magazine/0206sp2.htm (accessed on 9/1/09).

Food and Agriculture Organisation (FAO) (2002b) FAOSTAT Available at: www.apps.fao.org (accessed on 7/11/08).

Food and Agriculture Organisation (FAO) (1998) “Feeding the cities" excerpt from The State of Food and Agriculture: Food into Cities Collection DT/40-99E Rome: FAO.

Freie, John F. (1998) Counterfeit Community: The exploitation of our longings for connectedness Rowman \& Littlefield Publishers, Inc., Lanham, Maryland.

Gardner, G. (1997) Recycling organic waste: From urban pollutant to farm resource Worldwatch Paper No. 135, Worldwatch Institute, Washington DC.

Greene, Graham (1940) Power and the Glory Heinemann, London.

Greenpeace International (2005) Trading away our last ancient forests: The threats to forests from trade liberalization under the WTO. Report. Greenpeace International. Available at: http://www.greenpeace.org/international/press/reports?page=6\&related\%5fitem\%5fid=89363 (accessed on 26/1/09).

Gregory, P.J.; Ingram, J.S.I.; Andersson, R.; Betts, R.A.; Brovkin, V.; Chase, T.N.; Grace, P.R.; Gray, A.J.; Hamilton, N.; Hardy, T.B.; Howden, S.M.; Jenkins, A.; Meybeck, M.; Olsson, M.; Ortiz-Monasterio, I.; Palm, C.A.; Payn, T.W.; Rummukainen, M.; Schulze, R.E.; Thiem, M.; Valentin, C.; and Wilkinson, M.S. (2002) "Environmental consequences of alternative practices for intensifying crop production.” In Agriculture, Ecosystems and Environment 88, pp. $279-290$.

Gross International Happiness Available (2008) at:

http://www.grossinternationalhappiness.org/index.html (accessed on 18/12/08).

Halsey, Mark (2006) Deleuze and Environmental Damage: Violence of the Text Ashgate Publishing Company, Aldershot, Hampshire. 
Hamilton, Clive and Denniss, Richard (2005) Affluenza: When too much is never enough Allen \& Unwin, Crows Nest, NSW.

Hamilton, Clive (2003) Growth Fetish Allen \& Unwin, Crows Nest, NSW.

Hawken, P. (1993) The Ecology of Commerce HarperCollins.

Heinberg, Richard (2006) "Fifty million farmers" Address to the Twenty-Sixth Annual E. F. Schumacher Lectures, Stockbridge, Massachusetts.

Henderson, David R. (2008) “Opportunity Cost” in The Concise Encyclopedia of Economics Available at: http://www.econlib.org/library/Enc/OpportunityCost.html (accessed on 9/2/09).

Hilgers, K.R.; Haynes, C.; and Olson, J. (2008) “Assessing a garden-based curriculum for elementary youth in Iowa: Parental perceptions of change” in Horttechnology 18(1) pp. 18 23.

Hipwell, William (2007) “The Industria Hypothesis” in Peace Review: A Journal of Social Justice 19 pp. $305-313$.

Hipwell, William (2004) “A Deleuzian critique of resource-use management politics in Industria” in The Canadian Geographer 48(3) pp. 356 - 377.

Howorth, C.; Convery, I.; and O’Keefe, P. (2001) “Gardening to reduce hazard: Urban agriculture in Tanzania” in Land Degradation Development 12 pp. 285 - 291.

Hubbard, Michael and Onumah, Gideon (2001) “Improving urban food supply and distribution in developing countries: the role of city authorities” in Habitat International 25 pp. 431 - 446.

Indian Meteorological Department (2008a)

http://www.imd.ernet.in/section/climate/newdelhiweb.htm (accessed on 9/8/08).

Indian Meteorological Department (2008b) (http://www.imd.gov.in/section/climate/monsoononset.htm (accessed on 13/12/08).

Intergovernmental Panel on Climate Change (IPCC) (2007) Climate Change 2007: Synthesis Report Available at: http://www.ipcc.ch/pdf/assessment-report/ar4/syr/ar4_syr.pdf (accessed on 6/1/09).

International Development Research Centre (IDRC) (2006) "Shaping Livable Cities: stories of progress from around the world” Available at: http://www.idrc.ca/uploads/userS/11502208271CRA_WUF_ENG_FINAL.pdf (accessed on 11/10/07).

International Water Management Institute (IWMI) (2007a) Potentials for Urban and Peri-urban Agriculture in Serilingampally Circle, Hyderabad: "Creating a food and nutritionally secure 
future" A concept document presented to a multi-stakeholder forum, December 2007. IWMI c/o ICRISAT, Patancheru, Hyderabad.

International Water Management Institute (IWMI) (2007b) “Towards a food and nutritionally secure future: Establishment of kitchen gardens and school garden 'bright spots' in Serilingampally" Available at: http://www.ruaf.org/files/Serilingampally\%20Pilot\%20Project\%20Final.pdf (accessed on 4/11/08).

International Water Management Institute (IWMI) (No Date a) Revealing the face of water scarcity Available at: http://www.iwmi.cgiar.org/About_IWMI/Strategic_Documents/Annual_Reports/1998/WSac arcity.pdf (accessed on 26/1/09).

International Water Management Institute (IWMI) (No Date b) Urban and Peri-Urban Agriculture (UPA) in Hyderabad IWMI South Asia Regional Office, c/o ICRISAT, Patancheru, Hyderabad, India.

Ivanic, Maros and Martin, Will (2008) Implications of Higher Global Food Prices for Poverty in Low-Income Countries Policy Research Working Paper 4594 for the World Bank.

Jarosz, Lucy (2008) "The city in the country: Growing alternative food networks in Metropolitan areas” in Journal of Rural Studies 24 pp. 231 - 244.

Kahn, P.H. Jr. (2002) “Children's affiliations with nature: structure, development, and the problem of environmental generational amnesia” in Kahn, P.H., Jr and Kellert, S.R., (eds.) Children and Nature: Psychological, Sociocultural and Evolutionary Investigations MIT Press, Cambridge, USA pp. 93 - 116.

Kahn, P.H., Jr. and Friedman, B. (1995) "Environmental views and values of children in an innercity black community” in Child Dev. 66 pp. $1403-1417$.

Kapoor, Ilan (2004) "Hyper-self-reflexive development? Spivak on representing the Third World 'Other'” Third World Quarterly 25(4) pp. 627-647.

Khai, Nguyen Manh; Ha, Pham Quang; and Öborn, Ingrid (2007) "Nutrient flows in small-scale peri-urban vegetable farming systems in Southeast Asia-A case study of Hanoi” in Agriculture, Ecosystems and Environment 122 pp. 192 - 202.

Klein, Naomi (2000) No Logo Flamingo, London.

Kuchelmeister, Guido "Urban Forestry” in ETC-RUAF (2003) Annotated Bibliography on Urban Agriculture Available at: www.ruaf.org/node/700 (accessed on 16/9/08). 
Lado, Cleophas (1990) "Informal urban agriculture in Nairobi, Kenya" in Urban Land Policy July pp. $257-266$.

Limb, Melanie and Dwyer, Claire (eds.) (2001) Qualitative Methodologies for Geographers: Issues and Debates Arnold Publishers, London.

Losada, H.; Bennet, R.; Soriano, R.; Vieyra, J.; and Cortés, J. (2000) "Urban Agriculture in Mexico City: Functions Provided by the Use of Space for Dairy Based Activities” in Cities 17(6) pp. $419-431$.

Lovelock, James (2006) The revenge of Gaia: Why the Earth is fighting back-and how we can still save humanity Allen Lane, London.

Luck-Baker, Andrew (24/7/08) Farming in the City: Hyderabad Second programme for the BBC's "One Planet" documentary series. Podcast available at: http://blogspodsandfeedsforrbp.wordpress.com/2008/08/03/farming-in-the-city-2/ (accessed on $8 / 10 / 08)$.

Lynch, Kenneth (1995) "Sustainability and Urban Food Supply in Africa" in Sustainable Development 3 pp. $79-88$.

Lynch, K; Binns, T; and Olofin, C. (2001) "Urban agriculture under threat: The Land Security Question in Kano, Nigeria” in Cities 18(3) pp. 159 - 171.

Madaleno, Isabel (2000) “Urban Agriculture in Belém, Brazil” in Cities 17(1) pp. 73 - 77.

Martine, George; McGranahan, Gordon; Montgomery, Mark; and Fernández-Castilla, Rogelio (2008) The New Global Frontier: Urbanisation, Poverty and Environment in the $21^{\text {st }}$ Century Earthscan, London.

Maxwell, Daniel; Levin, Carol; and Csete, Joanne (1998) "Does urban agriculture help prevent malnutrition? Evidence from Kampala” in Food Policy 23(5) pp. 411 - 424.

Maxwell, Daniel (1996) "Highest and best use? Access to urban land for semi-subsistence food production” in Land Use Policy 13(3) pp. 181 - 195.

Maxwell, Daniel (1995) "Alternative Food Security Strategy: A Household Analysis of Urban Agriculture in Kampala” in World Development 23(10) pp. 1669 - 1681.

Maxwell, Joseph A. (2005) Qualitative Research Design: An Interactive Approach Sage Publications, London.

Menzies, Malcolm (1997) "What is Futures Thinking?" Available at: http://www.futurestrust.org.nz/content/view/27/41/ (accessed on 27/1/09). 
Midmore, D.J. and Jansen, H.G.P. (2003) “Supplying vegetables to Asian cities: is there a case for peri-urban production?” in Food Policy 23 pp. 13 - 27.

Millennium Ecosystem Assessment (MEA) (2005a) Living Beyond Our Means: Natural Assets and Human Well-Being Available at: http://www.millenniumassessment.org/documents/document.429.aspx.pdf $\quad$ (accessed on 9/1/09).

Millennium Ecosystem Assessment (MEA) (2005b) Ecosystems and Human Well-Being: Current State and Trends, Volume 1. Island Press, Washington. Available at: http://www.millenniumassessment.org/en/Condition.aspx (accessed on 9/1/09).

Miller, James R. (2005) “Biodiversity conservation and the extinction of experience” in TRENDS in Ecology and Evolution 20(8) pp. 430 - 434.

Mitchell, Bruce (1997) Resource and Environmental Management Longman, UK.

Mkwambisi, David; Fraser, Evan; and Dougill, Andrew (2007) Urban agriculture and poverty reduction: Evaluating how food production in cities contributes to livelihood entitlements in Malawi Sustainability Research Institute, School of Earth and Environment, The University of Leeds, UK.

Mohammad, Robina “'Insiders' and/or 'outsiders': positionality, theory and praxis” in Limb, Melanie and Dwyer, Claire (eds.) (2001) Qualitative Methodologies for Geographers: Issues and Debates Arnold Publishers, London.

Molden, David (ed.) (2007) Water for Food, Water for Life: A comprehensive assessment of water management in agriculture Earthscan, London.

Mougeot, J. A. Luc “Urban Agriculture: Definition, Presence, Potentials and Risks” in Bakker, N.; Dubbeling, M.; Guendel, S.; Sabel Koschella, U.; and de Zeeuw, H. (eds.) (2000) Growing Cities, Growing Food, Urban Agriculture on the Policy Agenda. DSE, Feldafing Germany

Moustier, Paule (ed.) (2007) Final Summary Report of SUSPER (Sustainable Development of PeriUrban Agriculture in South-East Asia) Hanoi.

Mubvami, Takawira and Manyati, Milika (2007) "HIV/Aids, Urban Agriculture and Community Mobilisation: cases from Zimbabwe” in Urban Agriculture Magazine 20 pp. 7 - 9.

Mutengu, Sherman; Hoko, Zvikomborero; Makoni, Fungai S. (2007) “An assessment of the public health hazard potential of wastewater reuse for crop production. A case of Bulawayo city, Zimbabwe” in Physics and Chemistry of the Earth 32 pp. 1195 - 1203.

Nabhan, G.P. and Trimble, S. (1994) The Geography of Childhood Beacon Press. 
Nugent, Rachel “The impact of urban agriculture on the household and local economies” pp. 67 - 97 in Bakker, N.; Dubbeling, M.; Guendel, S.; Sabel Koschella, U.; and de Zeeuw, H. (eds.) (2000) Growing Cities, Growing Food, Urban Agriculture on the Policy Agenda. DSE, Feldafing Germany.

Nurse, Keith (2006) “Culture as the Fourth Pillar of Sustainable Development” Prepared for the Commonwealth Secretariat, London. Available at: http://www.fao.org/sard/common/ecg/2700/en/Cultureas4thPillarSD.pdf $\quad$ (accessed on 8/1/09).

Oxford English Dictionary Available at: http://www.oxfordreference.com.helicon.vuw.ac.nz/views/GLOBAL.html?authstatuscode=2 $\underline{02}$ (accessed on 12/2/09).

Plumwood, Val (2002) Environmental Culture: The ecological crisis of reason Routledge, New York.

Preston, P. W. (1996) Development Theory: An Introduction Blackwell Publishers, Oxford.

Price, F. (2007). "Seedbeds in schools." New Zealand Listener 209(3503) Available at: http://www.listener.co.nz/issue/3503/columnists/9125/seedbeds_in_schools.html (accessed on $13 / 2 / 09)$.

Pyle, Robert M. (2003) “Nature Matrix: reconnecting people and nature” in Oryx 37(2) pp. 206 214.

Pyle, R.M. (2002) “Eden in a vacant lot: kids and species in the neighbourhood of life” in Kahn, P.H., Jr and Kellert, S.R., (eds.) Children and Nature: Psychological, Sociocultural and Evolutionary Investigations MIT Press, Cambridge, USA.

Pyle, R.M. (1978) “The extinction of experience” in Horticulture 56 pp. 64 - 67.

Ramachandraiah, C and Prasad, Sheela (2004) Impact of Urban Growth on Water Bodies: The Case of Hyderabad Working Paper Number 60 for Centre for Economic and Social Studies, Hyderabad, India.

Rao, Venkateswara and Rao, Srinivasa (1998) Influence of Urbanisation over the nearby Catchments of the City - A Case Study of Hyderabad, India JNT University, Hyderabad.

Raschid-Sally, Liqa; Carr, Richard; and Buechler, Stephanie (2005) "Managing wastewater agriculture to improve livelihoods and environmental quality in poor countries” in Irrigation and Drainage 54 S11-S22. 
Remenyi, Joe (2000) "Poverty Reduction and Urban Renewal Through Urban Agriculture and Microfinance: A Case Study of Dhaka, Bangladesh” From the DevNet Conference 2000 Available at: www.devnet.org.nz/conf/proceedings.html (accessed on 7/10/08).

Rose, Deborah (2005) “An Indigenous Philosophical Ecology: Situating the Human” in The Australian Journal of Anthropology 16(3), 294 - 305.

Rossi, Vanessa (October 2008) Synchronised Dive into Recession: Focus on Damage Limitation Briefing Paper for International Economics Programme, Chatham House, London. Available at: http://www.chathamhouse.org.uk/files/12340_bp1008recession.pdf (accessed on 6/1/09).

RUAF (2008a) "Hyderabad (India)” www.ruaf.org/node/507 (accessed on 13/7/08).

RUAF (2008b) “Cities Farming for the Future (CFF)" http://www.ruaf.org/node/448 (accessed on 4/11/08).

RUAF (2009a) "Pikine (Dakar - Senegal)” http://www.ruaf.org/node/500 (accessed on 16/2/09).

RUAF (2009b) “Chengdu” http://www.ruaf.org/index.php?q=node/1134 (accessed on 16/2/09).

RUAF (2009c) "Hyderabad" http://www.ruaf.org/index.php?q=node/507 (accessed on 16/2/09).

Ruet, Joël; Gambiez, Marie and Lacour, Emilie (2007) "Private appropriation of resource: Impact of peri-urban farmers selling water to Chennai Metropolitan Water Board” Cities 24(2) pp. 110 $-121$.

Rutkowski, Thomas; Raschid-Sally, Liqa; Buechler, Stephanie (2007) "Wastewater irrigation in the developing world-Two case studies from the Kathmandu Valley in Nepal” in Agricultural Water Management 88 pp. 83 - 91.

Said, Edward (1978) Orientalism Routledge \& Kegan Paul, London.

Sanchez-Rodriguez, Roberto "Urban Sustainability and Global Environmental Change: Reflections for and Urban Agenda” pp. 149 - 164 in Martine, George; McGranahan, Gordon; Montgomery, Mark; and Fernández-Castilla, Rogelio (2008) The New Global Frontier: Urbanisation, Poverty and Environment in the $21^{\text {st }}$ Century Earthscan, London

Scheyvens, Regina and Storey, Donovan (2003) Development Fieldwork: A Practical Guide Sage Publications, London.

Scott, C.A; Faruqui, N.I.; and Raschid-Sally, L. (eds.) (2004) Wastewater Use in Irrigated Agriculture: Confronting the Livelihood and Environmental Realities CAB International, Wallingford.

Sen, Amartya (1999) Development as Freedom Oxford University Press, Oxford 
Sen, Amartya (1981) Poverty and Famines: An essay on entitlement and deprivation Clarendon Press, Oxford

Smit, Jac and Bailkey, Martin “Urban Agriculture and the Building of Communities” pp. 145 - 171 in van Veenhuizen, Rene (ed.) (2006) Cities Farming for the Future: Urban Agriculture for Green and Productive Cities RUAF Foundation, International Development Research Centre, International Institute of Rural Reconstruction, Philippines.

Sodhi, N.S. et al. (1999) "Bird use of linear areas of a tropical city: implications for park connector design and management” in Land, Urb. Plan 45 pp. 123 - 130.

Statistics New Zealand (2006) Fertiliser use and the Environment Statistics New Zealand, Wellington.

Statistics New Zealand (2002) “The Framework for Sustainable Development Indicators” Appendix in Monitoring Progress Towards a Sustainable New Zealand Wellington. Available at: http://www.stats.govt.nz/analytical-reports/monitoring-progress/default.htm (accessed on 6/1/09).

Sumberg, James (1997) "Policy, milk and the Dar es Salaam peri-urban zone: a new future for an old development them?” in Land Use Policy 14(4) pp. 277 - 293.

The Hindu (11/8/2007) "Peddacheruvu gets a new look" Available at: http://www.hindu.com/2007/08/11/stories/2007081160540400.htm (accessed on 3/2/09).

The Hindu (20/2/2007) “Average annual income of citizen goes up in State” Available at: http://www.hindu.com/2007/02/20/stories/2007022011440400.htm (accessed on 3/2/09).

The Hindu (4/3/2003) “HMWSSB chief sees grave threat to reservoirs” Hyderabad Edition.

The World Conservation Union (IUCN) (2004) The Status of Globally Threatened Species Executive Summary Available at: http://www.iucn.org/themes/ssc/red_list_2004/GSA_book/Red_List_2004_exec_summary.pd $\underline{\mathrm{f}}$ (accessed on 11/2/08).

Thornton, Alec (In press 2008) "Pastures of plenty? Land rights and community-based agriculture in Peddie, a former homeland town in South Africa” in Applied Geography

Times of India (27/5/08) “Come, Join Green-Abad” Page 3.

Times of India (17/5/08) “Out-skirting the issue” Page 2.

Times of India (17/5/08) “Still going hack, hack” Page 2. 
Times of India (8/4/08) "Soon, city farming project in Pune" Available at: http://timesofindia.indiatimes.com/Soon_city_farming_project_in_Pune/rssarticleshow/2934 012.cms (accessed on 13/12/08).

Transparency International (TI) (2008) Corruption Perception Index 2008 Available at: http://www.transparencyindia.org/pdf/CPI_2008_table.pdf (accessed on 9/12/08).

Transparency International (TI) (2005) India Corruption Study 2005 Transparency International India, New Delhi. Available at: http://www.transparencyindia.org/publication/India\%20Corruption\%20Study\%202005\%20in \%20PDF.pdf (accessed on 9/12/08).

Turner, R. K. "Sustainability Principles and Practices" in Owen, Lewis and Unwin, Tim (eds.) (1997) Environmental Management - Readings \& Case Studies Blackwell, UK.

United Nations (UN) (2008a) “Millennium Development Goals" Available at: http://www.un.org/millenniumgoals/ (accessed on 4/11/08).

United Nations (UN) (2008b) Indicators of Sustainable Development: Guidelines and Methodologies - $\quad$ Third Edition Available at: http://www.un.org/esa/sustdev/natlinfo/indicators/methodology_sheets.pdf $\quad$ (accessed on 18/12/08).

United Nations (UN) (2005) "World Urbanisation Prospects: the 2005 Revision" Available at: http://www.un.org/esa/population/publications/WUP2005/2005wup.htm (accessed on 26/1/09).

United Nations Conference on Environment and Development (UNCED) (1992) Agenda 21 United Nations Conference on Environment and Development.

United Nations Development Programme (UNDP) (2007) Human Development Report 2007 / 2008 : Fighting climate change: Human solidarity in a divided world Palgrave Macmillan, New York.

United Nations Development Programme (UNDP) (1996) Urban Agriculture: Food, Jobs and Sustainable Cities UNDP, New York.

Ura, Karma (2008) GNH Index Available at: http://www.bhutanstudies.org.bt/admin/pubFiles/12.GNH4.pdf (accessed on 8/2/09).

Vagneron, Isabelle (2007) "Economic appraisal of profitability and sustainability of peri-urban agriculture in Bangkok” in Ecological Economics 61 pp. 516 - 529. 
van Veenhuizen, Rene (ed.) (2006) Cities Farming for the Future: Urban Agriculture for Green and Productive Cities RUAF Foundation, International Development Research Centre, International Institute of Rural Reconstruction, Philippines.

van Veenhuizen, Rene and Danso, George (2007) Profitability and sustainability of urban and periurban agriculture Agriculture Management, Marketing and Finance Occasional Paper 19 for the Food and Agriculture Organisation (FAO), Rome.

von Braun, Joachim (2007) The World Food Situation: New Driving Forces and Required Actions Report for the International Food Policy Research Institute, Washington, D.C.

von Braun, Joachim; McComb, John; Fred-Mensah, Ben; and Panya-Lorch, Rajul (1993) Urban food insecurity and malnutrition in developing countries: Trends, policies and research implications International Food Policy Research Institute, Washington DC.

White, Lynn Jr (1967) “The Historical Roots of Our Ecological Crisis” Science 155 pp. 1203 - 07.

Wikipedia (2008) http://en.wikipedia.org/wiki/Image:India_Andhra_Pradesh_locator_map.svg

(accessed on 7/9/08).

Wilson, E.O. (1984) Biophilia: The Human Bond with Other Species Harvard University Press, Cambridge, USA.

World Bank (2009) "Poverty" Website:

http://web.worldbank.org/WBSITE/EXTERNAL/TOPICS/EXTPOVERTY/EXTPA/0,,conte ntMDK:20153855 menuPK:435040 pagePK:148956 piPK:216618 theSitePK:430367,00.h $\underline{\text { tml }}$ (accessed on 26/1/09).

World Bank (2008) http://devdata.worldbank.org/wdi2005/Table2_5.htm (accessed on 13/10/08).

World Commission on Environment and Development (WCED) (1987) Our Common Future: Report of the World Commission on Environment and Development Available at: http://www.un-documents.net/wced-ocf.htm (accessed on 6/1/09).

Wright, Ronald (2004) A short history of progress Text Publishing, Melbourne.

WWF (2008) Living Planet Report 2008 Available at: http://assets.wwf.org.uk/downloads/lpr_2008.pdf (accessed on 6/1/08).

X-rates.com (9/2/09) Available at: http://www.X-rates.com/d/USD/table.html (accessed on 9/2/09).

Yasmeen, Gisèle (2001) Urban Agriculture in India: A Survey of Expertise, Capacities and Recent Experience CFP Report 32 for the International Development Research Centre. Available at: http://www.doccentre.net/Besharp/resources-expertise/Urban_Agriculture_In_India.pdf (accessed on 11/12/08). 
Zurbrügg, Christian; Drescher, Silke; Rytz, Isabelle; Maqsood Sinha, A. H. Md.; Enayetullah, Iftekhar (2005) "Decentralised composting in Bangladesh, a win-win situation for all stakeholders” in Resources, Conservation and Recycling 43 pp. 281 - 292. 


\section{Local Government Documents}

Andhra Pradesh Mission for Elimination Poverty in Municipal Areas (APMEPMA) (2008) “Mission for Elimination of Poverty in Municipal Areas: Report 23/6/08” Available at: http://www.apmepma.gov.in/downloads/TPO/Lr.Slums-Notification\%20.doc (accessed on 13/10/08).

Andhra Pradesh Tourism Development Corporation (APTDC) (No Date) Guide to Golconda Fort and Qutub Shahi Tombs

Government of Andhra Pradesh (3 April 2008a) Government Order 288 Available at: http://www.hudahyd.org/inside/G.O.288.doc (accessed on 9/8/08).

Government of Andhra Pradesh

http://www.aponline.gov.in/apportal/HomePageLinks/Schemes.htm (accessed on 6/8/08).

Government of Andhra Pradesh

(2007)

http:/www.aponline.gov.in/Quick\%20Links/Departments/Municipal\%20Administration\%20 and\%20Urban\%20Development/Govt-Gos-Acts/2007/GO.Ms.261.2007.pdf （accessed on 6/8/08).

Government of Andhra Pradesh (2002) Andhra Pradesh Water Land and Trees Act, 2002 Available at: www.ielrc.org/content/e0202.pdf (accessed on 26/1/09).

Greater Hyderabad Municipal Corporation (GHMC) (2008a) Greater Hyderabad, Greener Hyderabad GHMC, Hyderabad.

Greater Hyderabad Municipal Corporation (GHMC) (2008b) Indira Kranthi Patham - Urban: IKP(U) GHMC, Hyderabad.

Greater Hyderabad Municipal Corporation (GHMC) (2008c) http://www.ghmc.gov.in/hyd/hydhistory.asp (accessed on 15/9/08).

Greater Hyderabad Municipal Corporation (GHMC)

http://www.ghmc.gov.in/greaterhyd.asp (accessed on 6/8/08).

Greater Hyderabad Municipal Corporation (GHMC) (2008e) http://www.ghmc.gov.in/mch/orgl.asp (accessed on 5/8/08).

Greater Hyderabad Municipal Corporation (GHMC) (2008f) http://www.ghmc.gov.in/budget200809.ppt (accessed on 6/8/08). 
Greater Hyderabad Municipal Corporation (GHMC) (2008g) “Fund your Parks” Available at: http://ghmc.gov.in/fundyourparks/index.asp (accessed on 3/2/09)

Greater Hyderabad Municipal Corporation (GHMC) (2008h) “Tree Plantation” Available at: http://ghmc.gov.in/treeplantation/index.asp (accessed on 3/2/09).

Hyderabad Metropolitan Water Supply \& Sewerage Board (HMWS\&SB)

(2008) http://www.hyderabadwater.gov.in/rwhu.htm (accessed on 5/5/08).

Hyderabad Urban Development Authority (HUDA)

(2008a)

http://hmdahyd.org/inside/hudaplans.asp (accessed on 6/8/08).

Hyderabad Urban Development Authority (HUDA)

(2008b)

http://www.hudahyd.org/inside/hudaprofile.asp (accessed on 5/8/08).

Hyderabad Urban Development Authority (HUDA) (2008c) http://hmdahyd.org/inside/bppa01.asp (accessed on 13/10/08).

Hyderabad Urban Development Authority (HUDA)

(2008d)

http://hmdahyd.org/inside/document/ghep.doc (accessed on 11/10/08).

Hyderabad Urban Development Authority (HUDA)

(2008e)

http://www.hmdahyd.org/inside/pdfs/pentagon.pdf (accessed on 11/12/08).

Hyderabad Urban Development Authority (HUDA)

http://www.hmdahyd.org/inside/pdfs/giga.pdf accessed (on 11/12/08 (accessed on 11/12/08).

Hyderabad Urban Development Authority (HUDA) (2008g)

http://www.hmdahyd.org/inside/pdfs/elixir.pdf (accessed on 11/12/08).

Hyderabad Urban Development Authority (HUDA)

(2008h)

http://www.hmdahyd.org/inside/pdfs/menefer.pdf (accessed on 11/12/08).

Hyderabad Urban Development Authority (HUDA)

(2008i)

http://www.hmdahyd.org/inside/pdfs/regalbroadway.pdf (accessed on 11/12/08).

Hyderabad Urban Development Authority (HUDA) (2007) "Expression of Interest for preparation of Master Plan for the expanded jurisdiction of HUDA” Available at: http://hmdahyd.org/ (accessed on 3/2/09).

Hyderabad Urban Development Authority (HUDA) (26/4/2007) Public Notice: Expansion of the jurisdiction of Hyderabad Urban Development Authority Available at: http://www.hudahyd.org/inside/pn_ejhuda.doc (accessed on 30/7/08).

Hyderabad Urban Development Authority (HUDA) (2006) HUDA: Architects of Modern Hyderabad Srinivasa Litho, Hyderabad. 
Hyderabad Urban Development Authority (HUDA) (2003) A Plan for Sustainable Development: Hyderabad 2020 - Draft Master Plan for Hyderabad Metropolitan Area Manager (Public Relations), Hyderabad.

Municipal Corporation of Hyderabad (MCH) (2004) Parks: Reviving Nature's Bounty MCH, Hyderabad.

Municipal Corporation of Hyderabad (MCH) (2003) "City Development Plan” Available at: http://www.ghmc.gov.in/cdp/default.asp (accessed on 9/8/08). 


\section{Appendices}

\section{Appendix I: Daly's Triangle}

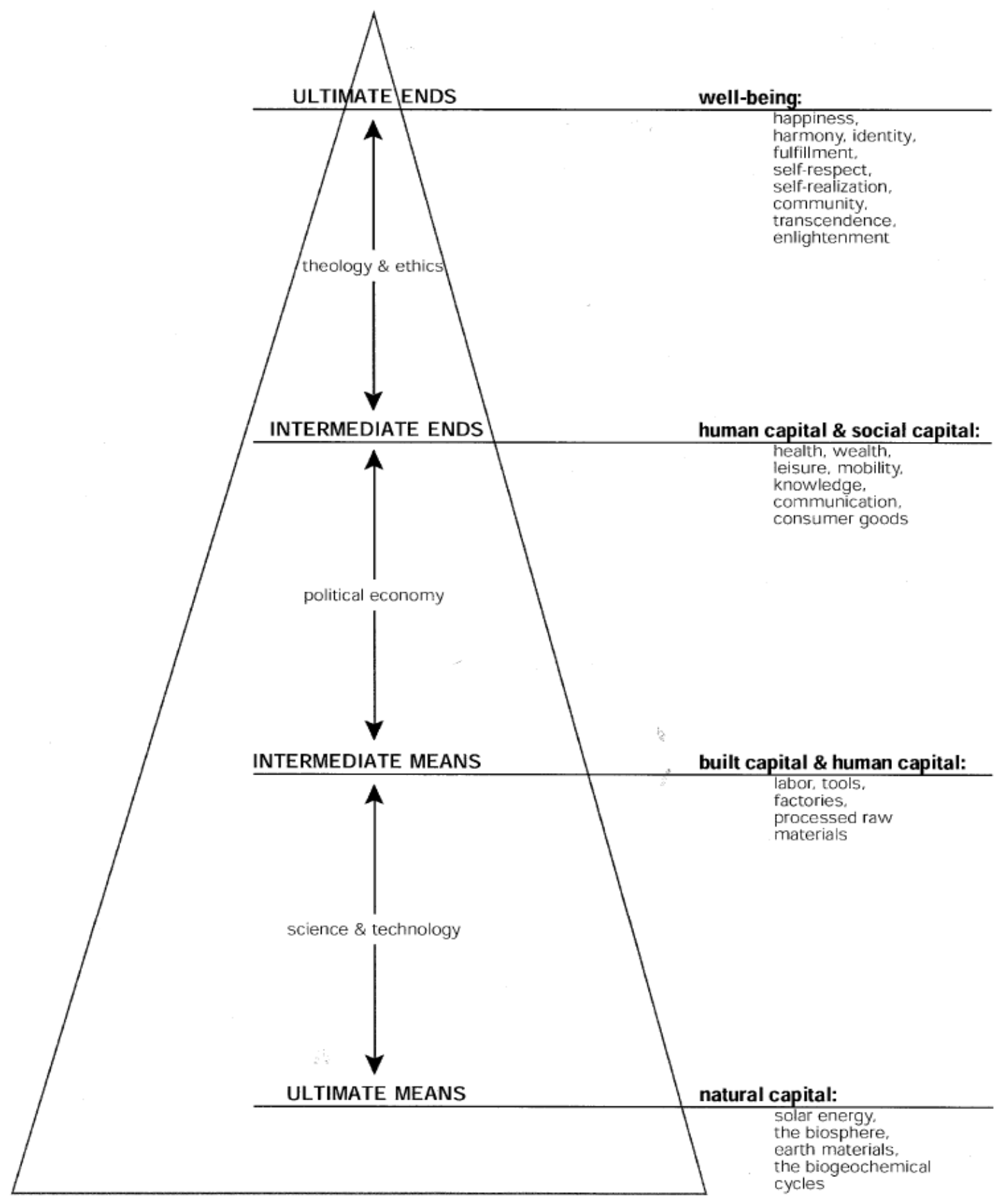

Source: Meadows (1998: 42). 


\section{Appendix II: Sustainable Livelihood's Framework}

This diagram depicts the Sustainable Livelihoods Framework as it is conceptualised by the UK's Department for International Development (1999).

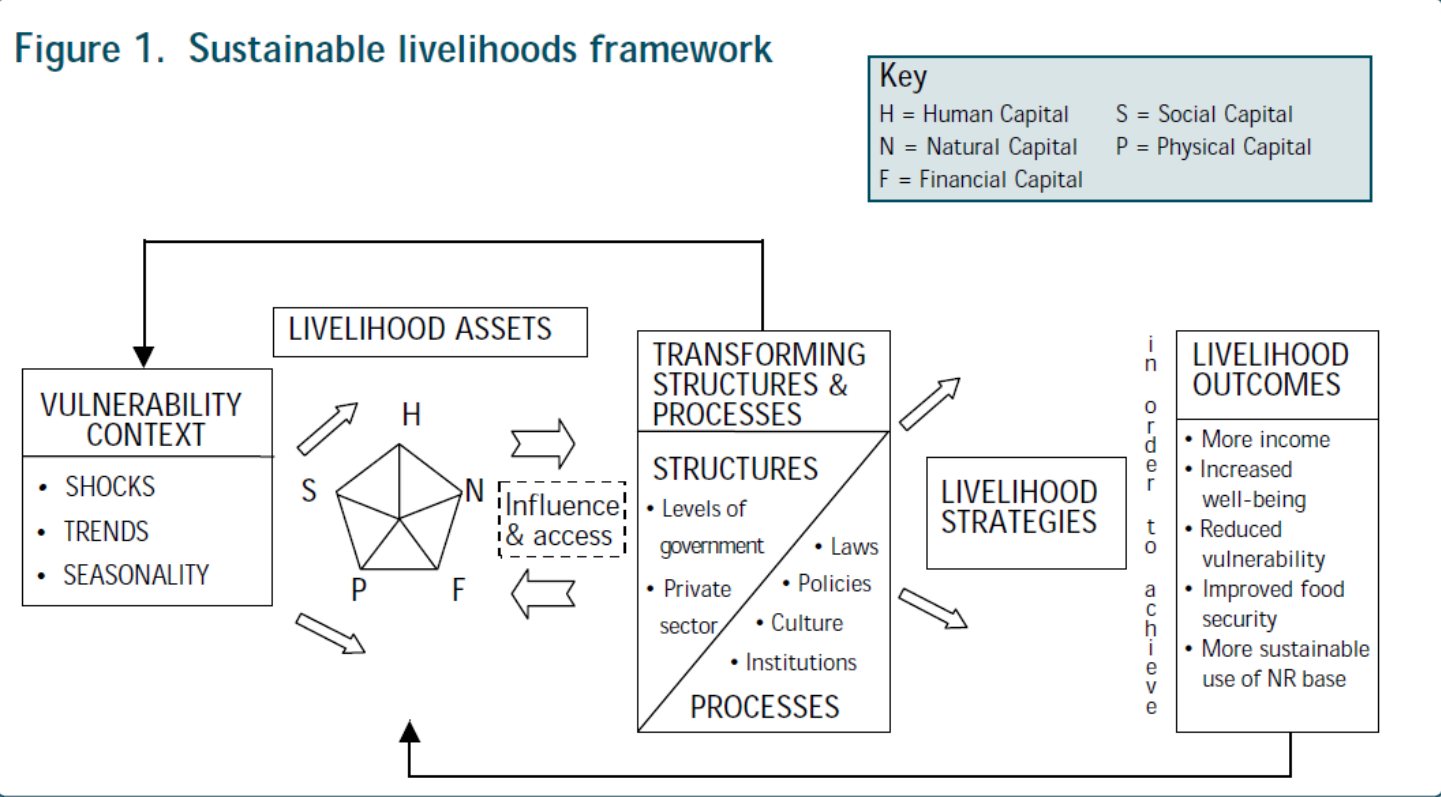




\title{
Appendix III: Participant Information Sheet
}

\author{
Master's Thesis Research Project: \\ "The efficacy of urban agriculture as a means of poverty alleviation in Hyderabad, India"
}

March, 2008

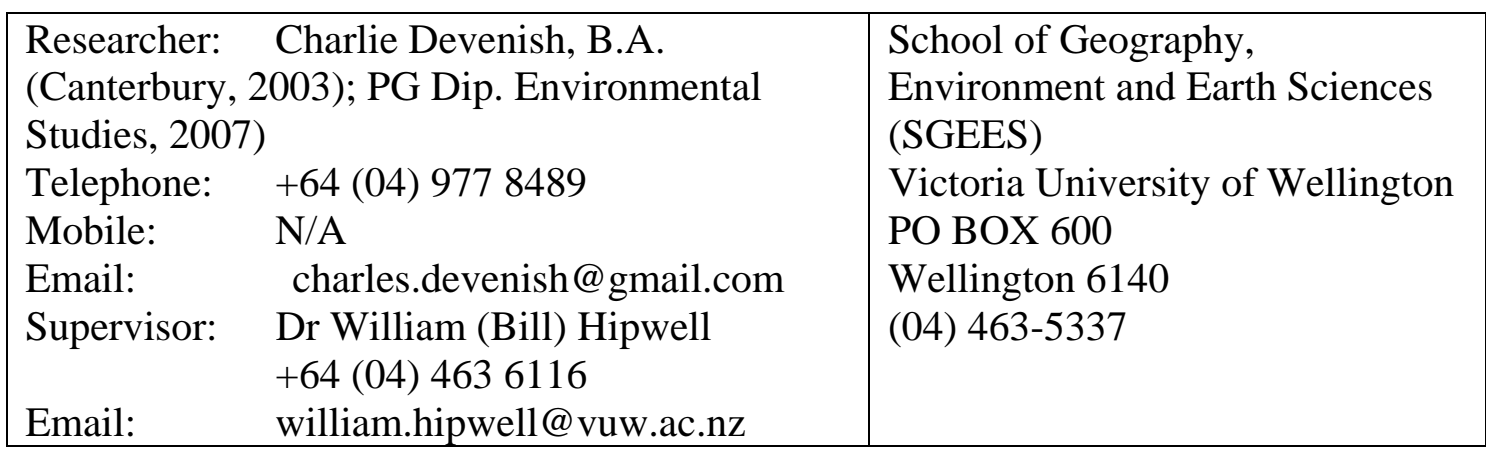

Dear Project Participant,

You are being asked to take part in an interview and/or a focus group for my master's thesis at Victoria University of Wellington. The project will investigate how effective urban agriculture is at alleviating social, cultural, economic and environmental poverty in Hyderabad, India. The key words for this research include: urban agriculture, poverty, development and environmental sustainability. The study will answer the following major question:

How effective is urban agriculture at alleviating social, cultural, economic and environmental poverty in Hyderabad, India?

The study will use a variety of research methods including literature reviews; investigation of both past and present urban agriculture projects directed by the local government, university and nongovernmental organisations in Hyderabad; experiential information gathered during the researcher's stay in Hyderabad; as well as focus groups and semi-structured interviews conducted with representatives of those organisations and communities involved with urban agriculture projects in Hyderabad.

I am inviting you to participate in a focus group and/or a semi-structured interview in which it is hoped that your direct experience and involvement with urban agriculture in Hyderabad will elaborate upon the other information gathered concerning this practice as a means of poverty alleviation in the city. Your own opinion and perspectives are welcome (please note the accompanying confidentiality and consent forms) in this focus group and/or interview. The focus group should last no longer than 90 minutes, while the interview will not exceed one hour.

\section{Confidentiality}

At the beginning of the interview / focus group you will be asked in clear, non-technical language whether you wish your identity to remain confidential. I will explain in detail how the results of the research may be used, including the potential for publication in the public domain, in the form of 
academic papers in peer reviewed journals or presentations at conferences. The Informed Consent Form (attached) will ask whether you require confidentiality or not, and how you wish to identify yourself in the research. If you require confidentiality you will be referred to by the means that you choose to specify under \#3 of the Informed Consent Form. If you do not require confidentiality, you will be asked to circle the relevant statement (see \#4 on the Informed Consent Form), and only then will your identity be published.

No names will appear on the interview transcripts. A letter-number code will be assigned to each interview respondent, and only this code, or other title specified by you, will appear in the published results (unless confidentiality is waived as described above).

The real names associated with the codes will be kept securely by me, and never made public without the permission of the individual(s) involved.

\section{Storage and Disposal of Data}

Access to the written and electronic material will be restricted to me and my supervisor (contact details above). All written material will be kept in a locked file and all electronic material will be password-protected. Three years after the conclusion of the research, any interview material, or similar, will be destroyed and the audio recordings of the interviews will be electronically wiped.

The results collected will be reported in my thesis, and may potentially be presented in academic journals and conferences. The thesis will be submitted for marking to the School of Geography, Environment and Earth Sciences, Victoria University of Wellington.

\section{Right of Withdrawal}

During the course of the interview / focus group, you will have the right to withdraw or refuse to answer any question(s) at any time. You may request that the transcript of your interview / focus group be destroyed and not used in the study, for any reason. You must inform me of your withdrawal no more than 8 weeks after the date of the interview / focus group.

\section{Revision of Transcript}

You have the right to check the interview / focus group transcript, and will be able to provide any corrections up until 1 September, 2008.

\section{Community Access to Research Results}

In order to ensure that the results of this research project are accessible to the participants, a summary of the completed research output will be available. You may request it by circling 'Yes' in Question 7 of the 'Informed Consent Form' (attached), or on later request by email to charles.devenish@gmail.com with "Research participant Hyderabad" as the subject line. Furthermore, copies of the completed research output will be available from the School of Geography, Environment and Earth Sciences Library, and in the Victoria University of Wellington electronic database of theses.

If you have any other questions about this project, please feel free to ask me now, or contact me, or my supervisor William (Bill) Hipwell later, from the contact details provided on the first page of this sheet.

Thank you for participating! 
Sincerely,

Charlie Devenish 


\section{Appendix IV: Informed Consent Form}

Master's Thesis Research Project:

“The efficacy of urban agriculture as a means of poverty alleviation in Hyderabad, India.”

INFORMED CONSENT FORM

\begin{tabular}{|ll|l|}
\hline Researcher: & Charlie Devenish & School of Geography, Environment \\
Telephone: & $+64(04) 9778489$ & and Earth Sciences (SGEES) \\
Mobile & N/A & Victoria University of Wellington \\
Supervisor & Dr William (Bill) Hipwell & PO BOX 600 \\
Tel. & +64 (04) 463 6116 & Wellington 6140 \\
Email: & charles.devenish@gmail.com & (04) 463-5337 \\
\hline
\end{tabular}

\section{Introduction}

The Victoria University of Wellington Human Ethics Committee, which has approved this research project, requires that all research involve Participants who: 1) are fully informed about the nature of the research; and 2) consent to participate. This "Informed Consent Form" has been designed in accordance with these requirements; to inform all Participants about the nature of the project and their participation in it. It is meant to ensure that research Participants and their communities are protected from any harm potentially arising from their participation in the research process.

\section{Purpose of the Study}

This study, for my master's thesis, is intended to answer the following question:

How effective is urban agriculture at alleviating social, cultural, economic and environmental poverty in Hyderabad, India?

Please also see the attached 'Information Sheet'

\section{Research Format}

Focus groups and semi-structured interviews are being conducted with representatives of local communities and organisations involved with urban agriculture in Hyderabad. The meeting will be arranged for a time and place that suits the participant(s) and should last no longer than one hour for the interview and 90 minutes for the focus group. The participant will be asked to provide their own experiences and opinions of urban agriculture as it applies to the alleviation of poverty within the city. This information will be used to elaborate upon work already conducted on this topic in Hyderabad and is intended to contribute to the growing literature on urban agriculture by providing a personal voice regarding its practice and effects.

1. I agree to an audio recorded interview / focus group meeting with Charlie Devenish

$$
\mathrm{Y} / \mathrm{N}
$$

2. I wish for my identity to remain confidential.

$$
\mathrm{Y} / \mathrm{N}
$$


If yes, please answer $\mathbf{3}$. If no, please skip to 4.

3. I would like to be identified as (please circle one):

a) An 'official' from the organisation I represent, or

b) A letter code, or

c) Other, please specify:.............................

4. I consent to information or opinions that I have given being attributed to me in any reports on this research. By circling ' $Y$ ', you are waiving confidentiality.

$$
\mathrm{Y} / \mathrm{N}
$$

5. I understand that I will have an opportunity to correct the transcript of the interview / focus group up until 1 September, 2008 and that the information I have provided can be completely withdrawn from the study up to eight (8) weeks after the interview has been conducted.

$$
\mathrm{Y} / \mathrm{N}
$$

6. I understand that the data I provide will not be used for any other purpose than described in the 'Information Sheet' or released to others without written consent.

$$
\mathrm{Y} / \mathrm{N}
$$

7. I would like to receive a summary of the results of this research when it is completed.

$$
\mathrm{Y} / \mathrm{N}
$$

If yes, My address is:

My email is:

I agree to take part in this research

Participant:

Name:

Date:

Signature:

Researcher:

I certify that this form and its attached "Information Sheet" cover letter provide a complete and accurate description of the aims and processes of this research project.

Name:

Date: 


\section{Appendix V: Confidentiality Waiver Form}

Master's Thesis Research Project:

"The efficacy of urban agriculture as a means of poverty alleviation in Hyderabad, India"

\section{WAIVER OF CONFIDENTIALITY}

I, have been interviewed by Charlie Devenish as part of "The efficacy of urban agriculture as a means of poverty alleviation in Hyderabad, India" research project. I have chosen that my identity will not remain confidential.

Charlie Devenish, Victoria University of Wellington, and any publications which use material from this research project have my permission to publicly identify me by name and use the transcript of the interview with me (after I have had the opportunity to review and modify it) as an accurate representation of what I have said.

Signature:

Date: 


\section{Appendix VI: Translator's Confidentiality Form}

Master's Thesis Research Project:

"The efficacy of urban agriculture as a means of poverty alleviation in Hyderabad, India"

\section{TRANSLATOR'S STATEMENT OF NON-DISCLOSURE}

I, — have been employed as a translator

by Charlie Devenish on "The efficacy of urban agriculture as a means of poverty alleviation in Hyderabad, India" research project. I understand that confidentiality is important to everyone taking part in this project. I promise that I will not discuss what was said in any of the interviews / focus groups that I have translated. I also promise that I will not reveal the names or identities of any of the project participants to anyone.

Signature:

Date: 


\section{Appendix VII: Focus Group Participant's Confidentiality Form}

Master's Thesis Research Project:

“The efficacy of urban agriculture as a means of poverty alleviation in Hyderabad, India."

\section{FOCUS GROUP STATEMENT OF NON-DISCLOSURE}

I, have taken part in a focus group organised

by Charlie Devenish as part of "The efficacy of urban agriculture as a means of poverty alleviation in Hyderabad, India” research project. I understand that confidentiality is important to everyone taking part in this focus group. I promise that I will not discuss what was said in this focus group with anyone who did not take part in it. I also promise that I will not reveal the names of other participants in this focus group to anyone.

Signature:

Date: 


\section{Appendix VIII: Provider's of research contact statement of non- disclosure}

Master's Thesis Research Project:

"The efficacy of urban agriculture as a means of poverty alleviation in Hyderabad, India”

\section{PROVIDER'S OF RESEARCH CONTACT STATEMENT OF NON-DISCLOSURE}

I, have provided Charlie Devenish contact with as part of "The efficacy of urban agriculture as a means of poverty alleviation in Hyderabad, India” research project. I understand that the said contact's confidentiality is important and I promise that I will not discuss their involvement in the project with anyone.

Signature:

Date: 


\section{Appendix IX: "Rainwater Harvesting Potential for Urban Agriculture in Hyderabad"}

Amerasinghe et al. (2008) "Rainwater Harvesting Potential for Urban Agriculture in Hyderabad” in Urban Agriculture Magazine 20 pp. 34 - 36.

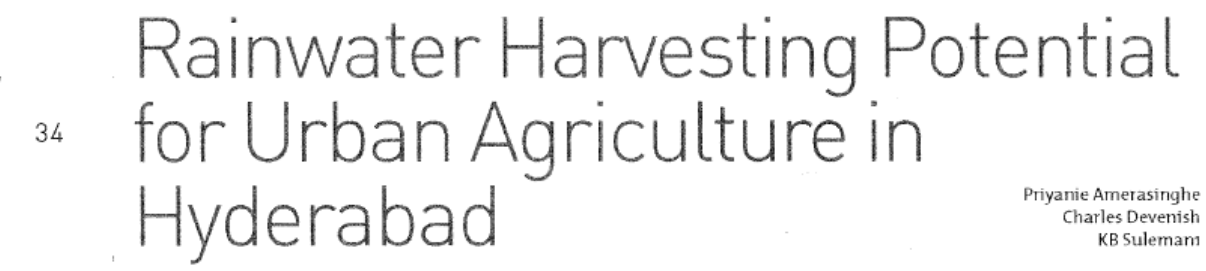

\begin{abstract}
Agriculture in and around Indian cities is under pressure due to rapid urbanisation and associated land use change, and coupled with pressure on already scarce water resources. The major beneficiaries of UA in the larger cities are low-income communities that make use of the available resources vacant land, river banks and wastewater-to supplement their meagre incomes. Rainwater is a valuable potential resource, and government attention to rainwater harvesting is growing, but its potential for UA is still poorly understood and documented.
\end{abstract}

Rainwater harvesting unit, with compost bin Photo: IWMI
Serilingampally

Hyderabad is a mega city, with a growing population of 7 million. In April 2007 the city limits were expanded (from 165 to 675 sq. $\mathrm{km})$, absorbing 10 surrounding municipalities. Serilingampally is one such municipality that came under the Greater Hyderabad Municipal Corporation's (GHMC) jurisdiction. Between 2003 and 2006 Serilingampally lost 61 percent of its arable land to real estate development (IWMI, 2007:19). Despite a booming IT sector and unprecedented economic growth, food security declined during this period for many of its inhabitants. Those who were once able to manage with the help of produce from their plots, have become dependent on food brought from afar with prices that are, in many cases, beyond their means. With nearly 30 percent of the population below the poverty line in 2003 Serilingampally has witnessed a shift in livelihood patterns among the low-income groups. Thus, the potential and need for localised household vegetable production for increased food

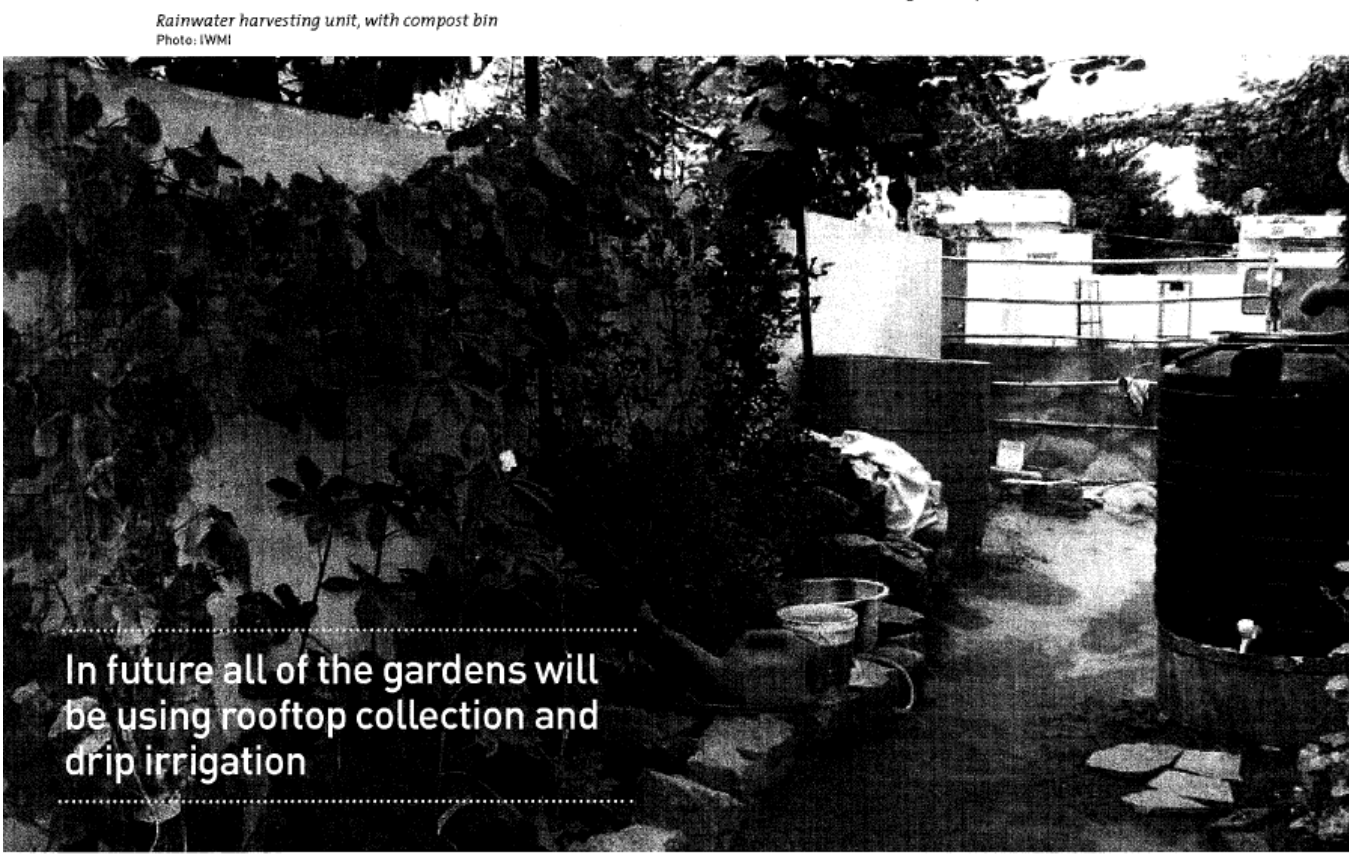




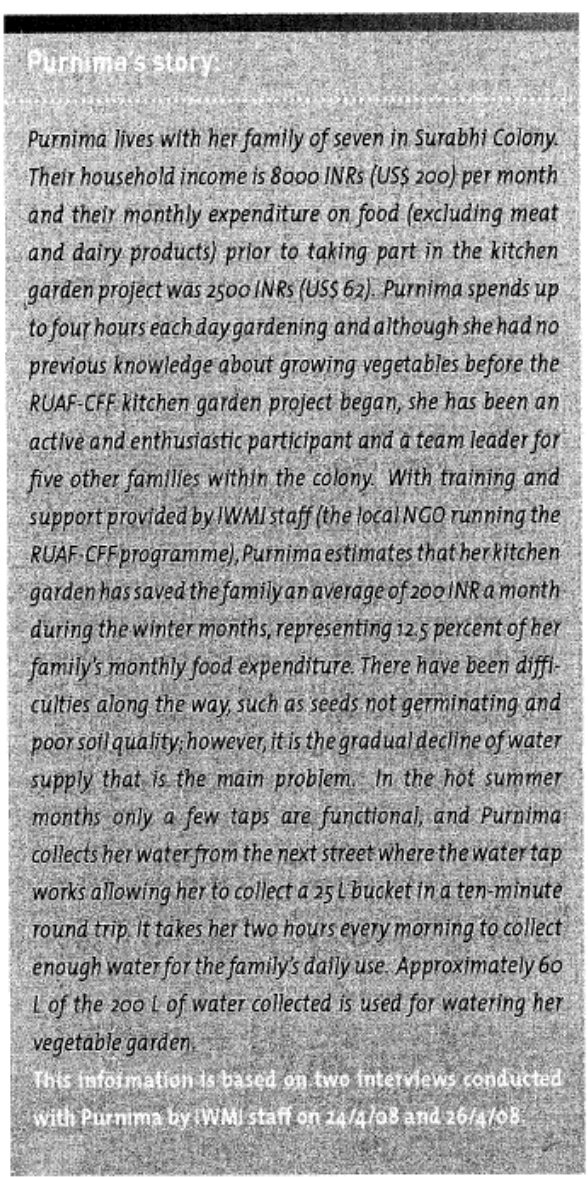

security is clear. In areas like Serilingampally, those with a home garden can be encouraged to develop it to improve their household food security.

\section{Surabhi Colony}

Surabhi Colony used to fall within Serilingampally municipality, but it is now within the CHMC of Hyderabad. It is situated on the western fringe of Hyderabad and is registered as a low-income community, allowing it access to the programmes of the Urban Poverty Alleviation and Livelinood Cell of the GHMC (www.ghmc. govin). Supported by strong community leaders and self-help groups, the members of the community are well positioned to represent themselves in seeking government support. Mixed livelihood activities are common despite the community's nonfarming heritage. Nevertheless, one of the new challenges facing the community is household food security. Thus the RUAF-CFF programme sought to assist 38 households in the Surabhi Colony (December 2007) to realise the potential of urban kitchen gardens, with a view to improving household food security. By the end of the first growing season (February), however, water proved to be a considerable barrier to the full realisation of urban agriculture's potential. As in most semiarid regions, the rains come all at once, during the monsoon months June to September; and in the summer (March - May), the temperature rises to 40 degrees Celsius and water shortages become even more acute.

The main agricultural systems in Hyderabad are fodder and vegetable cultivation, where the much-needed water for growing is extracted from the Musi River that runs through the city (see UA-Magazine no. 8). However, no such water course is available to the Surabhi Colony, where groundwater is the main source for domestic use and other purposes. This too is erratic and inadequate. From interviews with members of Surabhi Colony (April 2008) it appeared that perceptions of water availability and daily usage vary depending on the resident's proximity and access to the single bore well that supplies water to the entire colony.

In April 2008, the number of households in Surabhi Colony rose to 240. Fifty-one taps distribute water for domestic use throughout the colony and this all comes from a single motorised bore well. While such a supply can be considered a blessing, this water is hard and undrinkable and the supply is restricted to four hours a day. Taps closer to the pump benefit from high water pressure, while those further away suffer from inadequate pressure and insufficient supply. This situation is exacerbated in the summer as groundwater levels go down. In addition to the piped water from the colony bore well, there are five hand pumps (four public and one private) distributed throughout the colony. However, the residents are less inclined to use these given the effort involved in extracting this water. More recently, their persistent representation at meetings with the local authorities resulted in the supply of potable water from the Krishna water project (Personal communication with IWMI project officer Radha). Supply was to be one $5000 \mathrm{~L}$ tanker every other day, an achievable target in the rainy season. However, in the recent summer months, supply has been reduced to two or three deliveries per week, as the demand forfreshcleaner drinking water throughout the city hasincreased. With a population of approximately 600 , the average supply in summer works out to be between $2.38 \mathrm{~L}$ and $3.47 \mathrm{~L}$ of drinking water per person per day. For all other domestic purposes the bore well supply is the only source, but availability throughout the year is unreliable. So the kitchen gardens require an alternative source as a sustainable solution. While reusing greywater from kitchens is a potential option, the existing house plans are not conducive to this. All the washing (clothes and cooking utensils) is done outside where the water is stored in barrels or a concrete storage tank. A cemented area for washing where the effluent can be channelled to vegetable plots needs adequate planning, and investment of time and money.

It is in this setting that the imperative need for alternative sources of water, such as that provided by rainwater harvesting, to supplement the groundwater used for sustainable kitchen gardens becomes clear.

Rainwater for urban agriculture

Harvesting rainwater provides a free source of water, and utilising rainwater before it enters existing water systems within the urban area may provide a source of water that is less polluted than other sources of water within the city. If the water collected on rooftops is stored in private tanks it can be used by the residents, or, if directed to recharge the groundwater supply, it can help replenish local reserves. Thus, it can help reduce residents' dependence on local municipal supply and, depending on the 
Rainwater Harvesting Potential for Urban Agriculture in Hyderabad

storage capacity, has the potential to see them through times of seasonal water scarcity.

In addition, proper rainwater harvesting systems can help reduce pressure on the local infrastructure in times of heavy rainfall by storing or redirecting rainwater runoff from stressed stormwater drainage systems. In regions that experience monsoonal rainfall, a particular issue can be the overloading of these systems. Flooding and the potential for sewer overflows have obvious health risks which rainwater harvesting may-atleast in a limited capacity-help minimise (Hewa et al, 2006: 445.)

Rainwater harvesting includes three components: a watershed area to produce runoff, a storage facility (soil profile, surface reservoirs, or groundwater aquifers), and a target area for beneficial use of the water (agriculture, domestic, or industry) (Molden, 2007: 332). The rainwater harvesting potential of a building is calculated by multiplying the rainfall amount by the catchment area by the runoff co-efficient (see for instance www.rainwaterharvesting.org for more information).

In an urban setting, harvesting rainwater from one's rooftop is perhaps the most obvious example, but is not the only method available. Rainwater harvesting can be as simple as capturing water on a plastic sheet with its four comers tied to poles (Hewa et al., 2006: 445). Once captured, the rainwater can either be stored in a tank or container above ground and drawn from as necessary, or directed to an underground tank or pit where it is used to recharge the groundwater. The size of the storage container will be constrained by the space each housing plot has in its garden, and therefore a rainwater harvesting system that enables both limited storage and recharge of the local groundwater reserves would be preferable. Unless adequate water quality testing is carried out, the captured water should not be used for human consumption. The initial cost of construction of the catchment and storage system does not have to be high: a storage container of $500 \mathrm{~L}$ with the required pipes and labour can cost around INR 2000/.

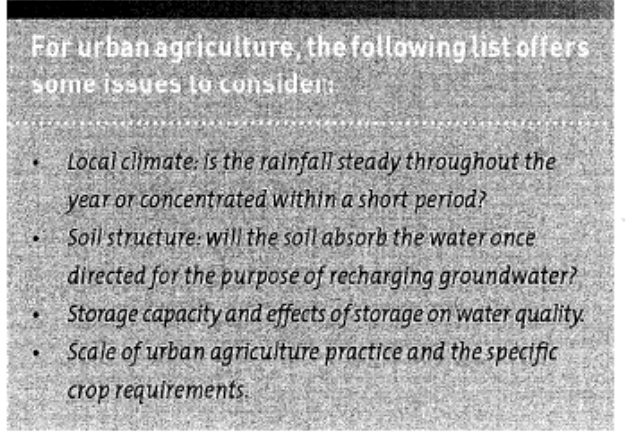

Given the water shortages identified in Surabhi Colony, utilising the rainwater harvesting potential of each house could make a considerable difference to the residents' daily life. Given the rainfall patterns of Hyderabad, rainwater will mostlikely be harvested and stored during the monsoon - the period when irrigation will be least necessary. The issue therefore is the dry summer months, which come some five months after the end of the monsoon. The groundwater recharge could extend the supply over a two month period, but a mere $500 \mathrm{~L}$ storage water tank would most likely not be adequate to see the household through the remainder of the period. This predicament therefore illustrates the need for a diversified rainwater harvesting system, which includes recharginglocal groundwater supplies, and which willenhance the water supply throughout the year for crops and other domestic uses.

Rainwater harvesting on the government agenda If Hyderabad city is to achieve the Hyderabad Metropolitan Water Supply \& Sewerage Board's (HMWS \& SB) vision to: "provide water of the highest quality, round the clock, at an affordable cost" (http://wwwhyderabadwater.govin/) and if Hyderabad Urban Development Authority's (HUDA) plan to deliver 150 litres of water per capita per day (HUDA, 2006: 67) is to be met, then the harvesting of rainwater for both storage and groundwater recharge are vital steps that must be taken immediately. The HMWS \& SB has already envisaged the potential for rainwater harvesting in the city: in its attempt to promote rainwater harvesting it has drafted plans for rainwater harvesting units and offered a 10 percent subsidy to help cover construction costs (See: http://www.hyderabadwater.gov.in/rwhu.htm).

The need for such planning and action is imperative, since rapid building construction, coupled with plans to lay roadways throughout Surabhi Colony mean that the potential for the natural recharge of groundwater is in jeopardy. Awareness of the importance of rainwater harvesting has been increased through the RUAF's programme. The colony's leaders must be motivated to establish a diversified rainwater harvesting system for the colony; if not the scarcity of water will only intensify.

Priyanie Amerasinghe and KB Suleman

IWMI India

Email: P.Amerasinghe@cgiar.org

Charles Devenish

Victoria University of Wellington, New Zealand

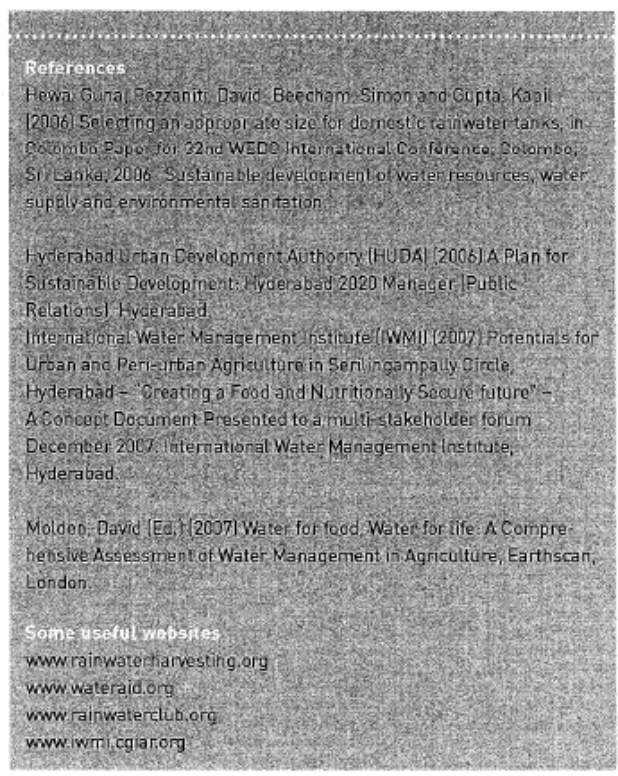




\section{Appendix X: Strategies for meeting the objective of IKP-(U)}

- "Building organizations for the poor;

- Empowering the poor by building their capacities;

- Establishing sensitive support mechanisms;

- Ensuring participatory monitoring and evaluation systems;

- Facilitating interface between Community Based Organisations (CBO) of the poor / and constitution of Town Level Bankers' Committee with representatives of poor in the Committee;

- Taking up placement-linked training programmes / skill development programmes;

- Facilitating the formation of CBOs of disabled persons at land / poor settlement / town levels and enabling the vulnerable sections to live with more dignity and self respect;

- Facilitating infrastructure improvement in slums;

- Facilitating housing for the poor;

- Taking up any programme that empowers the poor and / or addresses the various issues related to poverty elimination and human development" (GHMC, 2008: No Page). 


\section{Appendix XI: Tree plantation requirements detailed in the "Andhra Pradesh Water, Land and Trees Act, 2002”}

Table 4: Tree plantation requirements for residential land

\begin{tabular}{|l|l|}
\hline Area of plot & Number of trees \\
\hline Below 100sq. $\mathrm{m}$ & 3 \\
\hline $101-200$ sq. $\mathrm{m}$ & 5 \\
\hline $201-300$ sq. $\mathrm{m}$ & 10 \\
\hline 301 sq. $\mathrm{m}$ and above & $\begin{array}{l}10 \text { trees plus } 5 \text { trees for every increase of } \\
100 \text { sq. } \mathrm{m}\end{array}$ \\
\hline
\end{tabular}

(Rule 24 of the Rules framed under the Andhra Pradesh Water, Land and Trees Act, 2002 cited in HUDA, 2003: 130).

Table 5: Tree plantation requirements for commercial and institutional land

\begin{tabular}{|l|l|}
\hline Area of plot & Number of trees \\
\hline Below 200sq. $\mathrm{m}$ & 2 \\
\hline $201-500$ sq. $\mathrm{m}$ & 4 \\
\hline $501-1000$ sq. $\mathrm{m}$ & 6 \\
\hline 1001 sq. $\mathrm{m}$ and above & $\begin{array}{l}6 \text { trees plus } 2 \text { trees for every increase of } \\
100 \text { sq. } \mathrm{m}\end{array}$ \\
\hline
\end{tabular}

(Rule 24 of the Rules framed under the Andhra Pradesh Water, Land and Trees Act, 2002 cited in HUDA, 2003: 130). 


\section{Appendix XII: Open space standards as per building regulations}

A summary of the open space requirements identified in the local government legislation:

- All residential and commercial plots of 250sq. $m$ and less must have the following minimum non-construction zones around the plot's perimeter: $3 \mathrm{~m}$ from the front boundary; 0 and $3 \mathrm{~m}$ on the sides and 1.5m at the rear (HUDA, 2003: 124);

- Over and above the standard listed above, HUDA requires that all buildings on a plot of land over 2500sq. m in area must provide 15sq. m of open / recreational space per 100sq. m of built-up area (HUDA, 2003: 125);

- All land pooled to form a development area of at least 20 hectares (ha) must provide parks, playgrounds and open space on at least $10 \%$ of the development's total land area (Article 3-iii of Layout and Land Subdivision Regulations 2008 in the Andhra Pradesh Government Order 288, 3/4/08: 20);

- All owners of 'layout developments' with an area of at least 4ha must provide parks, playgrounds and open space on at least $10 \%$ of the development's total land area (Article 8-ii of Layout and Land Subdivision Regulations 2008 in the Andhra Pradesh Government Order 288, 3/4/08: 21), while those with an area of between 0.3 and 4ha must provide open space on 20\% of the total land area (HUDA, 2003: 145);

- In an interview with Mr B. Srinivas, Chief of Urban Forestry at the GHMC, it was uncovered that between 30 and $40 \%$ of land classed as 'industrial' must be set aside for open space (interview with Mr B. Srinivas, Hyderabad: 3/4/08). 